\title{
INDICAÇÕES PARA PROJETO DE MUROS DE ARRIMO EM CONCRETO ARMADO
}

ENG. PAULO CÉSAR DOMINGUES

Dissertação apresentada à Escola de Engenharia de São Carlos, da Universidade de São Paulo, como parte dos requisitos para obtenção do Título de Mestre em Engenharia Civil.

ORIENTADOR: JOSÉ SAMUEL GIONGO

SÃO CARLOS - SP 


\section{Class}

Cutt.

$-1922$

rombe

Ficha catalográfica preparada pela Seção de Tratamento da Informação do Serviço de Biblioteca - EESC-USP

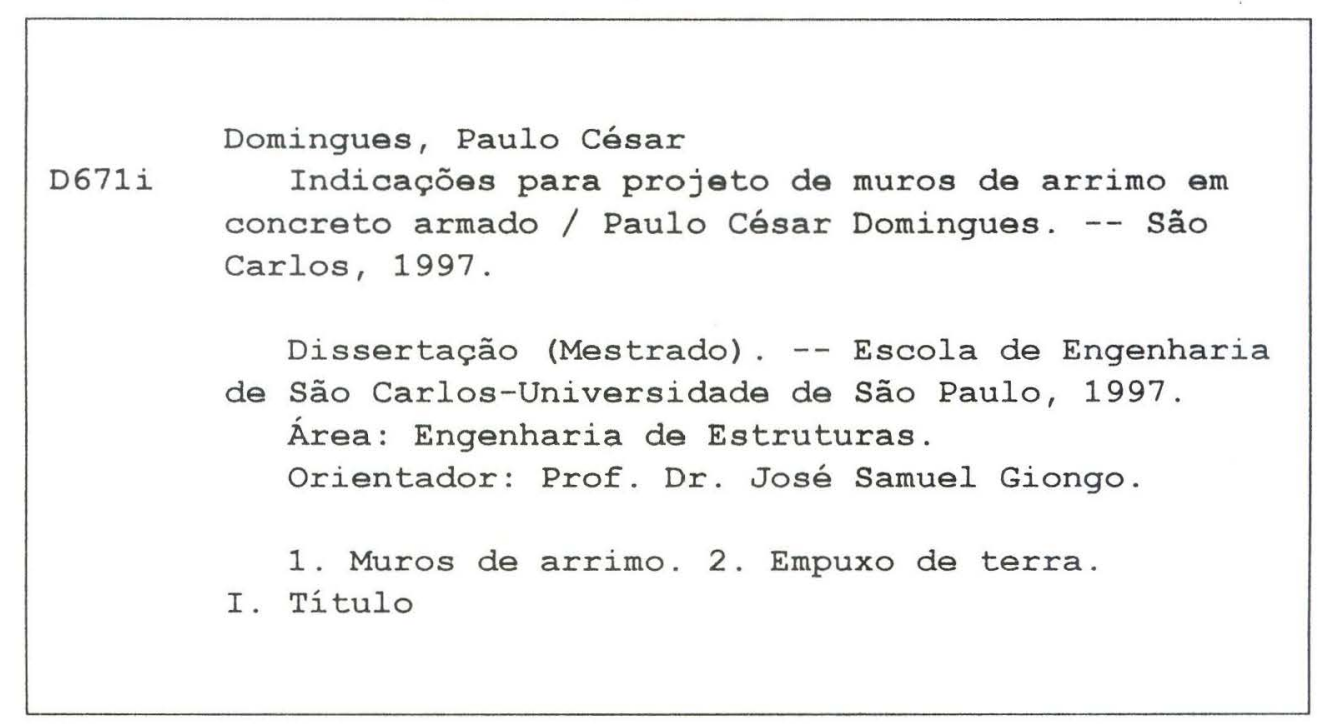


A meus pais e irmãos pelo apoio e incentivo para realização deste trabalho. 


\section{AGRADECIMENTOS}

A Deus, por tudo.

Ao meu orientador José Samuel Giongo pela paciência, dedicação e confiança ao longo do desenvolvimento do trabalho.

A Paulo e Flávia pela convivência e apoio.

Aos funcionários do Departamento de Estruturas, principalmente Nadir e Rosi pela colaboração.

Aos amigos Claudio, Werner, Solange e Cibele pela amizade incondicional.

Enfim, a todas as pessoas que direta ou indiretamente possibilitaram a realização deste trabalho 


\section{SUMÁRIO}

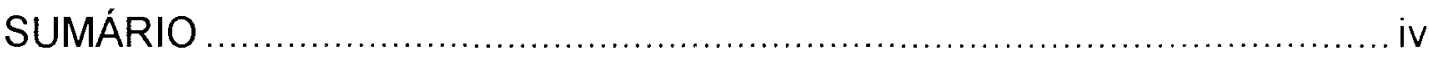

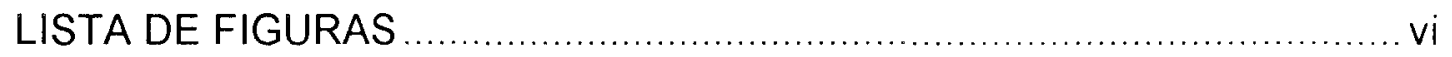

LISTA DE SÍMBOLOS ......................................................................... vii

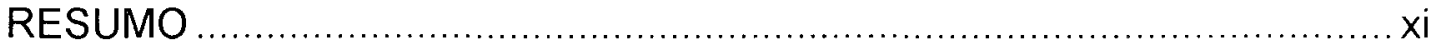

ABSTRACT

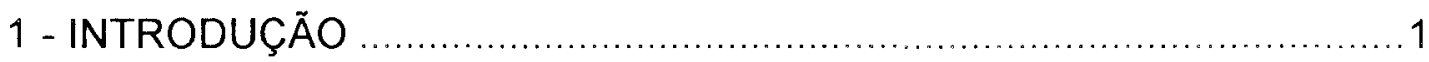

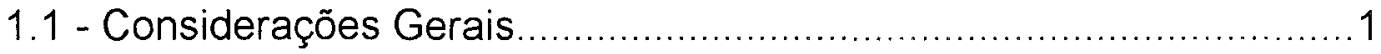

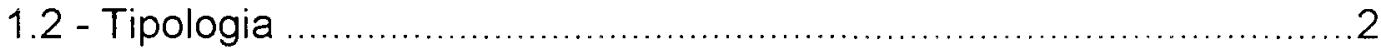

1.2.1 - Muro de Arrimo por Gravidade ........................................2

1.2.2 - Muros Isolados em Concreto Armado sem Contrafortes ..................5

1.2.3 - Muro em Concreto Armado com Contrafortes ........................9

1.2.4 - Muro de Arrimo de Edifícios que Possuem Subsolo ..........11

1.2.5 - Concepções Estruturais Alternativas ................................ 13

1.3 - Obras Complementares ........................................................ 20

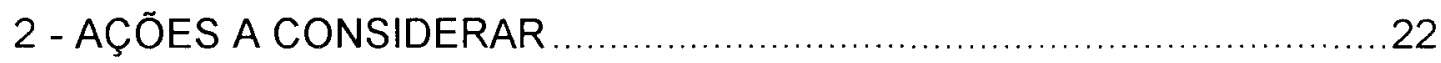

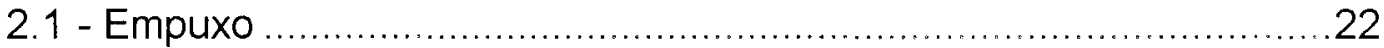

2.2 - Empuxo ativo, passivo e em repouso ........................................2 23

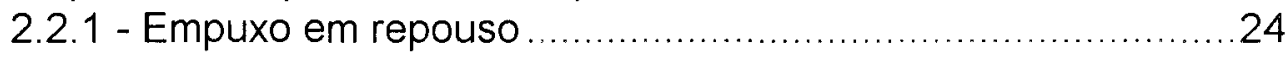

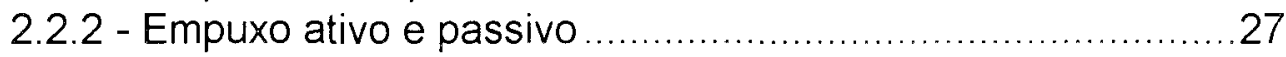

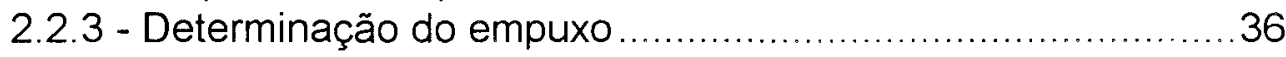

3 - VERIFICAÇÃO DA SEGURANÇA PARA MUROS ISOLADOS ...............41

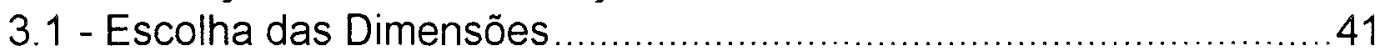

3.2 - Verificação da Estabilidade do Conjunto ……................................44

3.2.1 - Verificação da segurança contra o tombamento ..................46

3.2.2 - Verificação da segurança contra o deslizamento .................47

3.2.3 - Verificação da pressão no solo de apoio............................51

3.3 - Cálculo dos Esforços Solicitantes ...............................................52

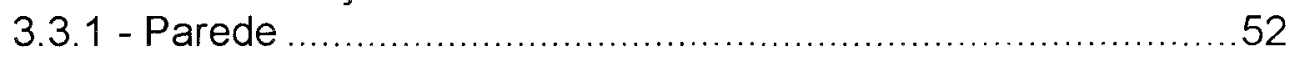

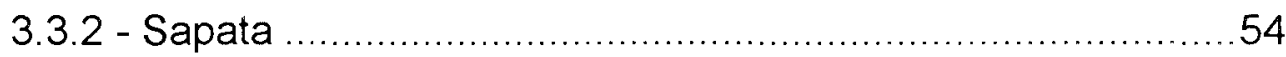

3.4 - Dimensionamento das armaduras ..............................................56

3.5 - Verificação da Segurança para Muro Isolado com Contrafortes ......56

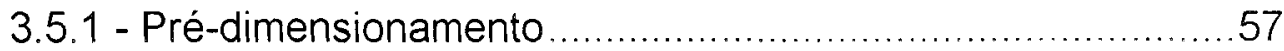


3.5.2 - Cortina entre os contrafortes .................................... 57

3.5.3 - Viga de coroamento de topo ......................................58

3.5 .4 - Viga de ancoragem ................................................ 58

3.5 .5 - Contrafortes ou gigantes ........................................ 59

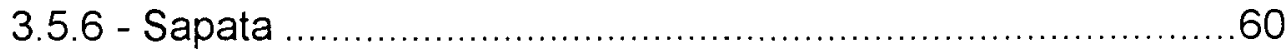

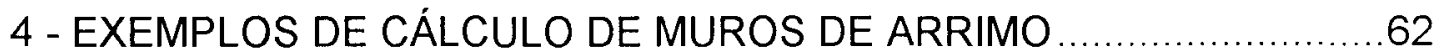

4.1 - Muro de Arrimo Isolado ...................................................662

4.2 - Muro de Arrimo Isolado com Contrafortes.................................82

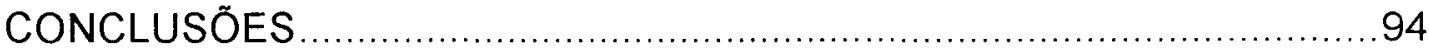

REFERÊNCIAS BIBLIOGRÁFICAS ............................................. 95 


\section{LISTA DE FIGURAS}

Figura 1.1 - Muro de gravidade com perfil retangular. ........................... 3

Figura 1.2 - Muro de gravidade com perfil trapezoidal (Moliterno 1980).......4

Figura 1.3 - Muro de gravidade com perfil escalonado (Moliterno, 1980) ....5

Figura 1.4 - Muro sem contraforte - Perfil clássico. ....................................6

Figura 1.5 - Muro sem contraforte - Perfil L............................................ 8

Figura 1.6 - Muro sem contraforte com perfis especiais............................ 8

Figura 1.7 - Muro atirantado (Rocha, 1974) ......................................... 9

Figura 1.8 - Muro com contrafortes. .................................................. 10

Figura 1.9 - Muro com contraforte e vigas intermediárias. ...................... 11

Figura 1.10 - Muros que funcionam como elemento de fundação...............12

Figura 1.11 - Muro exclusivamente de contenção de empuxo de terra.......13

Figura 1.12 - Alvenaria armada de blocos de concreto ............................ 14

Figura 1.13 - Muro tipo "Crib wall"................................................ 14

Figura 1.14 - Terra armada. ......................................................... 15

Figura 1.15 - Estaca raiz. .......................................................... 16

Figura 1.16 - Parede diafragma .................................................. 17

Figura 1.17 - Estaca prancha metálica. .............................................. 18

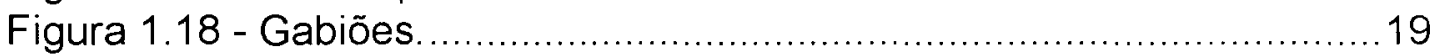

Figura 1.19 - Sacos de solo cimento. .................................................. 19

Figura 1.20 - Sistema de drenagem de um muro de arrimo. ..................... 21

Figura 2.1 - Empuxo ativo, passivo e em repouso...................................22

Figura 2.2 - Semi-espaço de um solo homogêneo ..................................2. 24

Figura 2.3 - Prtessão lateral na parede de contenção ..............................25

Figura 2.4 - Linhas de ruptura de Coulomb........................................ 27

Figura 2.5 - Pressões sobre um elemento de solo [Gaioto, 1979]. .............31 31

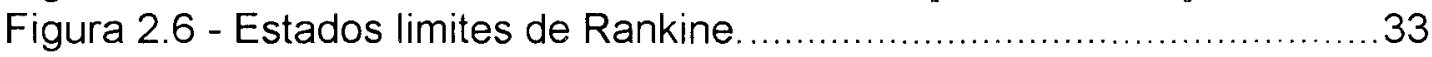

Figura 2.7 - Famílias de linhas de ruptura do método de Sokolovski........... 35

Figura 2.8 - Determinação do empuxo em terreno sem ação variável. ........37

Figura 2.9 - Determinação do empuxo para terreno com ação variável.......39

Figura 3.1 - Pré-dimensionamento segundo Huntington. ..........................44 42

Figura 3.2 - Pré-dimensionamento de acordo com Santos Netto................42

Figura 3.3 - Determinação do valor de $h_{2} \ldots \ldots \ldots \ldots \ldots \ldots \ldots \ldots \ldots \ldots \ldots \ldots \ldots . \ldots . \ldots \ldots$

Figura 3.4 - Mudanças possiveis nas dimensões do muro e da sapata......44

Figura 3.5 - Cargas verticais atuantes no muro e na sapata....................4 45

Figura 3.6 - Dentes de ancoragem Moliterno (1980) e Santos Netto (1994) ................................................................... 48

Figura 3.7 - Inclinação da sapata Santos Netto (1994).........................49

Figura 3.8 - esquema estático segundo Santos Netto (1994) ...................50

Figura 3.9 - Esquema estático das ações na fundação, Migliore (1987) . ...51 
Figura 3.10 - Distribuição de tensões no solo, Migliore (1987) .................51

Figura 3.11 - Esforços atuantes na parede do muro. ............................. 53

Figura 3.12 - Ações solicitantes na sapata...........................................54

Figura 3.13 - Esforços solicitantes no talão e na ponta da sapata.............55

Figura 3.14 - Verificação do equilíbrio da sapata..................................56

Figura 3.15 - Pré-dimensionamento dos contrafortes. ..........................55

Figura 3.16 - Armadura dos contrafortes........................................ 59 


\section{LISTA DE SÍMBOLOS}

$\mathrm{G}_{\mathrm{pp}}$ : ação devido ao peso próprio.

E : empuxo.

$E_{h}$ : empuxo horizontal.

$E_{p}$ : empuxo passivo.

$F_{\text {at }}$ : força de atrito

$\varphi \quad$ : ângulo de atrito interno do solo.

$\gamma_{t}$ : peso específico aparente.

$\sigma_{1}$ : tensão lateral.

$\sigma_{v} \quad$ : tensão vertical.

$\mathrm{K}_{\circ}$ : coeficiente de empuxo em repouso.

$\gamma_{1}$ : ângulo de rugosidade do muro.

$\alpha \quad$ : ângulo de inclinação do terreno adjacente

$\theta \quad$ : ângulo de inclinação do paramento interno do muro com a vertical

$\mathrm{E}_{\mathrm{a}}$ : empuxo ativo

$h_{m}$ : espessura da parede do muro de arrimo.

$h_{s}$ : espessura da sapata do muro de arrimo.

$\tau \quad$ : tensão de cisalhamento.

C : coesão entre os grãos.

$\mathrm{K}_{\mathrm{a}}$ : coeficiente de empuxo ativo.

$\mathrm{K}_{\mathrm{p}}$ : coeficiente de empuxo passivo.

$\mathrm{q}_{\mathrm{ep}}$ : ação devido ao empuxo.

$a_{\text {ext }}$ : largura da extremidade da sapata.

$a_{\text {int }}$ : largura da ponta da sapata.

$\mathrm{K}_{\text {clim }}$ : valor de $\mathrm{K}_{c}$, limite entre os domínios 3 e 4 .

$M_{d}$ : momento fletor de cálculo. 
$b_{w}$ : largura da seção retangular.

F.S. : fator de segurança.

$\mathrm{M}_{\mathrm{t}}$ : momento de tombamento devido ao empuxo.

$\mu \quad$ : coeficiente de atrito solo-concreto.

$f_{y d}$ : tensão de escoamento do aço.

$A_{s}$ : área de aço.

$A_{s e}$ : área de aço dos estribos.

$\checkmark$ : esforço cortante.

$f_{c k}$ : resistência característica do concreto à compressão.

$\tau_{\text {wd }}$ : tensão tangencial de cálculo devida ao esforço cortante.

$\tau_{w u} \quad$ : valor último da tensão tangencial de cálculo devida ao esforço cortante. 


\section{RESUMO}

Este trabalho tem como objetivo auxiliar no desenvolvimento do projeto de um muro de arrimo em concreto armado.

Será constituido de quatro fases distintas.

Na primeira fase, serão detalhados os tipos de muros de arrimo, bem como suas indicações de uso.

Numa segunda fase, serão levantadas as ações atuantes no muro. 0 estudo do empuxo sera feito a partir da teoria de Coulomb e Rankine.

$\mathrm{Na}$ fase seguinte serão fixadas as dimensões do muro a partir de um pré-dimensionamento, seguido da verificação da estabilidade do conjunto, onde é analisada a segurança ao deslizamento e tombamento. A partir daí, são calculados os esforços solicitantes no muro e na sapata, seguido do dimensionamento das armaduras de ambos.

Finalmente, na última fase, será feita a resolução detalhada de dois tipos de muro de arrimo. 


\section{ABSTRACT}

The objetctive of this work is to help in the development of reinforced concrete retaining wall projects.

There were four distinct phases.

In the first phase was detailed the retaining walls types, as their using indications.

In the second phase, it was showed the actions on the wall. The studying of pressure soil was made with Coulomb and Rankine theory.

In the next phase, was fixed the wall dimensions according to a first draft, followed by stability conditions, where was verificed sliding and falling safety. Then the wall and foundation internal forces were calculated, followed by the reinforcing bars calculation in both of them.

Finally, in the last phase, it was made a complete calculation of the two types of retaining wall. 


\section{1 - INTRODUÇÃO}

\section{1 - Considerações Gerais}

Juntamente com o desenvolvimento alcançado pelo Homem, principalmente nos últimos décadas, veio a necessidade de se ocupar regiões de difícil acesso e utilização como, por exemplo, as encostas de morros e montanhas próximos as regiões mais populosos, fazendo uso de tais espaços para construção de moradias, edifícios públicos e vias de transporte.

Para que o uso dessas regiões fosse possivel, foram realizadas obras de contenção, tornando esses locais suficientemente planos, a fim de garantir a utilização para construção de edificações ou a segurança de obras próximos a essas encostas.

As obras de contenção são utilizadas quando o espaço disponivel não é suficiente para manter uma diferença de nível da superfície através de taludes.

Assim, novas técnicas e teorias foram sendo desenvolvidas a fim de conhecer melhor o comportamento de tais obras, bem como a diminuição dos custos.

A seguir, estão descritos os tipos de muros mais usuais, assim como suas indicações de uso. 


\section{2 - Tipologia}

\subsection{1 - Muro de Arrimo por Gravidade}

São estruturas em que o peso próprio é o responsável pela sua estabilidade. Geralmente utilizados em locais onde o solo apresenta boa capacidade de suporte.

Os materiais empregados são concreto ciclópico ou alvenaria de pedra, podendo também ser utilizado solo-cimento ensacado.

Os concretos ciclópicos são concretos aos quais se incorporam pedras de grandes diaâmetros, dispostos regulamentes em camadas e convenientementes afastados para que a massa possa envolvê-las por completo. O volume de pedra é responsável por $40 \%$ do total do volume de concreto.

O muro de gravidade deve ser dimensionado de modo a não apresentar tensões de tração e garantir a resistência contra as ações laterais, oriundas do atrito entre as camadas de interface do solo com o mesmo.

O muro de gravidade, pode ser projetado em três perfis básicos: retangular, trapezoidal e escalonado.

\subsubsection{1 - Muro de gravidade com perfil retangular}

O muro de gravidade de perfil retangular (Figura 1.1) é econômico apenas para pequenas alturas (até $2,0 \mathrm{~m}$ ), sendo geralmente utilizado o concreto ciclópico. 


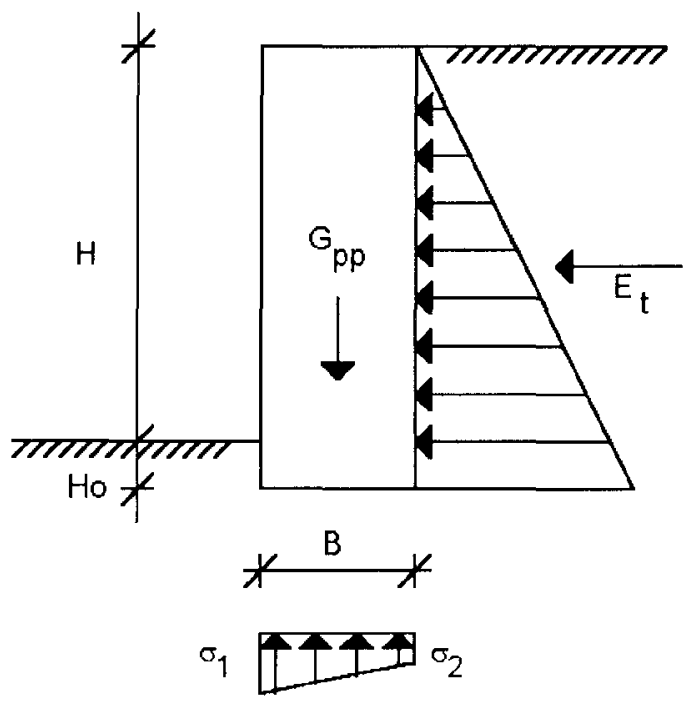

Figura 1.1 - Muro de gravidade com perfil retangular.

onde:

$\mathrm{H}$ - altura da superfície até o topo do muro;

$\mathrm{H}_{0}$ - altura do muro enterrado

B - largura da base

$E_{1}$ - Empuxo total

$\mathrm{G}_{\mathrm{pp}}$ - ação devido ao peso próprio

Segundo Moliterno (1980), pode-se adotar para o prédimensionamento as seguintes dimensões:

- Muro de alvenaria de tijolos $\mathrm{B}=0,40 \mathrm{H}$

- Muro de concreto ciclópico $\mathrm{B}=0,30 \mathrm{H}$

\subsubsection{2 - Muro de gravidade com perfil trapezoidal}

O muro de gravidade com perfil trapezoidal (Figura 1.2) é mais utilizado por ser mais econômico em relação ao perfil retangular e poder ser adotado para maiores alturas. O material utilizado também é o concreto ciclópico. 
A superfície inclinada do muro deve ser sempre que possivel de paramento externo inclinado, fazendo com que o centro de gravidade do muro fique para o lado do terreno.

O paramento externo vertical só deve ser usado em caso de exigência estética.
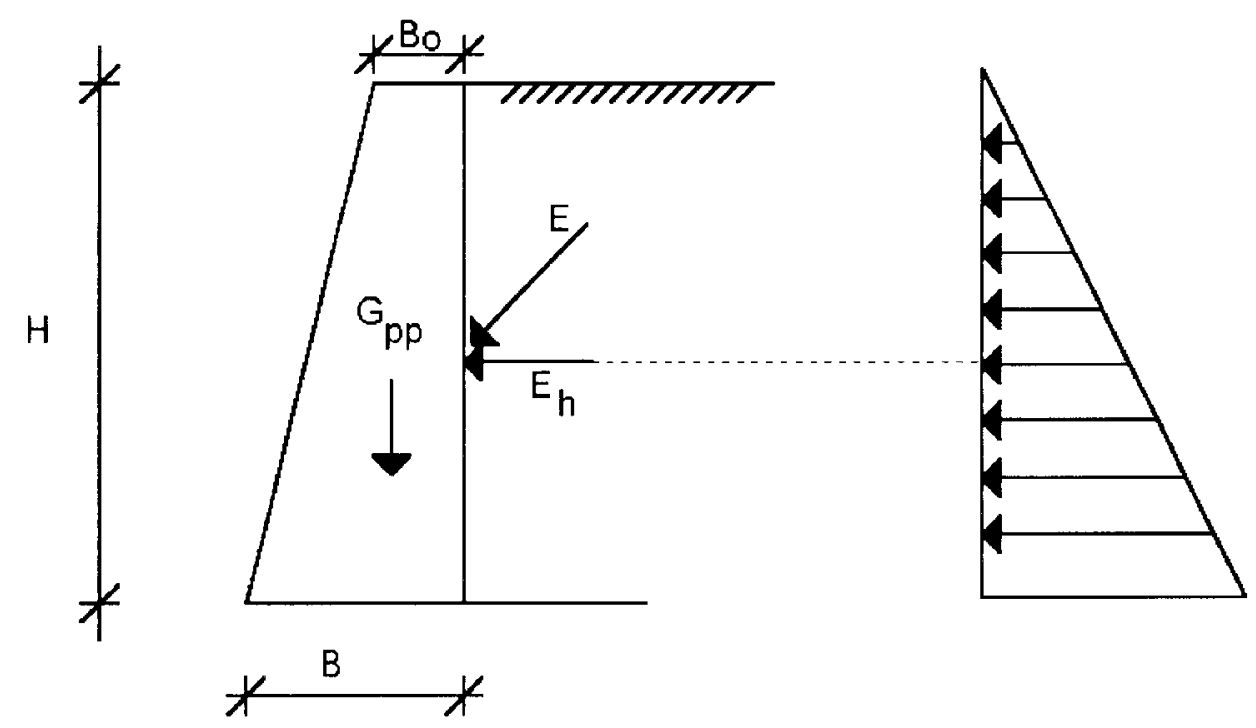

Figura 1.2 - Muro de gravidade com perfil trapezoidal (Moliterno 1980).

Moliterno (1980), propôe para o pré-dimensionamento as seguintes dimensões:

$$
\begin{aligned}
& B_{0}=0,14 H \\
& B=B_{0}+H / 3
\end{aligned}
$$

\subsubsection{3 - Muro de gravidade com perfil escalonado}

O muro com perfil escalonado é utilizado para situações idênticas à do muro trapezoidal. Executado em alvenaria de pedra, apresenta a vantagem de uma maior economia de material. 


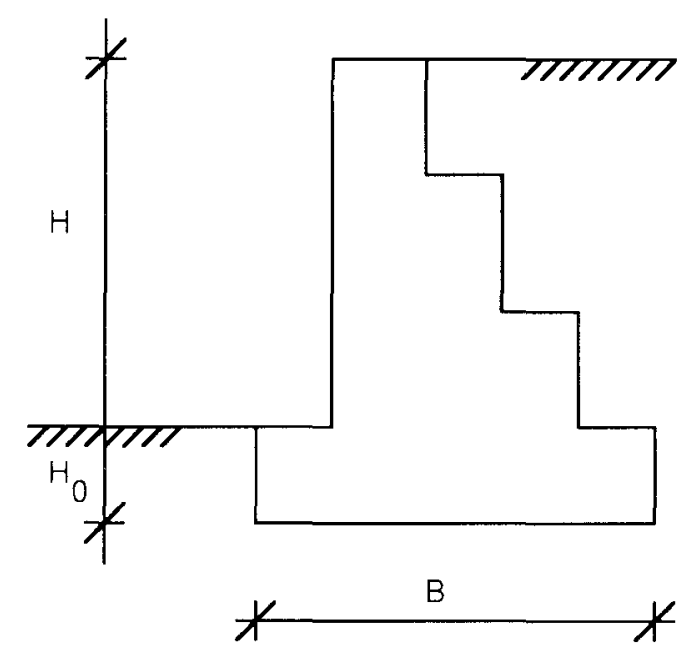

Figura 1.3 - Muro de gravidade com perfil escalonado (Moliterno, 1980).

\subsection{2 - Muros Isolados em Concreto Armado sem Contrafortes}

São compostos basicamente de duas lajes de concreto armado. A laje vertical é considerada engastada na base com o extremo superior em balanço. A laje horizontal se apoia no terreno, com finalidade estrutural de equilibrar o empuxo e servir de sapata.

Como seu peso próprio é inferior aos do muro de gravidade, pode ser empregado em solos que não apresentam alta resistência de suporte, bastando para isso uma conveniente análise da fundação, podendo, inclusive, fazer uso de estacas. Isto, porque o equilibrio do sistema é obtido com a massa de solo sobre uma sapata enterrada.

A laje vertical está submetida a uma ação variável devido ao empuxo do terreno e, a laje horizontal, apoiada no terreno, recebe a ação dos pesos próprios da laje vertical e do maciço de terra. Quando o muro for parcialmente enterrado, deve ser acrescido o peso deste maciço de terra em seu lado externo.

Para a escolha deste tipo de muro devem ser analisados os seguintes aspectos: 
- dificuldade de compactação do aterro no encontro das lajes;

- acréscimo de terreno requerido para este serviço;

- preparação de fôrmas, armaduras, concretagem e cura.

Silva Leme, recomenda que o emprego deste tipo de muro seja restrito a uma altura máxima de $5 \mathrm{~m}$.

Neste tipo de estrutura, qualquer que seja o comprimento do muro, o dimensionamento se faz considerando o comprimento unitário $(1 \mathrm{~m})$.

Os muros sem contrafortes apresentam quatro perfís básicos: perfil clássico,perfil $L$, perfis especiais e muros atirantados, como mostrados a seguir.

\subsubsection{1 - Muro sem contraforte com perfil clássico}

O perfil clássico serve de padrão de comparação para os demais sistemas. É um perfil utilizado para alturas entre $2 \mathrm{~m}$ a $4 \mathrm{~m}$. A Figura 1.4, mostra um esquema deste tipo de perfil.

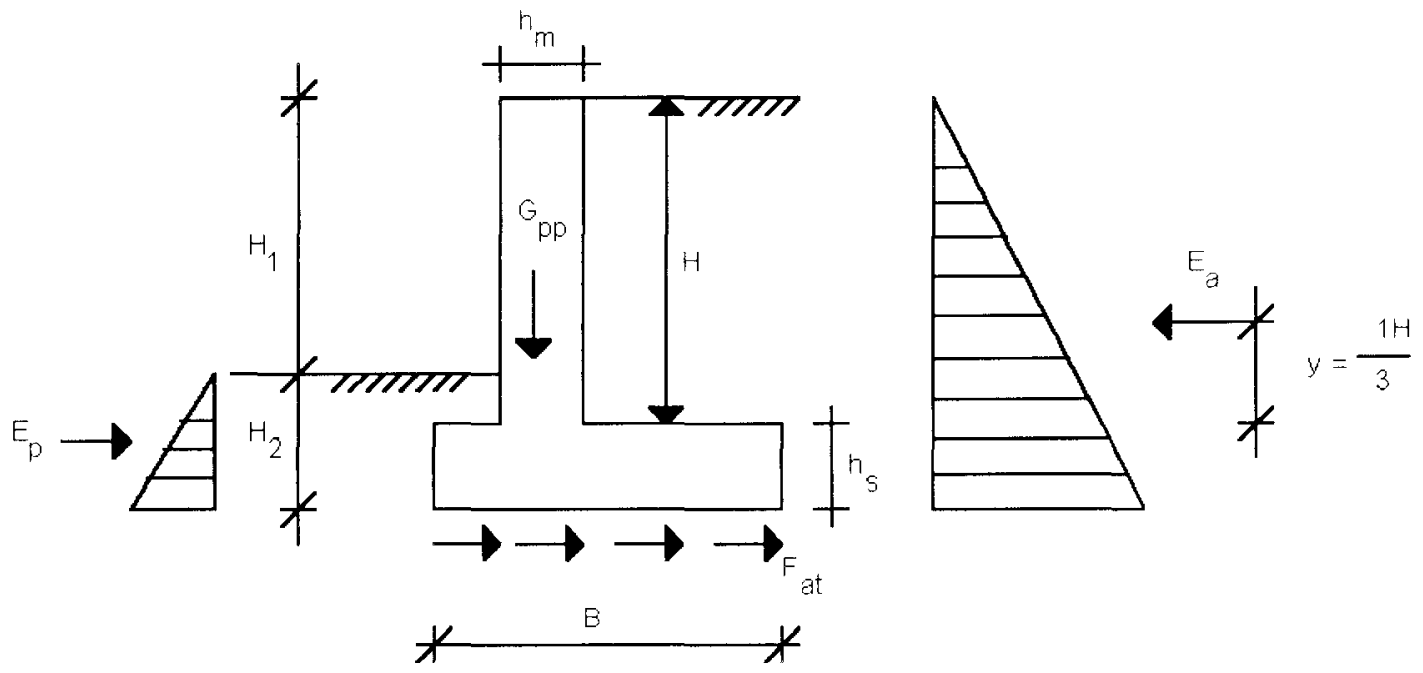

Figura 1.4 - Muro sem contraforte - Perfil clássico. 
De acordo com o desenho apresentado na Figura 1.4, têm-se:

$\mathrm{H}$ - altura total da parede de contenção;

B - largura total da sapata;

E - empuxo total aplicado à $1 / 3$ de $\mathrm{H}$;

$F_{a t}$ - força de atrito solo-estrutura.

As espessuras minimas da parede $\left(h_{m}\right)$ e da sapata $\left(h_{s}\right)$, usualmente adotadas com o mesmo valor, são determinadas a partir da seções transversais necessárias para resistir aos esforços solicitantes, ou sejam, momentos fletores e forças cortantes atuantes na região de engastamento.

O equilíbrio do muro de arrimo é obtido por ação da massa de solo na região interna, evitando o tombamento, e por ação do atrito entre o solo e a face inferior da sapata, evitando o deslocamento lateral.

\subsubsection{2 - Muro sem contraforte com perfil $L$}

É utilizado para pequenas alturas (até $2 \mathrm{~m}$ ). Os muros com perfil L podem apresentar ou não dente de ancoragem. O dente de ancoragem é usado para aumentar a resistência ao escorregamento, garantindo assim, maior ancoragem no terreno, como mostra a Figura 1.5.

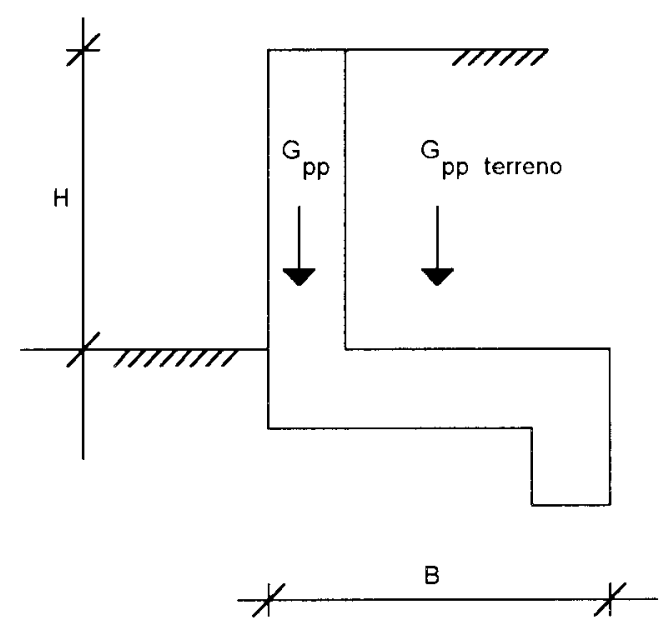


Figura 1.5 - Muro sem contraforte - Perfil L.

\subsubsection{3 - Muro sem contraforte com perfis especiais}

O muro de perfil especial mostrado na Figura 1.6, é utilizado para alturas de $2 \mathrm{~m}$ a $4 \mathrm{~m}$. São projetados com lajes intermediárias para aliviar a ação do empuxo de terra, mediante a ação do terreno do lado interno do muro, reduzindo assim os esforços na estrutura.

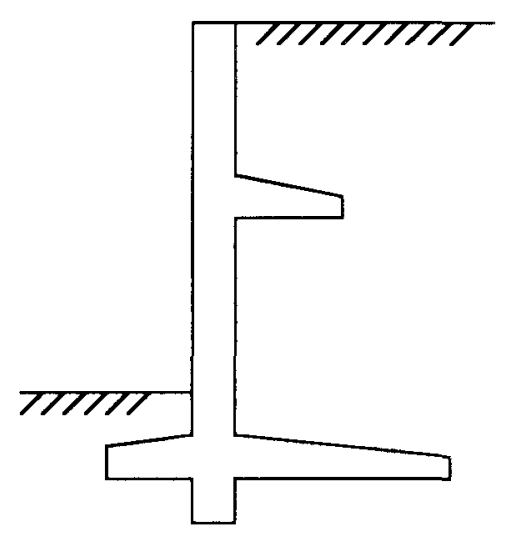

Figura 1.6 - Muro sem contraforte com perfis especiais.

\subsubsection{4 - Muro atirantado}

O muro atirantado é construído em terrenos com alturas de talude de $4 \mathrm{~m}$ a $6 \mathrm{~m}$. O topo do muro é preso por meio de tirantes fixados a uma placa de ancoragem. Essa placa esta rigidamente fixada em uma rocha ou solo resistente, a fim de evitar o seu deslocamento

Atualmente o muro atirantado vem sendo superado pelo uso de cortinas atirantadas, que apresentam maior facilidade e rapidez na construção.

A cortina atirantada, é composta por uma parede bastante rígida de concreto armado, que é fixada ao terreno através de cordoalhas de aço protendidas, recobertas por calda de cimento aplicado sob pressão. 


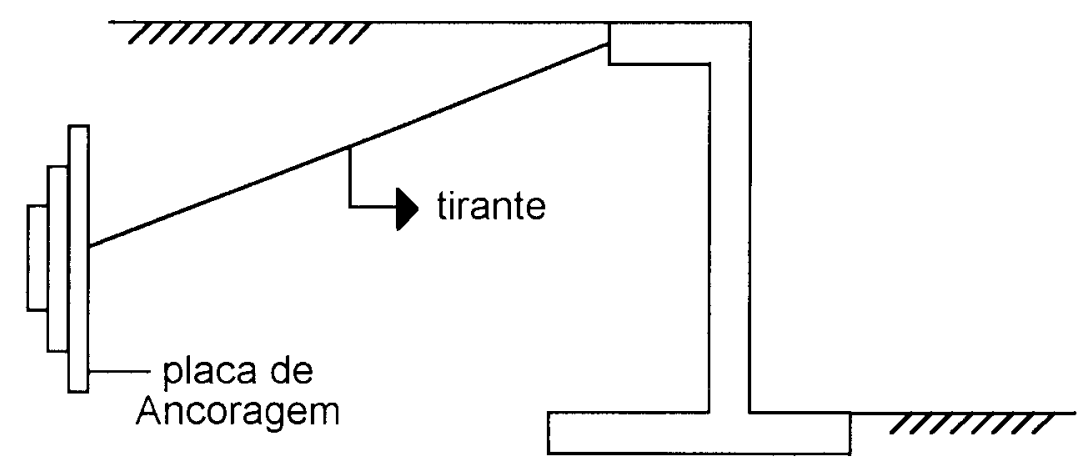

Figura 1.7 - Muro atirantado (Rocha, 1974).

\subsection{3 - Muro em Concreto Armado com Contrafortes}

São projetados para casos de terrenos que apresentam altura compreendida entre $6 \mathrm{~m}$ a $9 \mathrm{~m}$.

Neste caso, a laje vertical é calculada como contínua, recebendo como ação as pressões do terreno.

Os contrafortes, são elementos estruturais, que tem por finalidade transmitir as ações provenientes das lajes da cortina à sapata.

Os esforços solicitantes nas lajes verticais são determinados considerando-se engastados na ligação com os contrafortes, engastados na sapata e livres na borda superior.

O dimensionamento dos contrafortes é feito tomando-se como esforços os momentos fletores na laje vertical devidos ao empuxo, e os pesos próprios da laje e do contraforte.

Para o dimensionamento da sapata, consideram-se o empuxo total atuante nas lajes, assim como os pesos da terra e do muro no seu conjunto.

O uso do elemento estrutural de ancoragem só é projetado quando há necessidade de ancoragem devido ao escorregamento, por ser pequena a contribuição do atrito entre o solo e a face inferior da sapata. 

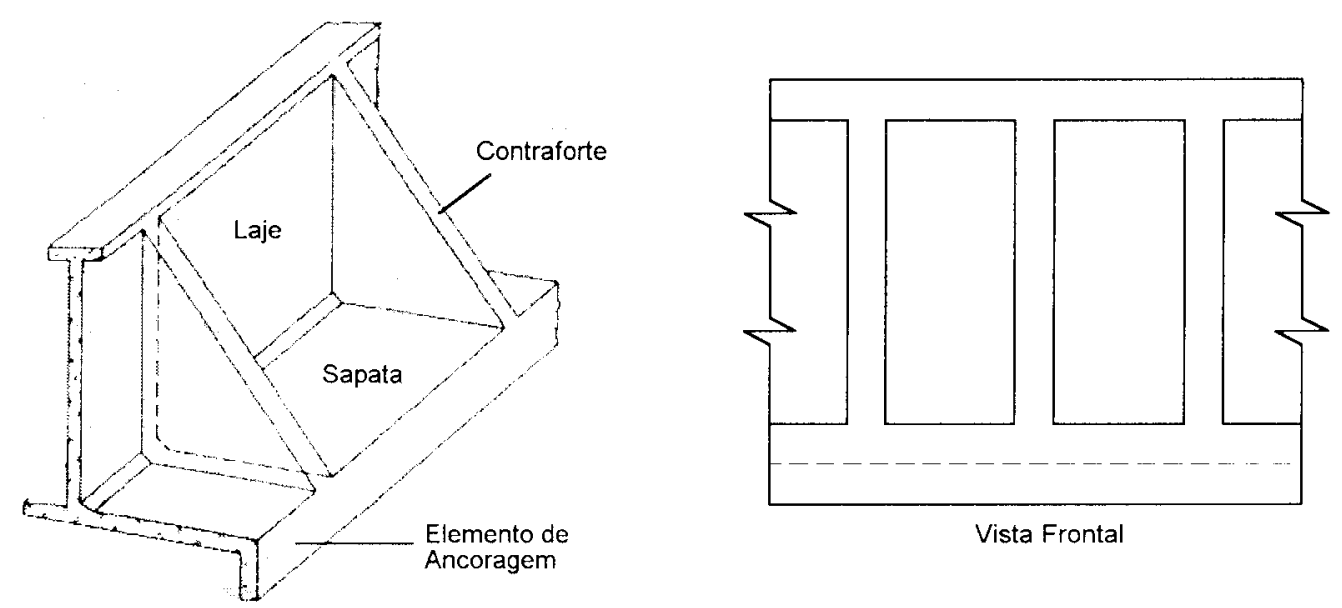

Figura 1.8 - Muro com contrafortes.

\subsubsection{1 - Muro com contrafortes e vigas intermediárias}

O muro com contrafortes e vigas intermediárias tem comportamento bastante parecido com o muro com contraforte, sendo acrescidas apenas as vigas intermediárias, que são vigas horizontais, consideradas como contínuas. Essas vigas se apoiam nos contrafortes, recebendo a ação horizontal que the é transmitida pelas lajes vizinhas.

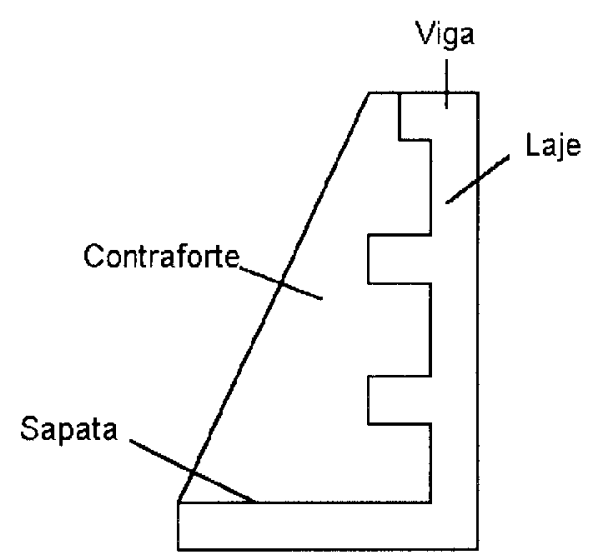

Vista Lateral

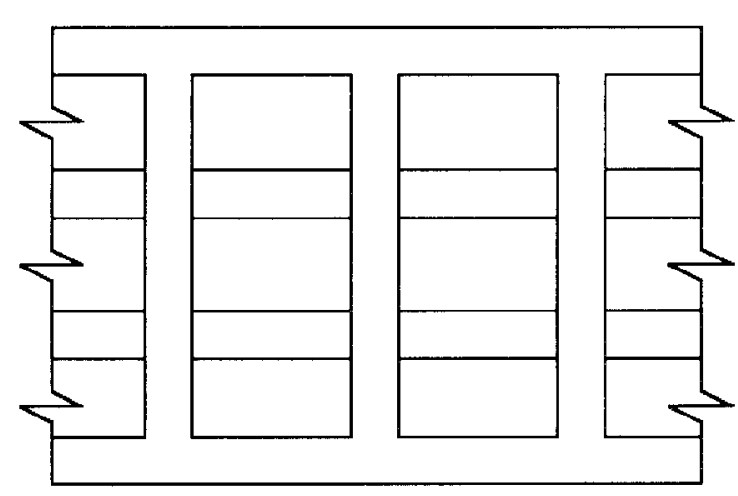

Vista Frontal

Figura 1.9 - Muro com contraforte e vigas intermediárias. 


\subsection{4 - Muro de Arrimo de Edifícios que Possuem Subsolo}

Para o caso de edifícios que possuem subsolo, o muro deve ser projetado para resistir ao empuxo de terra correspondente à diferença de nivel entre o terreno e o piso do subsolo.

A partir daí, pode-se destacar dois tipos de muro: os muros que funcionam como elemento de fundação e os muros exclusivamente para contenção do empuxo de terra.

\subsubsection{1 - Muros que funcionam como elemento de fundação}

Os muros que funcionam como elemento de fundação (Figura 1.10) têm dupla função: resistir ao empuxo de terra e transmitir as ações dos pilares ao terreno.

Os esforços solicitantes que servem como elemento de fundação são as forças cortantes e os momentos fletores que aparecem devido ao funcionamento do muro como viga.

O muro é estudado como viga continua, recebendo como ação a reação do terreno, que é oriunda da distribuição da ação dos pilares sobre o terreno.

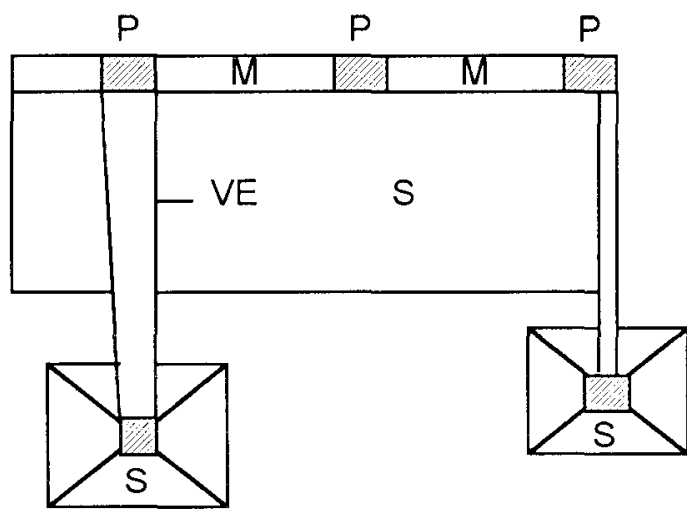

M - Muro

P - Pilar

S - Sapata

VE - Viga de Equilíbrio 
Figura 1.10 - Muros que funcionam como elemento de fundação.

\subsubsection{2 - Muros exclusivamente de contenção do empuxo de terra}

Os muros exclusivamente para contenção do empuxo de terra (Figura 1.11), não funcionam como elemento de fundação, tendo como função vencer a diferença de nível entre o terreno e o piso do subsolo.

Toda sua ação, não somente devido ao empuxo, mas também às ações verticais e o peso próprio são transmitidas aos pilares, uma vez que não há fundação própria para o muro

Para as ações verticais, peso próprio do muro e ações das lajes do pavimento térreo, a verificação da segurança do muro deve ser feita considerando-se os critérios de viga-parede.

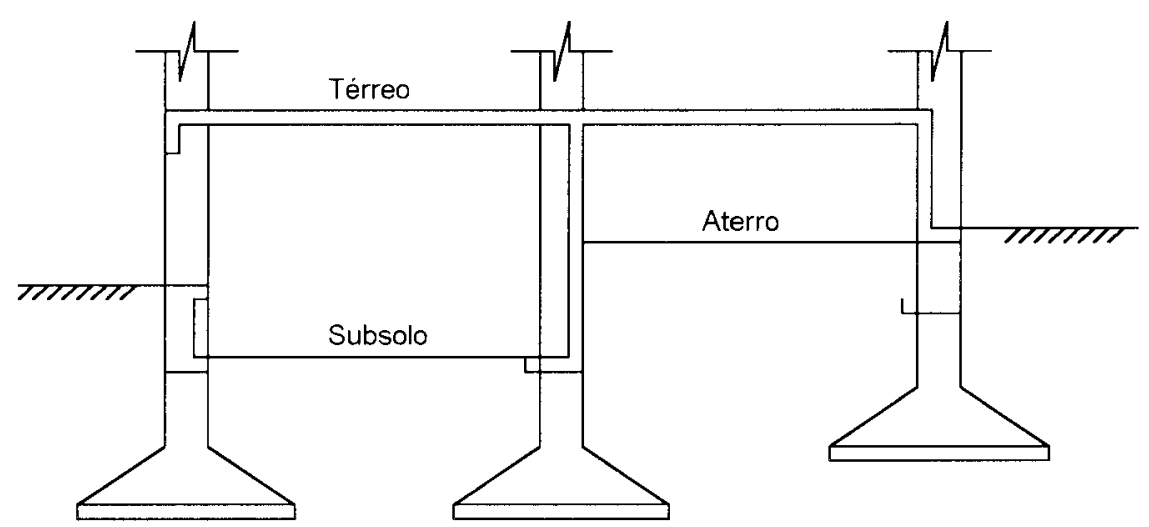

Figura 1.11 - Muro exclusivamente de contenção de empuxo de terra.

\subsection{5 - Concepções Estruturais Alternativas}

\subsubsection{1 - Muro de arrimo em alvenaria armada de blocos de concreto}


Pode ser utilizado tanto para muros corridos tanto para muros com contrafortes. Oferece grandes facilidades de execução, porém só recomendado para muros de pequena altura.

Neste tipo de muro (Figura 1.12) não é necessário utilizar fôrmas para a construção, o que gera economia e rapidez de execução.

A parede está submetida à flexão e deve ser considerada engastada na laje da sapata.

Os critérios para verificação da segurança da parede de alvenaria devem seguir os indicados por normas e compêndios de alvenaria estrutural.

Piscinas de pequenas alturas também podem ser executadas com este processo, desde que se verifique a impermeabilidade.
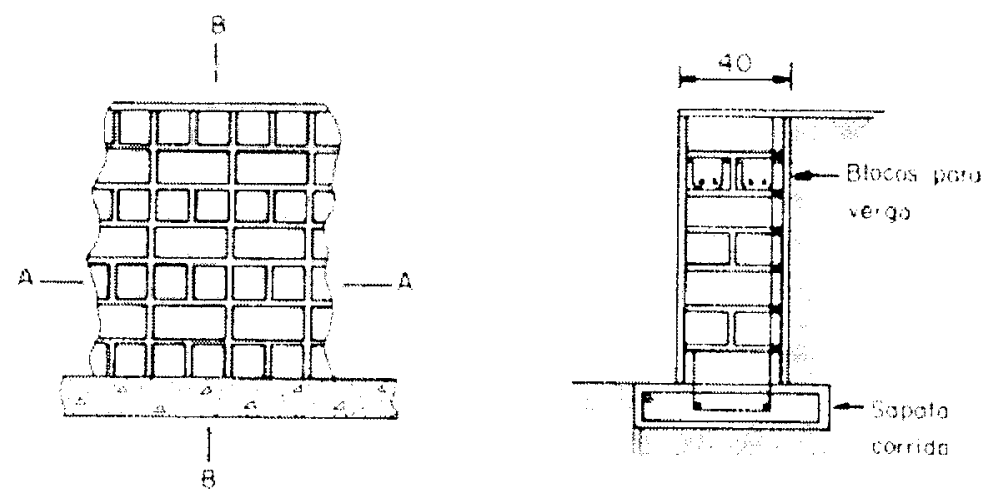

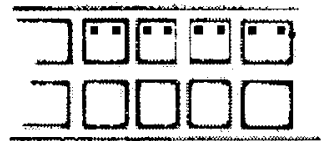

Corte A-A

Corte B-B

Figura 1.12 - Alvenaria armada de blocos de concreto

\subsubsection{2 - Muro de arrimo tipo "Crib wall"}

Também conhecido como muro em forma de fogueira (Figura 1.13), executado em elementos pré-moldados de concreto armado, peças de madeira e eventualmente pneus, empregados para pequenos desníveis. 
O equilíbrio do sistema é obtido com o preenchimento de seu interior com terra devidamente compactada. Sua maior restrição é a estética, uma vez que é bastante deformável.
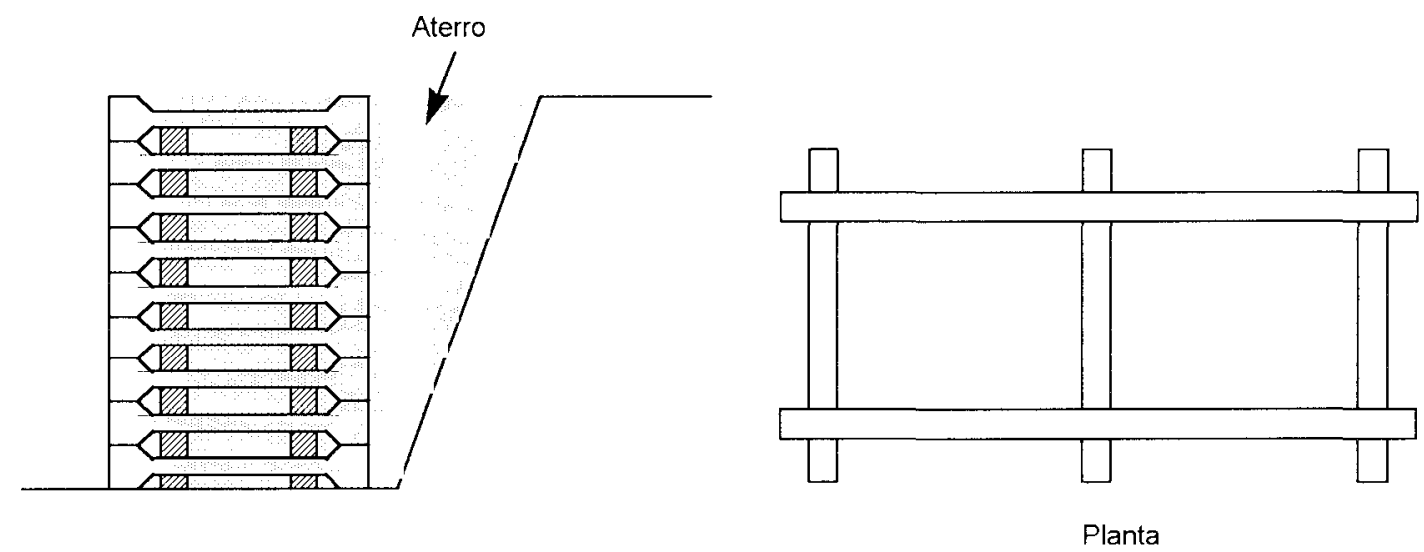

Figura 1.13 - Muro tipo "Crib wall"

\subsubsection{3 - Muro de arrimo em terra armada}

É constituído por placas pré-moldadas de concreto armado (Figura 1.14), com encaixe próprio, formando um mosaico e contendo uma tira de aço galvanizado com proteção de polietileno e o próprio solo local. Tal processo exige a execução de um aterro rigorosamente controlado entre o corte e o tardoz junto às placas.

A disposição das fitas entre as camadas de solo compactadas aumenta a resistência do solo ao cisalhamento, formando uma massa de solo estável. As fitas são ligadas aos elementos pré-moldados de concreto armado por meio de conectores metálicos, fixados no elemento prémoldado, onde as fitas são parafusadas.

Esta solução exige grandes movimentos de terra, sendo mais utilizadas onde se fazem necessário aterro. 


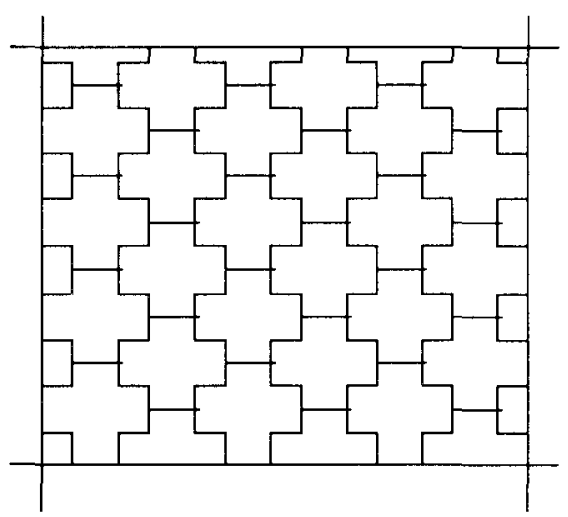

a) vista

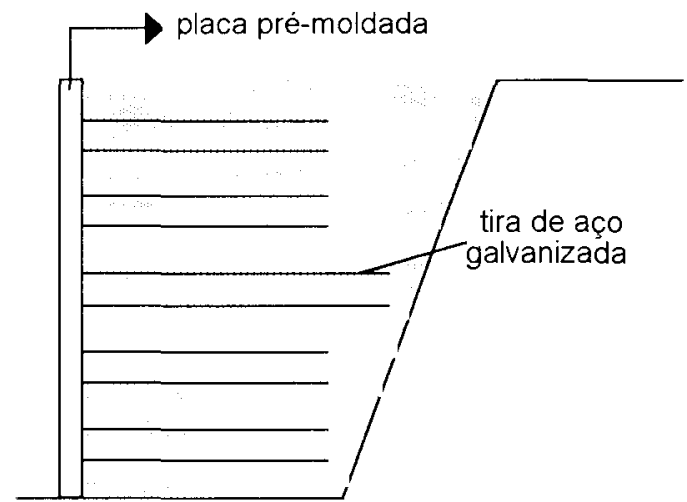

b) corte vertical

Figura 1.14 - Terra armada.

\subsubsection{4 - Muro de arrimo com fundação em estaca raiz}

De uma maneira geral, o sistema consiste na perfuração do terreno com equipamento rotativo com diâmetro de $100 \mathrm{~mm}$, revestindo o furo com tubo plástico, onde é introduzido uma barra de aço seguida da injeção de argamassa de cimento (Figura 1.15).

O conjunto formado por um elevado número de estacas, resulta na consolidação do solo circunvizinho.

É um sistema de contenção de talude, também utilizado para consolidação de estruturas quando as estacas de grandes diâmetros se tornam inadequadas. 


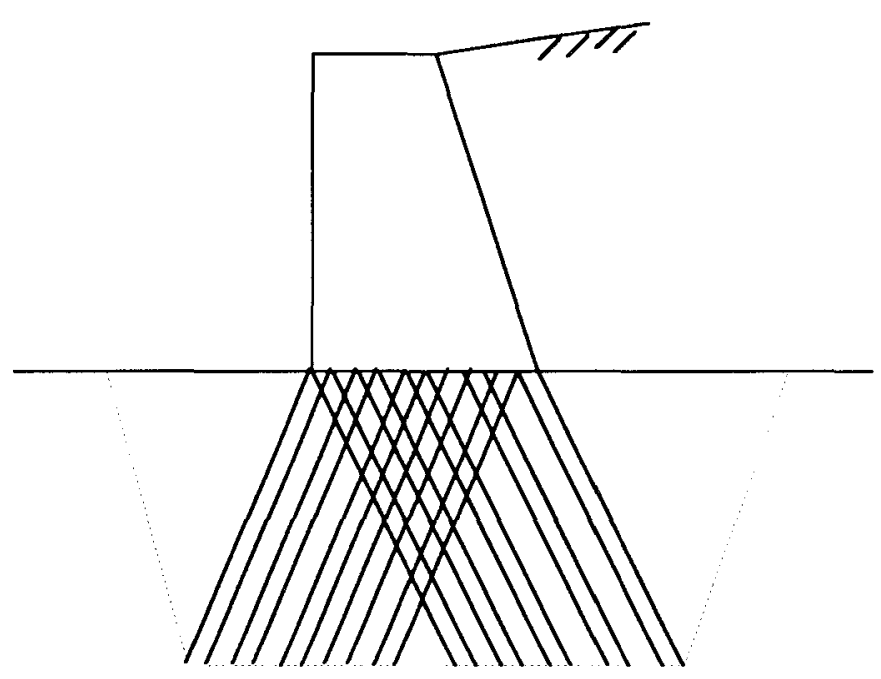

Figura 1.15 - Estaca raiz.

\subsubsection{5 - Parede diafragma}

São cortinas de concreto armado, moldadas no solo, em painéis sucessivos, dando origem a uma parede bastante rígida e forte. As cortinas também podem ser pré-moldadas

O processo construtivo da parede, resume-se em quatro fases distintas (Figura 1.16):

A escavação é feita em trincheiras alternadas com equipamento tipo "clam-shell". Estas trincheiras vão sendo constantemente cheias com lama betonítica a fim de evitar o desmoronamento.

Terminada a escavação, mantém-se a trincheira cheia de lama a fim de provocar pressão hidrostática equilibrante e, por ação química, impermeabilizar as paredes da trincheira.

A próxima etapa consiste na introdução de uma armadura, previamente montada, seguida do lançamento do concreto, fazendo uso da técnica de concretagem submersa, conseguindo, assim, o total reaproveitamento da lama. 
Finalmente, após a concretagem é escavado o restante de solo à frente do paramento externo, permanecendo apenas uma ficha (parte do perfil que fica enterrada).

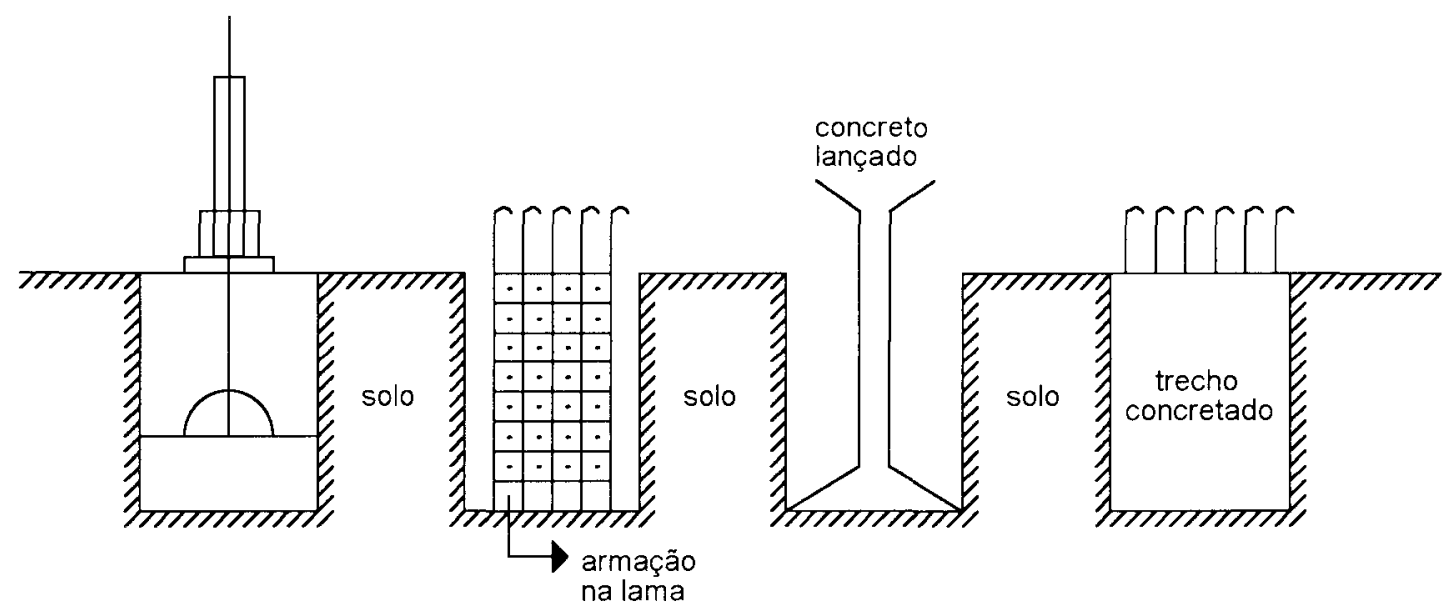

Figura 1.16 - Parede diafragma.

\subsubsection{6 - Estaca prancha metálica}

São estacas verticais de perfis metálicos, cravados de maneira a formar um alinhamento longitudinal, mantendo-se em equilíbrio pelo engastamento da ficha (Figura 1.17).

No caso de muros muito altos há a necessidade de atirantar ou escorar a prancha na sua parte superior.

A execução da cravação é feita com martelos de ar comprimido ou de vibração.

Devido às suas características, as estacas prancha, são indicadas para contenções em presença de água, sendo bastante difundida em obras portuárias. 


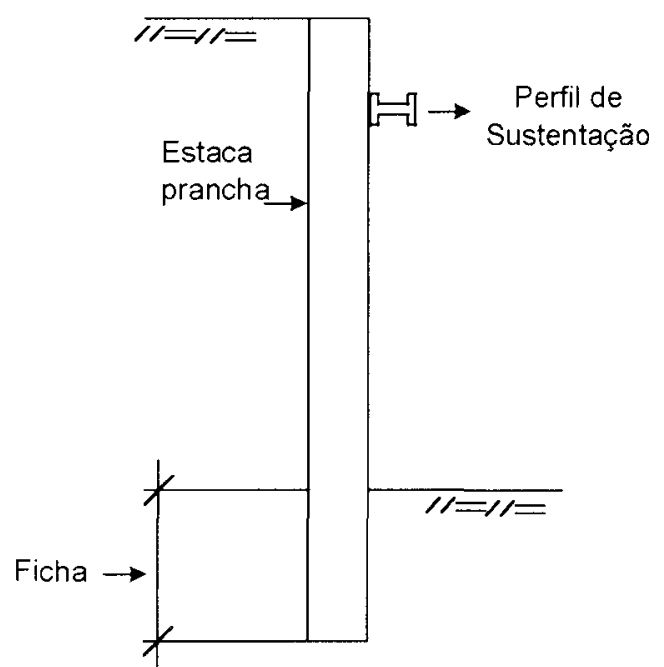

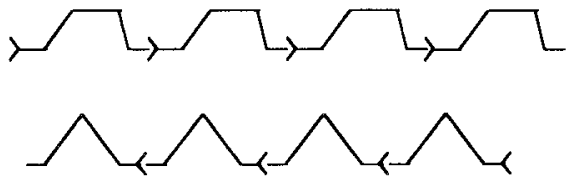

b) Seções transversais

a) corte vertical

Figura 1.17 - Estaca prancha metálica.

\subsubsection{7 - Gabiões}

Constitui um elemento estrutural que funciona por gravidade.

Consiste numa cesta de forma paralelepipédica de arame galvanizado de malha hexagonal (Figura 1.18), na qual são colocadas pedras de diâmetros aparentes de $20 \mathrm{~cm}$ à $30 \mathrm{~cm}$.

O empilhamento de várias cestas dá origem a um maciço em condições de resistir esforços horizontais, devido ao seu elevado peso próprio.

Sua principal vantagem é a elevada permeabilidade e grande flexibilidade, dando origem a estruturas monoliticas altamente drenantes e capazes de sofrerem deslocamentos e deformações sem se romperem.

Caso ocorra corrosão da tela durante a vida útil da obra, pode-se aplicar um jateamento de argamassa de cimento e areia no local, transformando o conjunto em um muro de concreto ciclópico.

Os gabiões são utilizados para proteção de margens de cursos d'agua, controle de erosão e obras de emergência. 

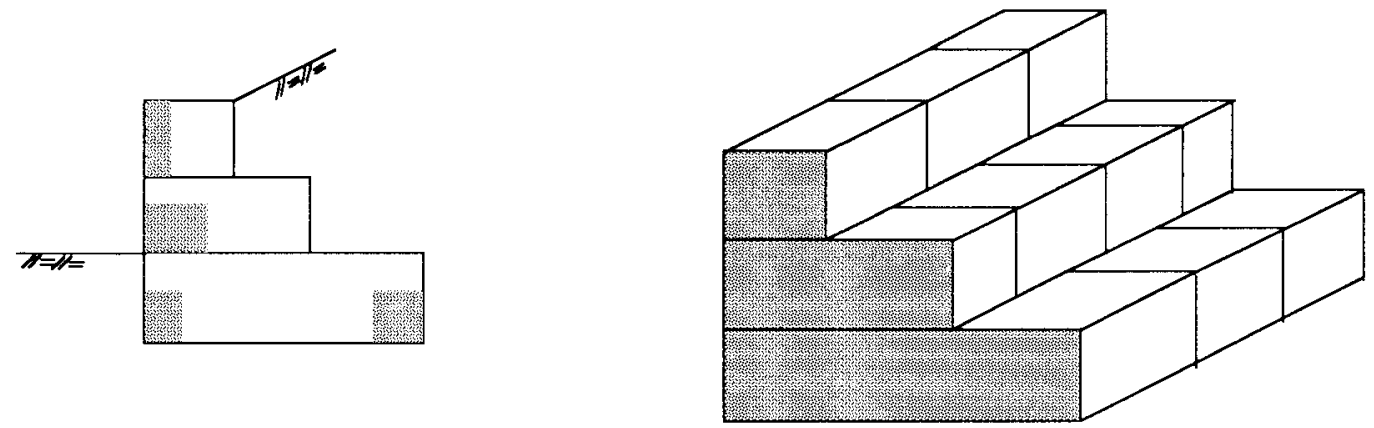

Figura 1.18 - Gabiões.

\subsubsection{8 - Sacos de solo cimento}

Funcionam por gravidade. É executado em sacos de aniagem ou de geossintéticos, preenchidos com solo cimento no teor de $8 \%$ à $10 \%$ de volume de cimento. Esses sacos são empilhados, resultando um maciço (Figura 1.19). É também empregado o uso de fôrmas de modo a obter as configurações desejadas.

Têm sido empregados sacos com capacidade de 35 litros (60 kg)

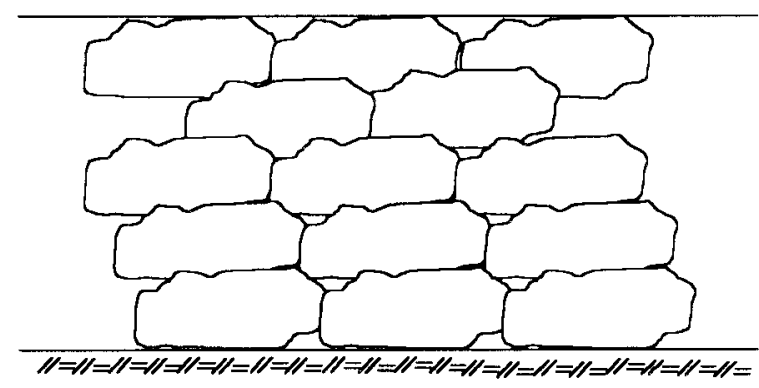

Figura 1.19 - Sacos de solo cimento 


\section{3 - Obras Complementares}

A drenagem em muros de arrimo se faz necessária devido à presença de água no terreno contido. Essa água, provoca o aumento do empuxo hidrostático, incrementando assim as pressões laterais sobre a estrutura de contenção.

Dimensionar a estrutura para suportar essas pressões laterais não é a melhor alternativa. A fim de conservar o solo seco e não provocar aumento de empuxo, faz-se uso de um sistema de drenagem.

Este sistema, mostrado na Figura 1.20, é formado basicamente por uma camada de solo mais permeável que o contido, geralmente areia e pedra britada, e a colocação de barbacãs, permitindo assim o rápido escoamento da água para o lado externo.

Os barbacãs são orifícios abertos no muro de arrimo, geralmente constituido por um tubo de pvc, com diâmetros que variam de $50 \mathrm{~mm}$ à $100 \mathrm{~mm}$, espaçados de $1 \mathrm{~m}$ a $2 \mathrm{~m}$ tanto na direção vertical quanto na horizontal, que estão associados à camada drenante vertical de pedra britada e areia. Esses tubos devem devem ser tampados com tela de nailon ou latão do lado da terra, a fim de evitar a fuga do material filtrante, no caso, areia e pedra britada.

A camada de areia e pedra britada deve ter espessura compreendida entre $15 \mathrm{~cm}$ à $20 \mathrm{~cm}$, dependendo exclusivamente das condições do solo.

Tubos drenos são manilhas furadas na parte superior, colocadas ao longo do talão da sapata, tendo como função conduzir a água para bueiros ou galerias de águas pluviais.

$\mathrm{Na}$ interface do solo contido com o mais permeável, é usual a colocação de uma manta de fios poliester, denominada Bidim. Essa manta Bidim tem a função de reter a penetração de partículas finas do solo contido para a camada drenante de areia e pedra britada, bem como permitir o escoamento da água acumulada. 


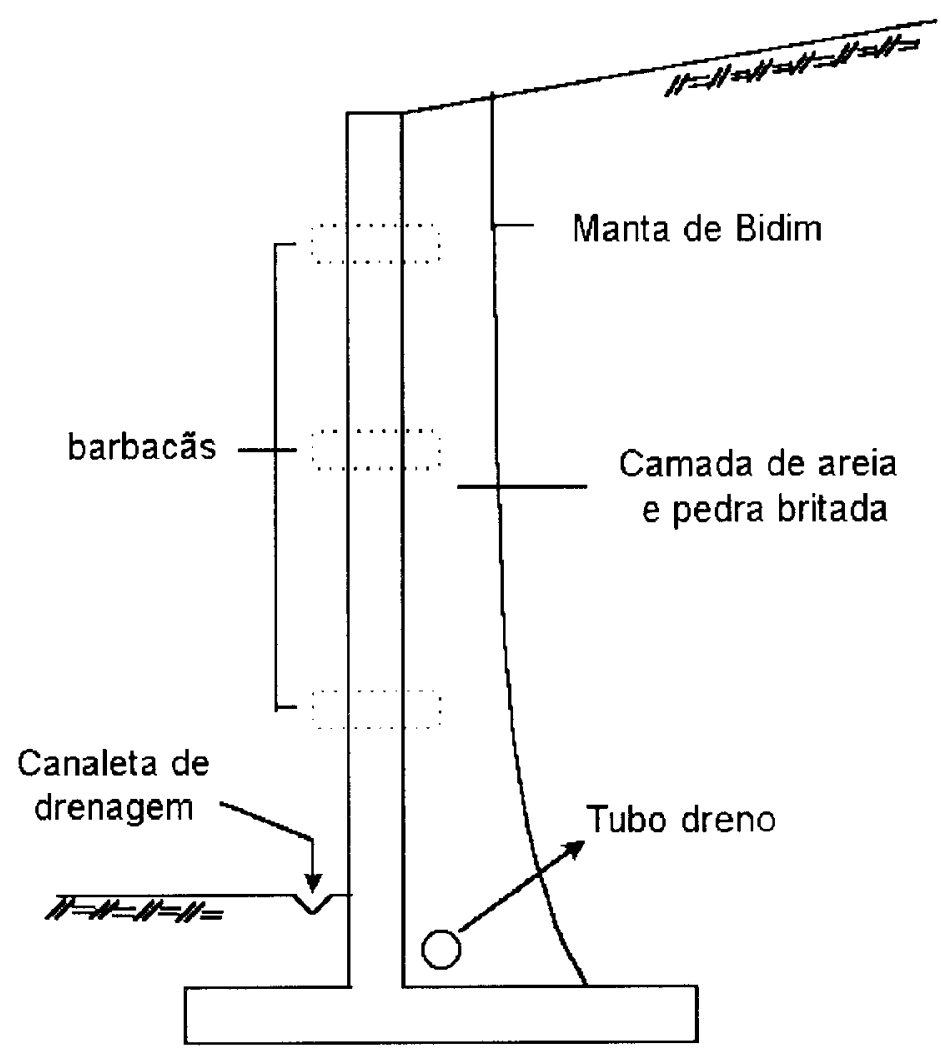

Figura 1.20 - Sistema de drenagem de um muro de arrimo. 


\section{2 - AÇÕES A CONSIDERAR}

\section{1 - Empuxo}

Empuxo é a força resultante de pressões laterais, de terra e/ou água exercidas contra o muro.

A determinção das tensões e deformações nos solos é um problema que envolve diversas grandezas, tais como o desnivel a ser vencido, ângulo de atrito interno do solo, coesão e peso especifico da massa de solo, deformação sofrida pela estrutura, permeabilidade e fluxo de água, tipos de solos, configração geométrica do terrapleno e da estrutura de contenção, entre outros.

Terzaghi observou experimentalmente em modelos, que as intensidades das pressões laterais que atuam sobre a estrutura de arrimo variam em função das translações dadas à estrutura, da seguinte forma: - À medida que a estrutura de arrimo é afastada do terrapleno, as pressões diminuem gradativamente até um valor mínimo.

- Se a estrutura de arrimo é empurrada contra o maciço, as pressões aumentam até um valor máximo.
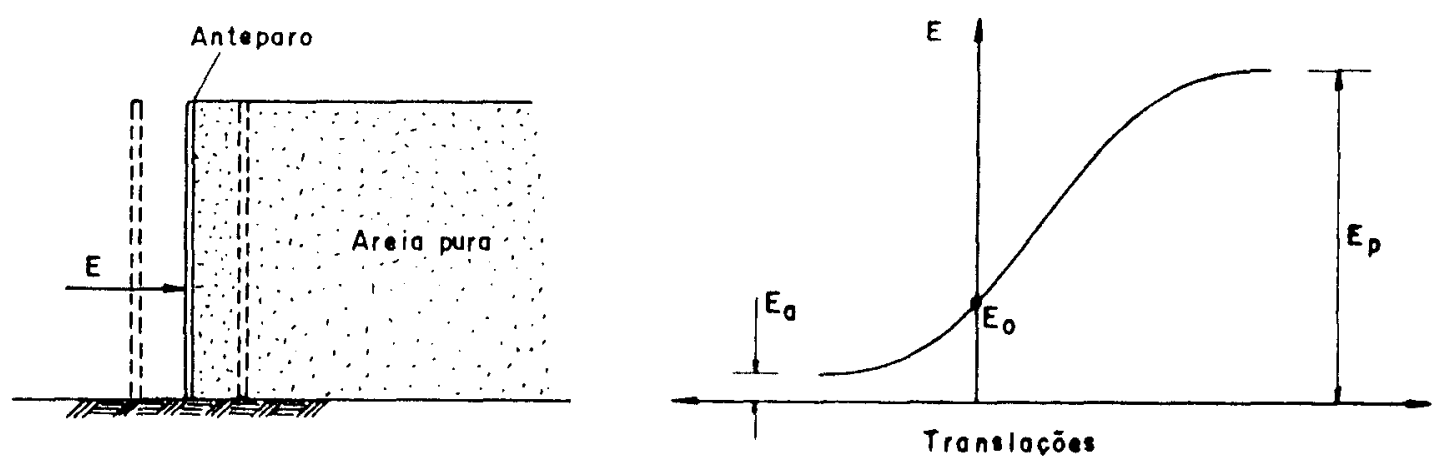

Figura 2.1 - Empuxo ativo, passivo e em repouso 
$E_{a}=$ empuxo ativo - é o valor mínimo do empuxo

$E_{p}=$ empuxo passivo - é o valor máximo do empuxo

$E_{o}=$ é a resultante da pressão lateral quando a estrutura não sofre deformação

É sempre bom estar atento ao excesso de umidade e encharcamento de água no solo, fatores estes que aumentam o efeito do empuxo, sendo necessária a utilização de drenagem ao longo da altura do muro.

\section{2 - Empuxo ativo, passivo e em repouso}

Os estudos para o cálculo do empuxo foram formulados por Coulomb em 1773, Poncelete em 1840 e Rankine em 1856, teorias estas conhecidas como antigas, que oferecem bons resultados para o caso de muros de gravidade construídos em alvenaria ou concreto ciclópico.

Para o caso de muros elásticos ou isolados, construídos em concreto armado, têm-se as teorias modernas. Destacam-se as de Resal (1910), Caquot (1949), Boussinesq (1885), Muller Breslau (1906), sendo que nos ultimos 30 anos foi Terzaghi que apresentou os resultados mais práticos.

Tendo em vista a grande diversidade de grandezas a considerar, os modelos matemáticos que tem sido propostos para determinação do empuxo ou são muito simples, apresentando bons resultados apenas para problemas particulares ou para alguma grandeza que se deseja conhecer, ou são por demais complexos, de dificil utilização na prática.

$\mathrm{Na}$ determinação da resultante do empuxo, alguns modelos levam a resultados bastante próximos, o que conduz a utilização de modelos mais simples. 


\subsection{1 - Empuxo em repouso}

Considere um semi-espaço de um solo homogêneo de peso específico $\left(\gamma_{t}\right)$, sem qualquer solicitação atuando na superfície e, que por hipótese não há água neste solo, como mostra a Figura 2.2.

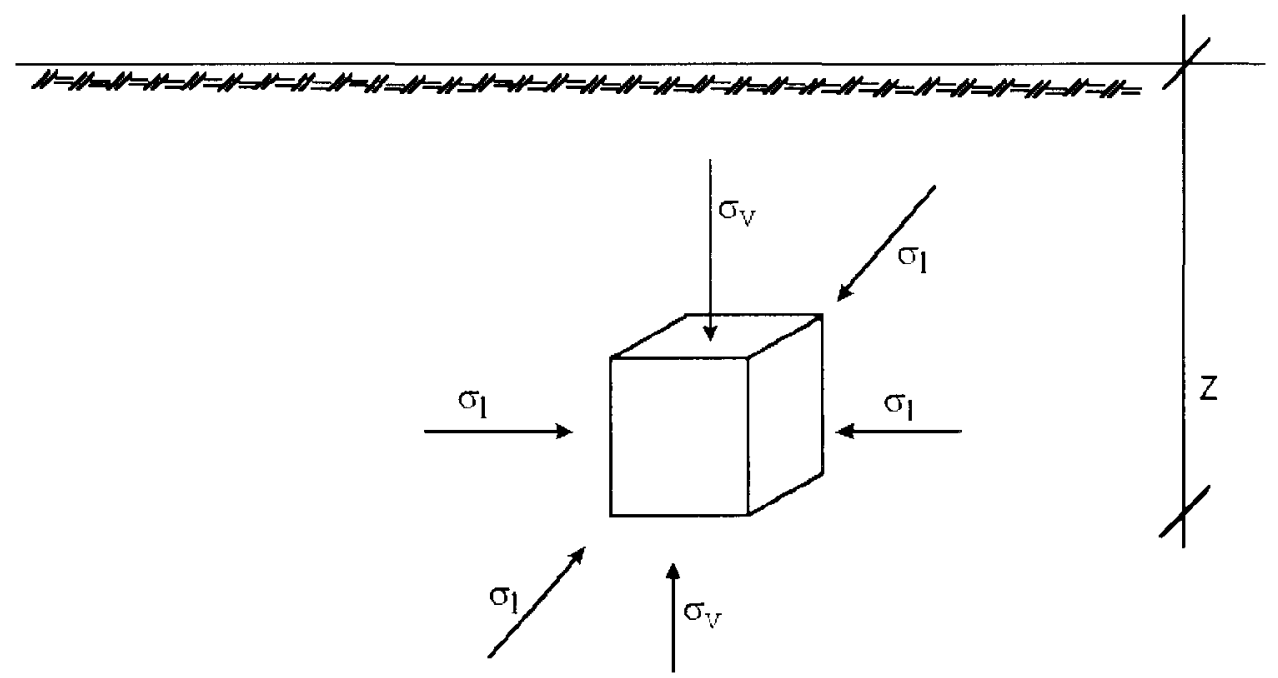

Figura 2.2 - Semi-espaço de um solo homogêneo.

As tensões existentes no solo são devidas exclusivamente às ações resultantes do peso próprio. Assim, a tensão vertical $\left(\sigma_{v}\right)$, a uma profundidade $\mathrm{z}$, será igual a:

$$
\sigma_{v}=\gamma_{1} z
$$

Em virtude da simetria existente, as pressões laterais são iguais, acarretando a ausência de tensões tangenciais nos planos vertical e 
horizontal, pelo que as tensões principais terão exatamente as direções horizontal $\left(\sigma_{\ell}\right)$ e vertical $\left(\sigma_{v}\right)$.

Esta é a situação do empuxo em repouso, quando ainda não foram introduzidas quaisquer deformações associadas à realização de operações afetando este solo.

Imagine que uma parte do semi-espaço poderia ser retirada, procurando substituir seus efeitos por uma parede vertical, sem que deste modo o solo sofresse qualquer deformação (Figura 2.3)

As tensões exercidas sobre a parede seriam exatamente as mesmas da situação original, ou seja, variáveis com a profundidade z e a sua resultante é dita empuxo em repouso.

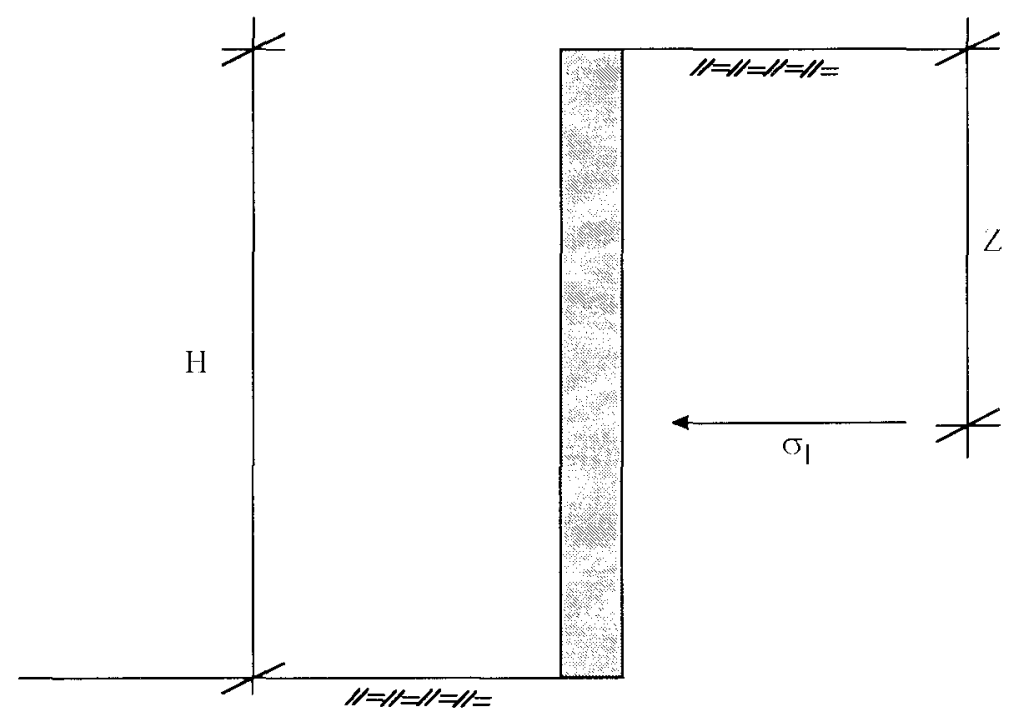

Figura 2.3 - Pressão lateral na parede de contenção

A relação entre as pressões lateral e vertical, denominada de coeficiente de empuxo em repouso, é definida pela expressão 2.2.

$$
\mathrm{k}_{0}=\frac{\sigma_{\ell}}{\sigma_{\mathrm{v}}}
$$


O valor de $k_{0}$ é aproximadamente constante com a profundidade para solos de origem sedimentar natural ou deposição artificial com restrição às deformações laterais. Sendo assim, quando apenas estiver atuando o peso próprio do solo, as pressões laterais variarão linearmente, para uma largura unitária da parede, através da expressão 2.3.

$$
\sigma_{f}=k_{0} \gamma_{t} z
$$

Para solos normalmente consolidados (solos arenosos e argilas normalmente adensadas), Jaky em 1944, determinou de maneira empírica o valor de $k_{0}$, como sendo:

$$
k_{0}=(1-\operatorname{sen} \phi)
$$

onde $\phi$ é o ângulo de atrito interno do solo.

O valor do empuxo em repouso de um terrapleno horizontal, sem ação de sobrecarga, agindo sobre uma parede vertical, de altura $H$, indeslocável, é dado por:

$$
E_{0}=\int_{0}^{H} \sigma, d z=\int_{0}^{H} k_{0} \gamma_{y} d z
$$

Que integrando, vem:

$$
E_{0}=\frac{1}{2} k_{0} \gamma_{t} H^{2}
$$

Caso a parede venha a apresentar algum deslocamento, a pressão lateral será diferente daquela de repouso, enquanto que a tensão vertical manter-se-á constante.

Quanto ao valor da pressão lateral, ela irá evoluindo a partir do seu valor em repouso, diminuindo ou aumentando conforme o deslocamento da 
parede é no sentido de afastamento (empuxo ativo) ou de aproximação do terreno (empuxo passivo), respectivamente.

\subsection{2 - Empuxo ativo e passivo}

O estudo do empuxo ativo e passivo é feito a partir das teorias antigas e modernas, já comentadas no item 2.2, como detalhadas a seguir.

\subsubsection{1 - Teoria de Coulomb}

Coulomb [1776] parte do princípio de que ocorre um deslizamento segundo uma superfície plana, devido a mobilização da resistência ao cisalhamento ou atrito $e$, analisa as forças que agem na cunha limitada por esta superfície, pelo tardoz e pela superfície do terrapleno

Este deslizamento ocorre segundo uma superfície de curvatura em forma de espiral logarítmica, que é substituída, por motivos práticos, por uma superfície plana que passa a ser denominada plano de ruptura, plano de deslizamento ou plano de escorregamento (Figura 2.4).
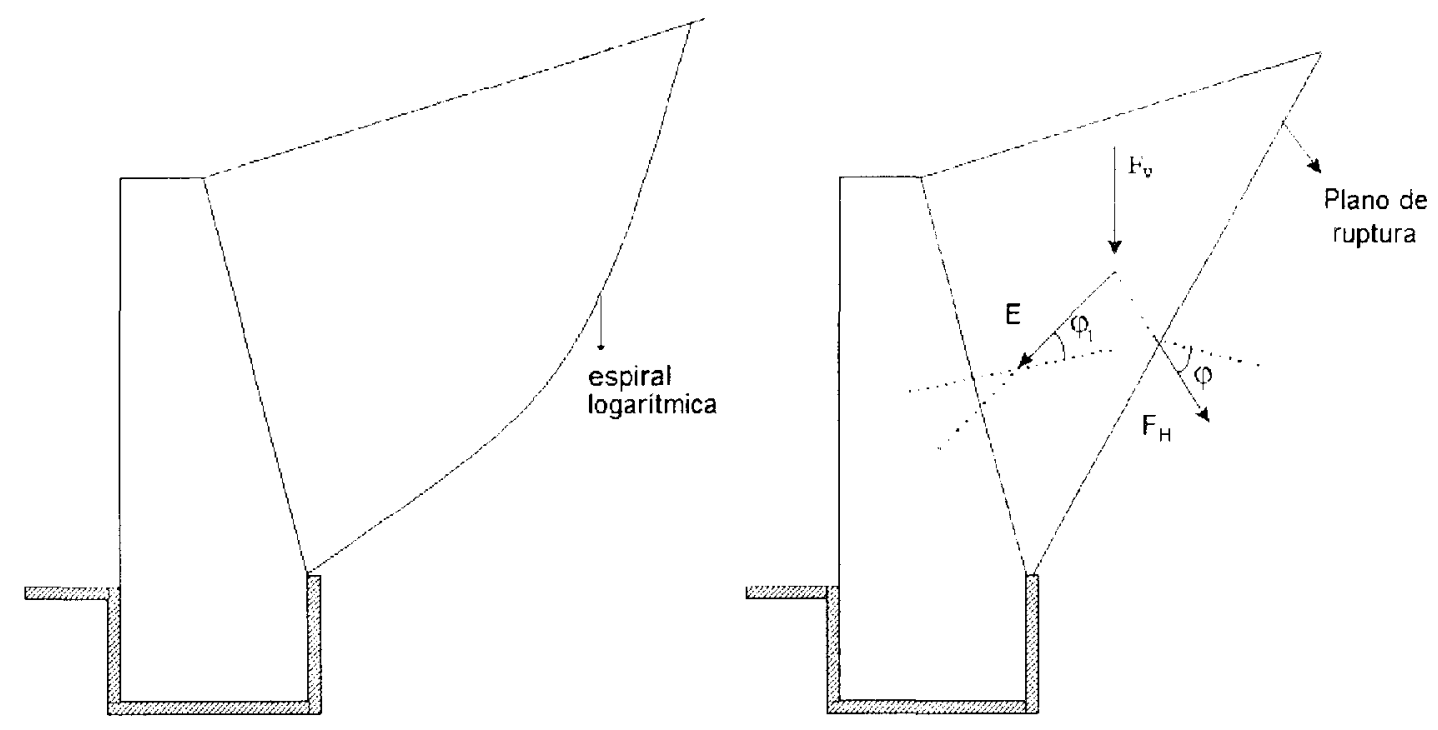
Figura 2.4 - Linhas de ruptura de Coulomb

O empuxo faz com a normal ao paramento do lado da terra, um ângulo $\varphi_{1}$ (coeficiente de atrito entre a terra e o muro).

As forças consideradas agindo sobre a cunha sãoo seu peso próprio $(P)$, a reação do terreno $\left(F_{H}\right)$ e a reação da estrutura de arrimo $(E)$.

Esta grandeza E é considerada como uma pressão distribuída ao longo do muro, cujo diagrama de distribuição, para simplificação de cálculo, é admitida linear.

Partindo de uma coluna de líquido, $E=0,5 \gamma_{1} h^{2}$, e corrigindo esta expressão levando em consideração o atrito entre as partículas do solo com o muro, a rugosidade do muro e a inclinação do terreno com a horizontal, através de um coeficiente $k$ (coeficiente de empuxo de Coulomb), chega-se à expressão (2.7) para solos arenosos:

$$
E=\frac{1}{2} \gamma_{t} k h^{2}
$$

Sendo:

$$
\begin{aligned}
& \gamma_{1} \text { - peso específico do solo } \\
& \text { k - coeficiente de empuxo } \\
& \mathrm{h} \text { - altura do muro }
\end{aligned}
$$

O valor do coeficiente de empuxo foi definido por Rebhann como sendo:

$$
k=\frac{\operatorname{sen}^{2}(\beta+\varphi)}{\operatorname{sen}^{2} \beta \operatorname{sen}(\beta+\varphi)\left[1+\sqrt{\frac{\operatorname{sen}(\varphi-\alpha) \operatorname{sen}\left(\varphi+\varphi_{1}\right)}{\operatorname{sen}(\beta-1) \operatorname{sen}(\beta+\alpha)}}\right]^{2}}
$$

onde:

$\alpha=$ ângulo de inclinação do terreno adjacente; 
$\theta$ = ângulo de inclinação do paramento interno do muro com a vertical;

$\beta=90-\theta$;

$\varphi=$ ângulo de talude natural ou angulo de atrito interno;

$\varphi_{1}=$ ângulo de atrito entre a terra e o muro ou ângulo de rugosidade do muro

O valor do coeficiente $k$ pode ser simplificado, nos casos de aplicações práticas, modificando a expressão 2.8, nos seguintes casos:

a - Paramento interno liso e vertical

$$
\varphi_{1}=0 ; \quad \theta=0 ; \quad \beta=0
$$

b - Paramento interno liso, inclinado do lado da terra e terreno horizontal

$$
\alpha=0 ; \quad \varphi_{1}=0
$$

c - Paramento interno liso, inclinado do lado da terra e terreno com inclinação

$$
\alpha=\varphi ; \quad \varphi_{1}=0
$$

d - Paramento interno liso, vertical e terreno com inclinação

$$
\alpha=\varphi ; \quad \theta=0 ; \quad \varphi_{1}=0
$$

e - Paramento interno liso, vertical e terreno adjacente horizontal

$$
\alpha=0 ; \quad \varphi_{1}=0 ; \quad \theta=0
$$


Quando o solo for coesivo, deve ser considerada a coesão atuante na superfície de ruptura e no paramento da parede de contenção.

Um dos problemas apresentados pelos solos coesivos é a variação de volume devido a variações climáticas e a erosão causada por infiltração de água, entre outros fatores que poderão causar deformações.

Como critério de segurança deve-se considerar a coesão em obras onde há controle técnico permanente da drenagem superficial do terreno.

\subsubsection{2 - Teria de Rankine}

A teoria baseia-se na hipótese de que uma ligeira deformação do solo, é suficiente para gerar um estado limite plástico em toda massa de solo que pode movimentar-se, atingindo a máxima resistência ao cisalhamento deste solo.

Esta mobilização pode produzir um estado ativo se o solo sofre expansão ou passivo caso o solo sofre retração.

Fazem-se, assim, necessário algumas hipóteses para a utilização da teoria de Rankine, o que pode ser observado na Figura 2.6, desde que não haja percolação de água. 

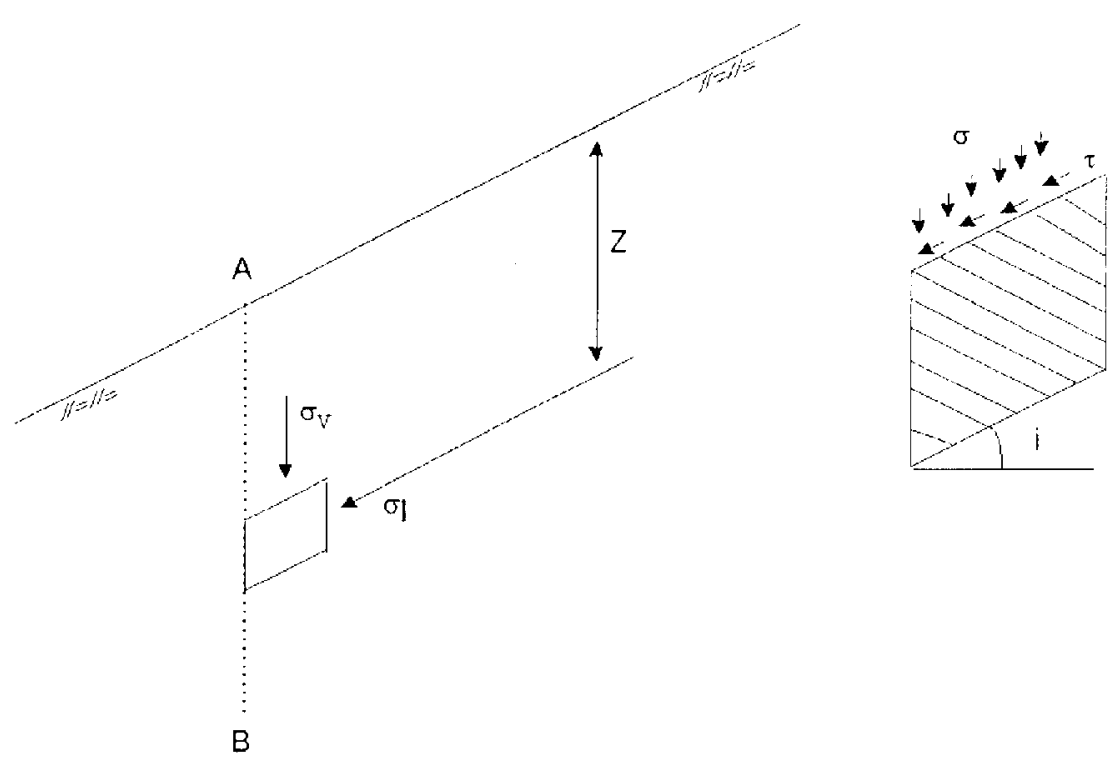

Figura 2.5 - Pressões sobre um elemento de solo [Gaioto, 1979].

As pressões $\sigma_{v}$ e $\sigma_{\rho}$ constituem um par conjugado de tensões. Fazendo uso da Teoria de Mohr, calcula-se $\sigma_{f}$ na condição de ruptura, provocada por um deslocamento do plano $A B$ para a esquerda, ou para a direita, que produz expansão ou retração do solo.

Atingindo o estado limite, as tensões laterais $\left(\sigma_{\ell}\right)$, numa região de massa de solo, ficam determinadas e a obtenção do empuxo consiste na integração daquelas tensões ao longo de toda a altura do muro, a cada metro, pela expressão:

$$
E=\int_{0}^{H} k \sigma_{v} d z
$$

A partir dos valores das componentes normal $\left(\sigma=\gamma z \cos ^{2} \mathrm{i}\right)$ e cisalhante $\left(\tau=\gamma z\right.$ seni cosi), da pressão vertical $\left(\sigma_{v}\right)$, lançados no gráfico de Mohr, chega-se ao valor do coeficiente $k$ através de relações geométricas, pelo qual é representado o critério de resistência e o estado de tensões num ponto qualquer da massa de solo em plastificação. 
O valor dos coeficientes ativo a passivo, valem respectivamente:

$$
\begin{aligned}
& k_{a}=\frac{\cos i-\sqrt{\cos ^{2} i-\cos ^{2} \varphi}}{\cos i+\sqrt{\cos ^{2} i-\cos ^{2} \varphi}} \\
& k_{p}=\frac{\cos i+\sqrt{\cos ^{2} i-\cos ^{2} \varphi}}{\cos i-\sqrt{\cos ^{2} i-\cos ^{2} \varphi}}
\end{aligned}
$$

No caso de muros, com terrapleno de superficie horizontal e parede de contenção vertical, as expressões $(2.10)$ e (2.11), por apresentarem $i=0$ podem ser reduzidas à:

$$
\begin{aligned}
& k_{a}=\operatorname{tg}^{2}(45-\varphi / 2) \\
& k_{p}=\operatorname{tg}^{2}(45+\varphi / 2)
\end{aligned}
$$

Para a situação de solos coesivos, as expressões (2.12) e (2.13) resultam:

$$
\begin{aligned}
& \mathrm{k}_{\mathrm{a}}=\operatorname{tg}^{2}(45-\varphi / 2)-\frac{2 \mathrm{c}}{\sigma_{v}} \operatorname{tg}(45-\varphi / 2) \\
& k_{p}=\operatorname{tg}^{2}(45+\varphi / 2)+\frac{2 c}{\sigma_{v}} \operatorname{tg}(45+\varphi / 2)
\end{aligned}
$$

Finalmente, os valores dos empuxos ativo e passivo de Rankine, valem respectivamente, considerando as expressões 2.16 e 2.17 :

$$
E_{i}=\frac{1}{2} \gamma H^{2} \cos i \operatorname{tg}^{2}(45-\phi / 2)-c H \operatorname{tg}(45-\phi / 2)
$$




$$
E_{p}=\frac{1}{2} \gamma H^{2} \cos i \operatorname{tg}^{2}(45-\phi / 2)+c H \operatorname{tg}(45-\phi / 2)
$$

O método tem validade para o caso de estruturas de parede vertical e sem atrito no contato solo-parede. Somente assim, se consegue as condições de plastificação total da massa de solo junto à parede, como mostra a Figura 2.6

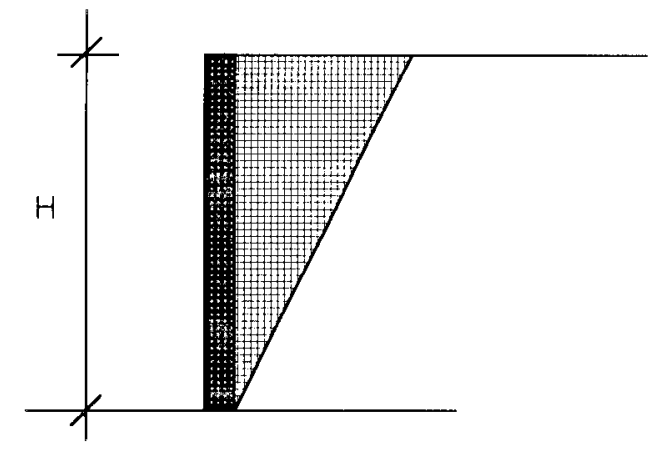

a) Estado ativo

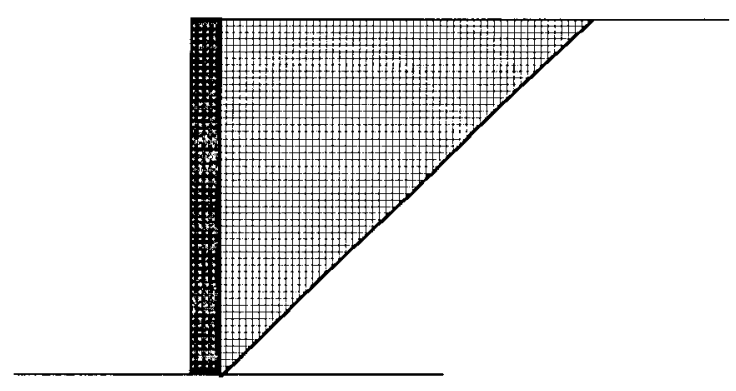

b) Estado passivo

Figura 2.6 - Estados limites de Rankine.

Para se obter as condições de plastificação total, não pode haver atrito no contato solo-parede, porque nesta situação se desenvolvem tensões tangenciais que obviamente interferem no equilíbrio do conjunto.

\subsubsection{3 - Outros métodos}

O método de Boussinesq [1885], surgiu no sentido de superar a limitação do método de Rankine, que admite não existir atrito entre o solo e parede.

Boussinesq admitia a hipótese de que as distribuições de tensões eram do tipo triangular. Com isto, conseguiu apenas obter alguns resultados mediante integração aproximada, válida apenas para o caso de empuxo ativo e para valores dos ângulos $(\omega)$ ângulo de inclinação do terreno 
adjascente e $(\beta)$ ângulo de inclinação do muro com a vertical, positivos e pequenos.

Caquot [1949], desenvolveu um método que possibilita a generalização da aplicação do método de Boussinesq, tornando possível o cálculo do empuxo ativo e passivo, para qualquer valor dos ângulos $\omega$ e $\beta$, para solos com e sem coesão, podendo também considerar a presença de sobrecargas uniformemente distribuidas na superfície.

Neste método, Caquot resolveu as equações, numericamente por processos aproximados e, apresentou ábacos para a solução do problema do empuxo no caso de paramento reto inclinado e superfície livre também inclinada. Os ábacos ( Rocha, A M. vol.3) fornecem o valor do coeficiente K', para o cálculo do empuxo total. Com o valor de k', chegaram às seguintes expressões:

$$
\begin{aligned}
& q_{e p 1}=k^{\prime} \gamma_{t} h_{0} \\
& q_{e p 2}=k^{\prime} \gamma_{t} h
\end{aligned}
$$

Nas expressões (2.18) e (2.19) $h_{0}$ é a altura de terra equivalente à sobrecarga e h é a altura do muro.

O coeficiente $k$ 'é obtido no ábaco em função dos parâmetros $(\beta)$ inclinação do paramento do muro; $(\omega)$ inclinação do terrapleno e $(\varphi)$ ângulo de atrito interno do solo

O valor do empuxo total, que é aplicado no centro de gravidade do trapézio, é dado por:

$$
E=\frac{q_{e p 1}+q_{e p 2}}{2} h
$$

O ábaco também fornece o valor do ângulo $(\alpha)$ que o empuxo resultante faz com a normal ao paramento do muro. 
Sokolovski [1960] parte das equações que determinam a distribuição de tensões no solo através do Critério de Resistência de Mohr-Coulomb, que define a máxima resistência ao cisalhamento do solo num certo plano de deslizamento.

A Figura 2.7, mostra que o plano onde ocorre o deslizamento é relacionado com um plano vertical $X O Z$, onde se impõe um estado plano de tensões.

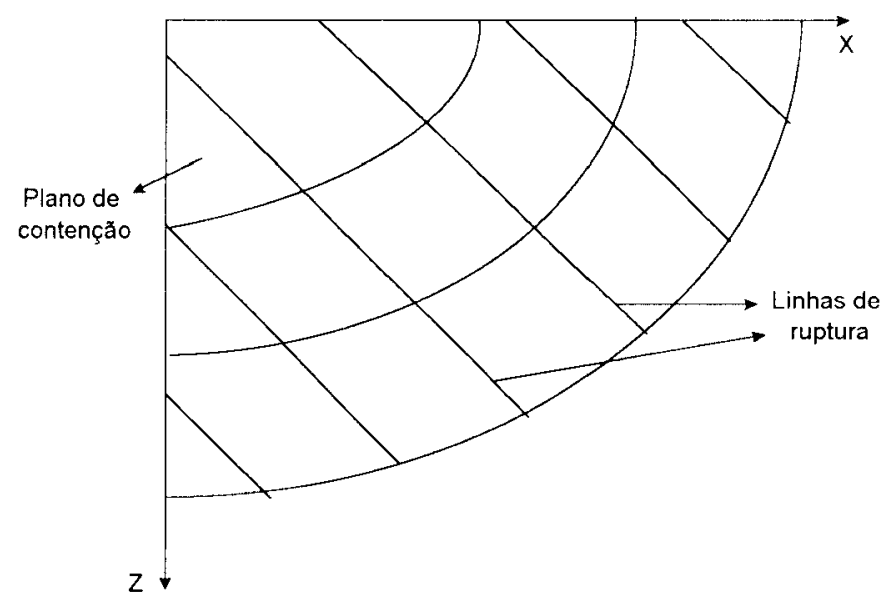

Figura 2.7 - Famílias de linhas de ruptura do método de Sokolovski.

A solução é constituída por duas famílias de curvas, onde estas famílias são linhas de deslizamento no meio do solo. A aplicação deste método fica condicionado ao conhecimento inicial das tensões num ponto de coordendas $(x, y)$,

para que a partir deste ponto seja gerada uma malha de pontos no cruzamento das linhas de ruptura.

A precisão do método é maior quanto maior for o número de pontos na malha escolhida, fazendo necessário o uso de programa para computador para maior precisão.

A resultante das tensões atuantes sobre a estrutura de contenção é o empuxo, podendo ser determinado em módulo, direção, sentido e ponto de aplicação para o caso particular do problema. 
Terzaghi, considera fundamental que no caso de muros deformáveis, o valor do empuxo de terra seja função da deformação do muro.

A partir desta consideração, e de resultados obtidos através de ensaios em modelo realizado no Masschusetts Institute of Techonology, Terzaghi pode concluir que:

Para o caso de movimento de rotação em torno da base do muro, basta um deslocamento da ordem de grandeza de $0,001 \mathrm{H}$, em que $\mathrm{H}$ é a altura do muro, para que se instale uma situação de equilibrio ativo.

Para que ocorra uma situação de empuxo passivo é necessário um deslocamento da ordem de grandeza de $0,02 \mathrm{H}$ à $0,05 \mathrm{H}$.

Com relação ao ponto de aplicação do empuxo, Terzaghi mostra que ele não está situado no terço como supõe a teoria de Coulomb e Rankine, mas que se aproxima mais do centro do muro.

\subsection{3 - Determinação do empuxo}

A determinação analítica do empuxo leva em consideração três situações possíveis: terreno sem ação variável aplicada, terreno com ação variável aplicada e nível freático superior ao da base do muro.

\subsubsection{1 - Terreno sem ação variável aplicada}

Para este caso, a determinação do empuxo é definida pelas equações abaixo, de acordo com a Figura 2.8 .

\section{- Empuxo}




$$
E=\frac{1}{2} \gamma_{t} \mathrm{kh}^{2} \quad[\mathrm{kN} / \mathrm{m}]
$$

\section{- Direção do empuxo}

$\delta=\theta+\varphi_{1}$

- Ponto de aplicação

$$
y=h / 3
$$

\section{- Componentes do empuxo}

$$
\begin{aligned}
& \text { horizontal: } E_{h}=E \cos \delta \\
& \text { vertical: } E_{v}=E \operatorname{sen} \delta
\end{aligned}
$$

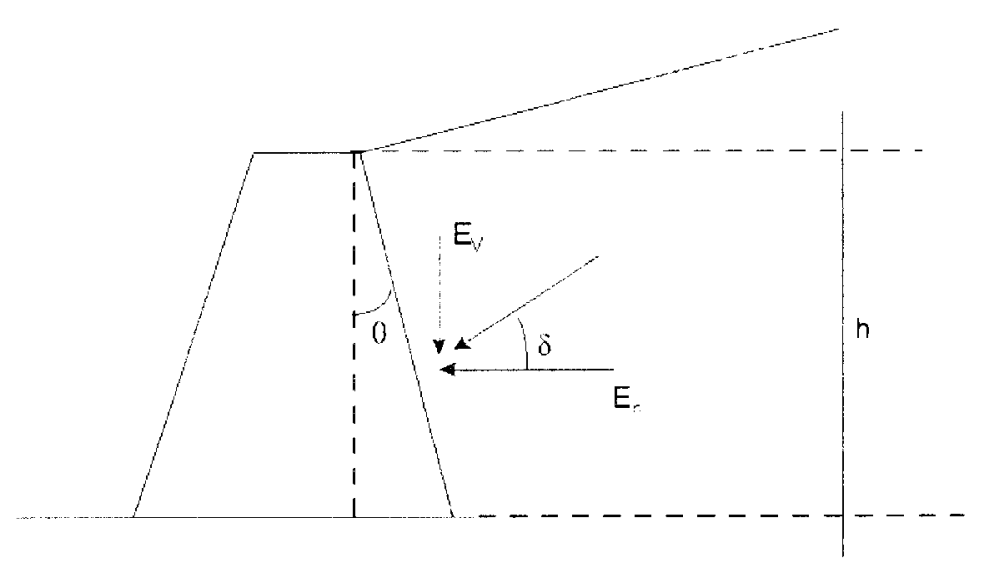

Figura 2.8 - Determinação do empuxo em terreno sem ação variável. 


\subsubsection{2 - Terreno com ação variável aplicada}

Para o caso de existência de ações variáveis aplicadas, supõe-se que o muro apresenta um acréscimo na altura vertical $\left(h_{0}\right)$. Estas ações variáveis podem ser associadas a uma altura fictícia de solo além do nivel do terreno como pode ser visto na Figura 2.9. São ações provenientes de máquinas, multidões, construções, etc.

\section{- Altura de terra equivalente à ação variável}

$$
\mathrm{h}_{0}=\frac{\mathrm{q}}{\gamma_{\mathrm{t}}} \quad[\mathrm{m}]
$$

\section{- Altura total}

$$
\mathrm{H}=\mathrm{h}+\mathrm{h}_{0} \quad[\mathrm{~m}]
$$

- Empuxo

$$
E=\frac{1}{2} k \gamma_{1} h^{2} \quad[k N / m]
$$

- Direção do empuxo

$$
\delta=\varphi_{1}+\theta
$$

\section{- Pressões}

$$
\begin{aligned}
& \text { no topo: } \quad \mathrm{ep}_{\text {sup }}=k \gamma_{\mathrm{t}} \mathrm{h}_{0} \\
& \text { na base: } \quad e \mathrm{p}_{\mathrm{inf}}=\mathrm{k} \gamma_{\mathrm{t}} \mathrm{H}
\end{aligned}
$$


O ponto de aplicação que está situado no baricentro do diagrama de pressões, é definido pela expressão 2.32, podendo ser efetuada em função das alturas do muro, como na expressão 2.33 .

$$
\begin{aligned}
& y=\frac{h}{3} \times \frac{2 e p_{\text {sup }}+e p_{\text {inf }}}{e p_{\text {sup }}+e p_{\text {inf }}} \\
& y=\frac{h}{3} \times \frac{2 h_{0}+H}{h_{0}+H}
\end{aligned}
$$
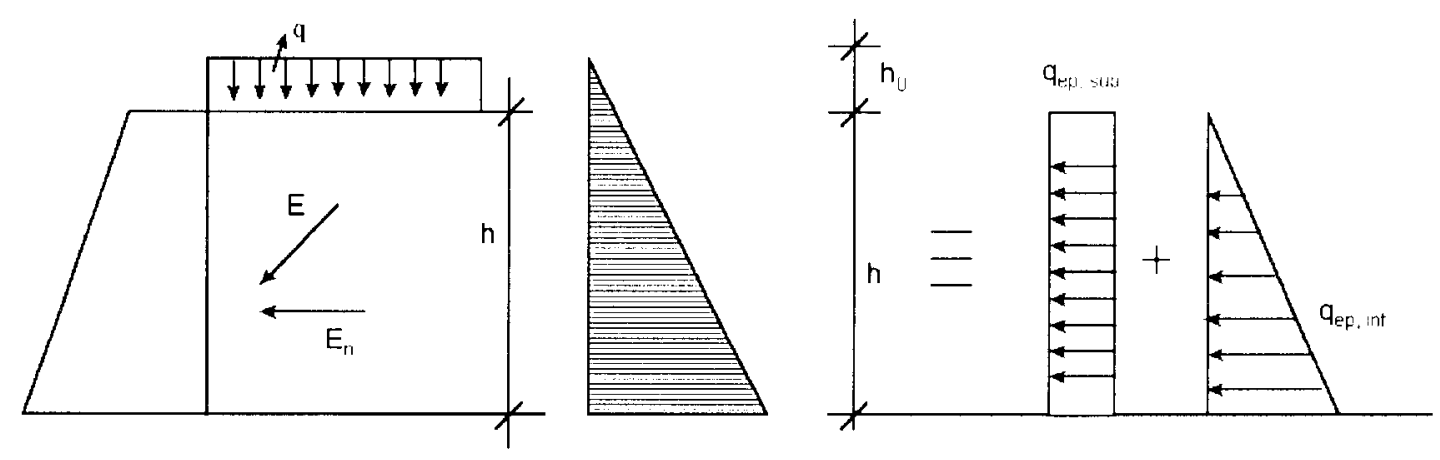

Figura 2.9 - Determinação do empuxo para terreno com ação variável.

\subsubsection{3 - Nivel freático superior ao da base do muro}

Quando há movimento de água no terrapleno, aparecem forças de percolação, que alteram consideravelmente o valor do empuxo sobre o muro de arrimo.

Para que essas forças de percolação sejam levadas em consideração é necessário conhecer a rede de percolação de água no maciço arrimado.

Definida uma cunha qualquer de ruptura, além das forças anteriormente atuantes, tem-se a pressão neutra $(u)$ atuando normalmente no plano de ruptura considerado. 
A intensidade dessa força é obtida através da rede de percolação em um ponto qualquer, onde uma equipotencial corta o plano de ruptura considerado. A pressão neutra é sua carga piezométrica nesse plano

Pode-se dessa forma traçar o diagrama de pressões neutras no trecho onde o plano de ruptura é comum com a rede de percolação, e a partir desse diagrama, por integração obtém-se a pressào neutra resultante nesse plano 


\section{3 - VERIFICAÇÃO DA SEGURANÇA PARA MUROS ISOLADOS}

Diferentes fases do projeto fazem parte da verificação da segurança. A priori faz-se a fixação das dimensões a partir de um prédimensionamento, seguido da verificação da estabilidade do conjunto, onde é analisada a segurança ao tombamento e ao deslizamento.

Numa segunda fase são calculados os esforços solicitantes no muro, bem como os esforços internos da sapata, a partir dos quais fazem-se os dimensionamentos das armaduras de ambos.

\section{1 - Escolha das Dimensões}

$\mathrm{Na}$ fixação das dimensões, o único dado conhecido é a altura do muro $(H)$, pois as cotas do terreno, inferior e superior, são conhecidas no projeto de implantação do mesmo. As outras medidas devem ser determinadas a partir de um pré-dimensionamento, que posteriormente devem ser confirmadas na verificação das resistências das seções.

Alguns processos usados para o pré-dimensionamento, são a seguir comentados.

Huntington [ ], sugere que a espessura tanto da parede quanto da sapata (h) e a largura da sapata (b), devem estar compreendidas entre os seguintes valores:

$$
\mathrm{h}=\frac{\mathrm{H}}{12} \text { a } \frac{\mathrm{H}}{10} \text {, onde } \mathrm{H} \text { é a altura do muro. }
$$

A largura da sapata (b) pode variar de $0,4 \mathrm{H}$ à $0,7 \mathrm{H}$, comumente sendo adotado o valor de $b=0,5 \mathrm{H}$ 


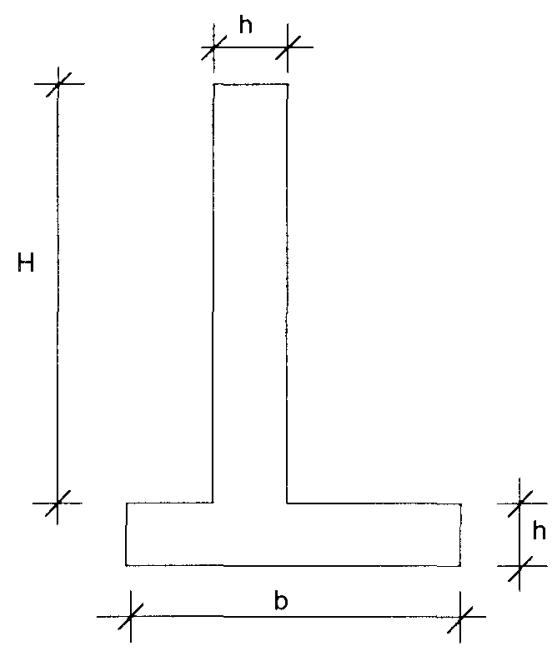

Figura 3.1 - Pré-dimensionamento segundo Huntington.

Santos Netto [1994] sugere as seguintes medidas de acordo com a Figura 3.2:

- a largura da sapata deve medir aproximadamente $\ell=0,5 \mathrm{H}$;

- extremidade da sapata, ou seja, $a_{\text {ext }}=\mathrm{H} / 6$

- o talão da sapata, ou seja, $a_{\text {int }}=\ell-a-h_{2}$

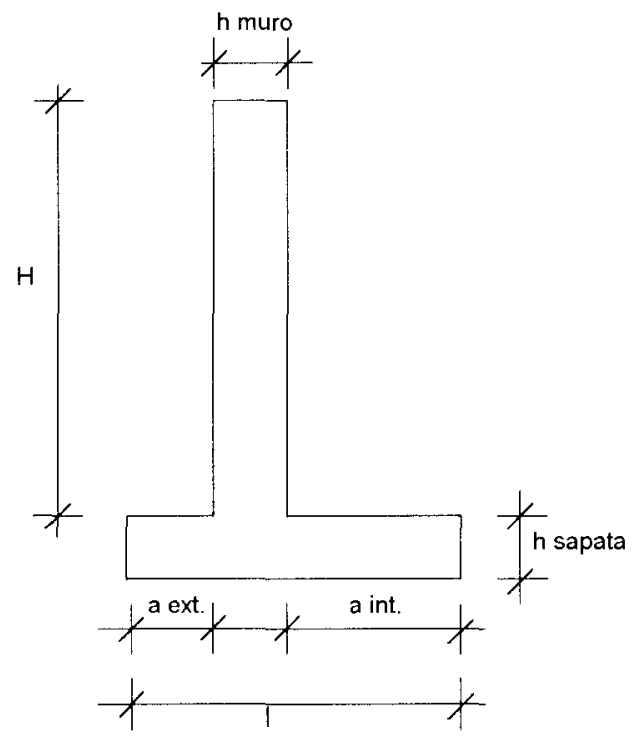

Figura 3.2 - Pré-dimensionamento de acordo com Santos Netto.

$O$ valor de $h_{2}$ é obtido a partir da altura útil da seção de concreto (d), através da expressão: 


$$
\mathrm{h}_{2}=\mathrm{d}+\frac{\phi}{2}+\mathrm{c}
$$

onde: $\phi=$ diâmetro da barra da armadura

$c=$ cobrimento de concreto, que para o caso de muro de arrimo, não deve ser inferior a $3 \mathrm{~cm}$ do lado da terra.

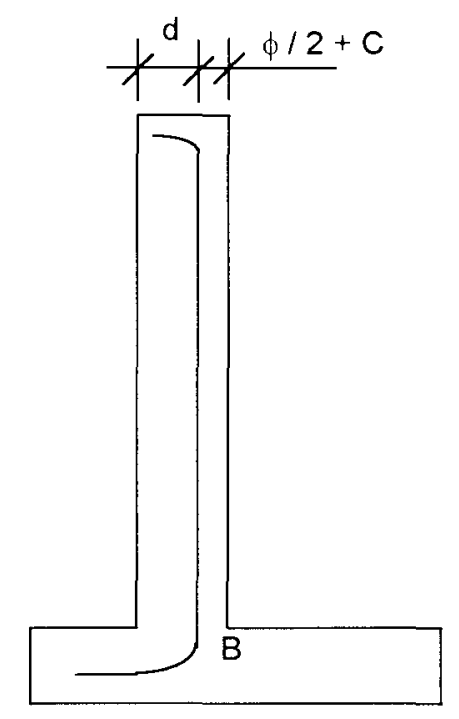

Figura 3.3 - Determinação do valor de $h_{2}$.

O valor da altura útil da seção transversal do muro (d) é obtido pela expressão:

$$
d^{2}=\frac{k_{c l i m} M_{d}}{b_{w}}
$$

onde: $\mathrm{K}_{\mathrm{clim}}=$ valor de $\mathrm{K}_{\mathrm{c}}$, limite entre os domínios 3 e 4 para se ter seção sub-armada;

$M_{d}=$ momento fletor de cálculo, no ponto $B$, devido ao empuxo de terra;

$b_{w}=$ medida da largura unitária do muro, ou seja, $100 \mathrm{~cm}$. 
O muro não precisa necessariamente apresentar a mesma largura em toda a sua altura. No topo esta medida pode ser menor desde que obedeça as seguintes condições limites:

$$
\begin{aligned}
& h_{0}=4 \times \text { diâmetro do agregado graúdo } \\
& h_{0}=15 \mathrm{~cm}
\end{aligned}
$$

A sapata também pode ter uma espessura variável, adotando para altura da extremidade um valor entre $10 \mathrm{~cm}$ à $30 \mathrm{~cm}$.

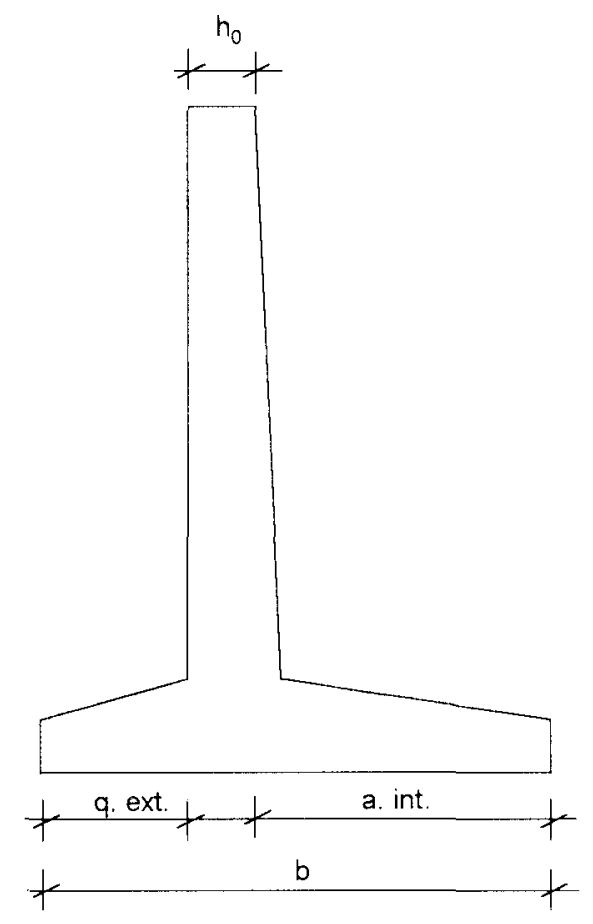

Figura 3.4 - Mudanças possiveis nas dimensões do muro e da sapata.

\section{2 - Verificação da Estabilidade do Conjunto}


Uma vez realizado o pré-dimensionamento, inicia-se a verificação da estabilidade do conjunto. Esta fase consiste na verificação da segurança ao tombamento e ao deslizamento.

Para que se possa chegar aos cálculos finais é necessário primeiramente obter as ações verticais e horizontais e os respectivos momentos, bem como as componentes tangencial e normal atuantes no muro.

As ações verticais são compostas pelo peso próprio do muro e da sapata e pelo peso de terra atuando sobre o muro, como, mostra a Figura 3.5 .

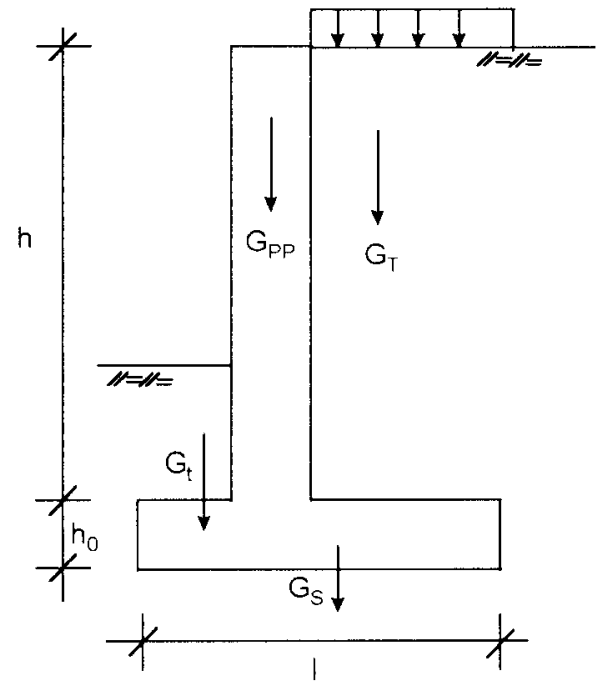

Figura 3.5 - Cargas verticais atuantes no muro e na sapata.

$\mathrm{G}_{\mathrm{pp}}=$ peso próprio do muro

$\mathrm{G}_{\mathrm{T}}=$ peso próprio de terra sobre o talão da sapata

$\mathrm{q}$ = ação da sobrecarga

$\mathrm{G}_{\mathrm{s}}=$ peso próprio da sapata

$\mathrm{G}_{\mathrm{t}}=$ peso próprio de terra sobre a ponta da sapata

A ação horizontal é composta exclusivamente pelo empuxo ativo. Para que se possa considerar o empuxo passivo é necessário que se tenha 
a garantia da permanência de terra sobre a extremidade da sapata durante a vida útil da obra.

Os braços de alavanca para o cálculo dos momentos devem ser calculados em relação ao ponto $A$, como mostra a Figura 3.5.

Tendo sido calculadas as ações verticais e horizontais e os braços de alavanca, chega-se finalmente aos momentos.

A componente normal é a soma de todas as ações verticais, e a componente tangencial, neste caso, se refere exclusivamente ao empuxo.

Com os valores das componentes normal e tangencial chega-se à posição do centro de pressão, ou seja, o ponto de aplicação da resultante (u), medida a partir do ponto A.

$$
\mathrm{u}=\frac{\mathrm{M}}{\mathrm{F}_{\mathrm{N}}}
$$

O valor de u deve ser tal que esteja contido dentro da laje de fundação.

\subsection{1 - Verificação da segurança contra o tombamento}

Para que se tenha garantida a estabilidade estática da estrutura, ou seja, para que não ocorra colapso do muro devido a uma rotação em torno do ponto $A$, adota-se um coeficiente de segurança de pelo menos 1,5 de acordo com a expressão 3.5:

$$
F S=\frac{\sum M_{A}}{M_{1}} \geq 1,5
$$

onde: $\sum \mathrm{M}_{\mathrm{A}}$ é o somatório dos momentos devido às ações verticais;

$M_{t}$ é o momento de tombamento devido ao empuxo. 


\subsection{2 - Verificação da segurança contra o deslizamento}

A segurança contra o deslizamento deve ser analisada a partir da soma das forças na direção horizontal. Conta-se apenas com a componente tangencial $(T)$, já que para a consideração da aderência no solo, seria necessário a realização de ensaios de cisalhamento do terreno, ou " in situ".

Neste caso, a única força que deve resistir à componente $T$ é a força de atrito existente entre a sapata e o solo de fundação. Esta força de atrito é definida como sendo:

$$
F_{a}=\mu F_{N}
$$

onde: $\mu$ é o coeficiente de atrito solo-concreto, cujos valores são pré-fixados, em função da superficie de contato entre o solo e a sapata.

Para que se tenha uma garantia de segurança adota-se um coeficiente de segurança (FS) não inferior à 1,5, que na equação de equilíbrio resulta:

$$
\begin{aligned}
& F_{a}=\mu F_{N}=T \\
& F S \times T=\mu F_{N} \\
& F S=\mu \frac{F_{N}}{T} \geq 1,5
\end{aligned}
$$

Caso as condições de segurança não sejam satisfatórias, e não se queira aumentar o tamanho do talão da sapata, faz-se uso de alguns artifícios, que têm por finalidade aumentar a resistência contra 0 deslizamento. 


\section{a - Dente na sapata}

O dente na sapata garante maior ancoragem no terreno, porque muda a superfície de deslizamento, provocando atrito solo-solo, aumentando assim o coeficiente de atrito $\mu$.

O dente deve estar localizado entre o talão e a ponta da sapata, ou na extremidade do talão, como, mostra a Figura 3.6. A posição do dente de ancoragem depende principalmente de detalhes de execução.
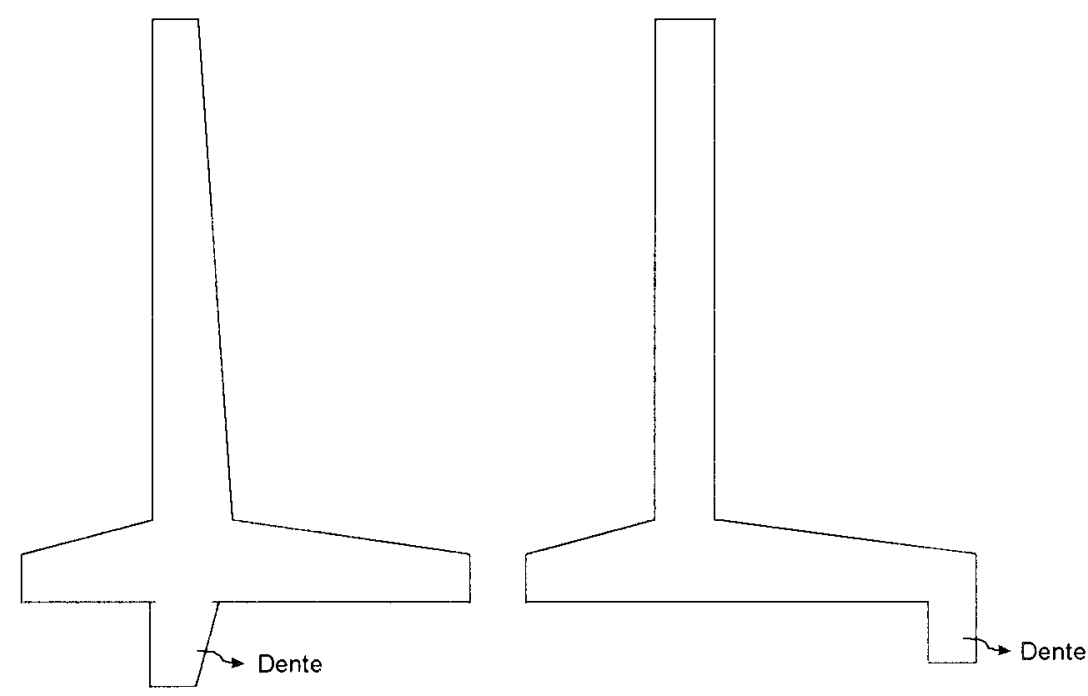

Figura 3.6 - Dentes de ancoragem Moliterno (1980) e Santos Netto (1994).

\section{b - Inclinação da base da sapata}

A inclinação da sapata aumenta a ação da resultante normal, aumentando assim a resistência contra o deslizamento.

O esquema da Figura 3.7 mostra como fica o cálculo da resistência ao deslizamento após sua inclinação. 

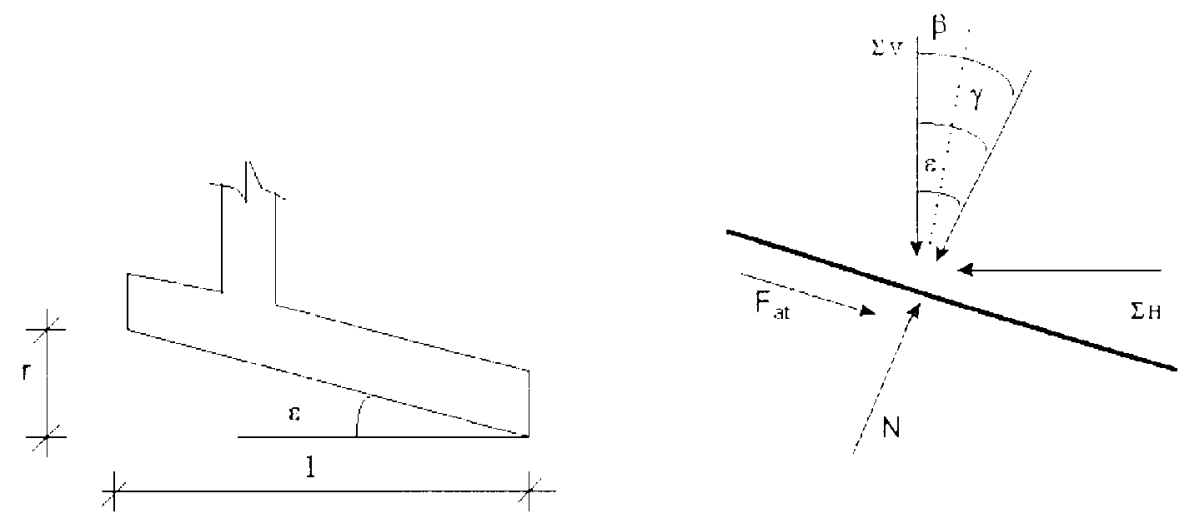

Figura 3.7 - Inclinação da sapata Santos Netto (1994).

Da Figura, faz-se necessário conhecer o valor do angulo $\gamma$, que é obtido pelas seguintes equações:

$$
\begin{aligned}
& \beta=\operatorname{arctg} \frac{\sum H}{\sum F} \\
& \varepsilon=\operatorname{arctg} \frac{r}{\varphi}
\end{aligned}
$$

e, finalmente:

$$
\gamma=\beta-\varepsilon
$$

Calculado o valor de $\gamma$, chega-se à condição de estabilidade do muro, através da equação (3.11), como mostra a Figura 3.8.

$$
F_{\text {at }}=1,5(R \operatorname{sen} \gamma)
$$




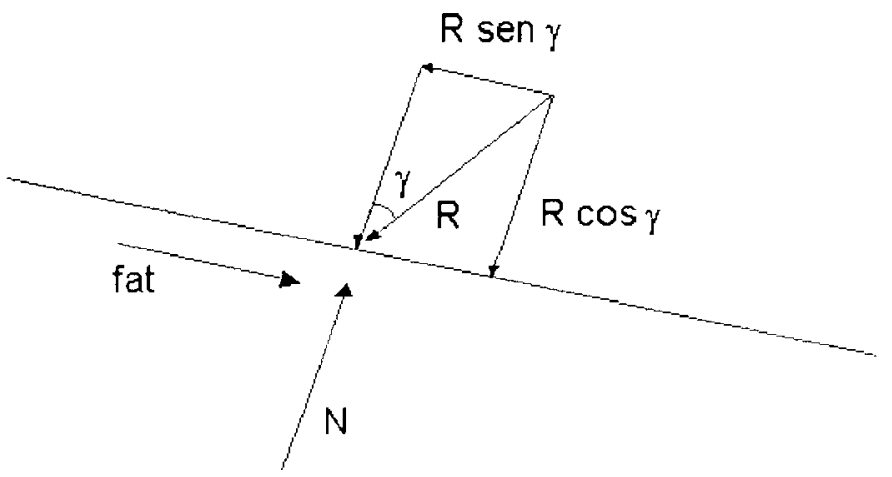

Figura 3.8 - esquema estático segundo Santos Netto (1994).

Analisando a Figura 3.8, podem ser escritas as seguintes expressões:

$$
\begin{aligned}
& R \cos \gamma=F_{N} \\
& F_{\text {at }}=\mu F_{N} \\
& F_{\text {at }}=\mu R \cos \gamma
\end{aligned}
$$

Substituindo os valores de 3.12 na equação 3.11 , resulta:

$$
\mu R \cos \gamma \geq 1,5 R \operatorname{sen} \gamma
$$

Sendo que

$$
\frac{\mu}{\operatorname{tg} \gamma} \geq 1,5
$$




\subsection{3 - Verificação da pressão no solo de apoio}

$\mathrm{Na}$ análise da verificação da tensão máxima e mínima do solo de apoio, admite-se simplificadamente uma tensão linear de tensões de modo a equilibrar a resultante da ação da gravidade e do empuxo, reduzindo o sistema de forças ao centro de pressão, como mostra a Figura 3.9.
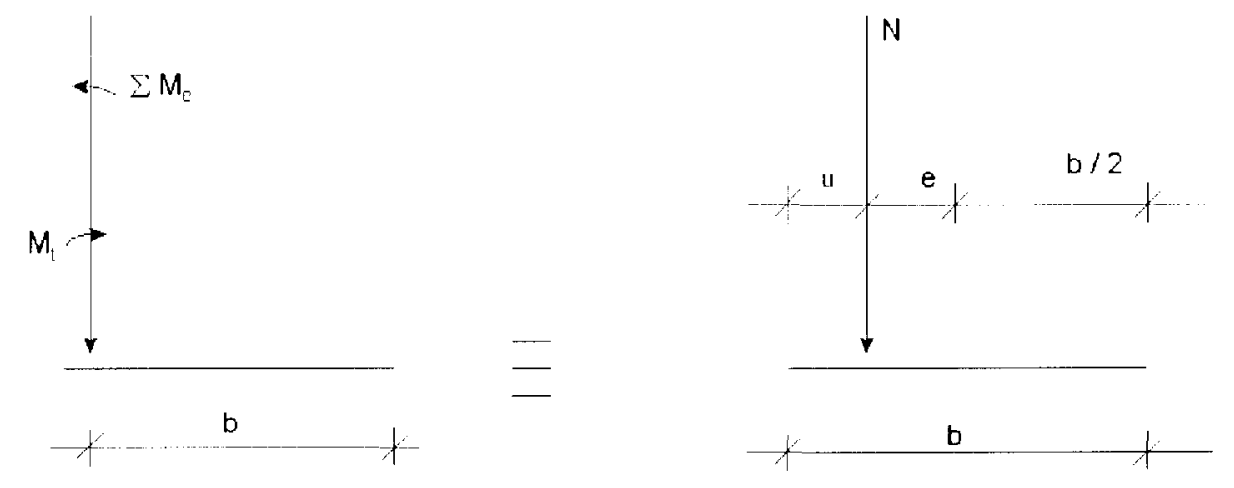

Figura 3.9 - Esquema estático das ações na fundação, Migliore (1987).

Já a distribuição de tensões no solo pode ser trapezoidal ou triangular, de acordo com a posição da resultante $\mathrm{N}$, que pode estar dentro ou fora do núcleo central da base da sapata, como mostrado na Figura 3.10.
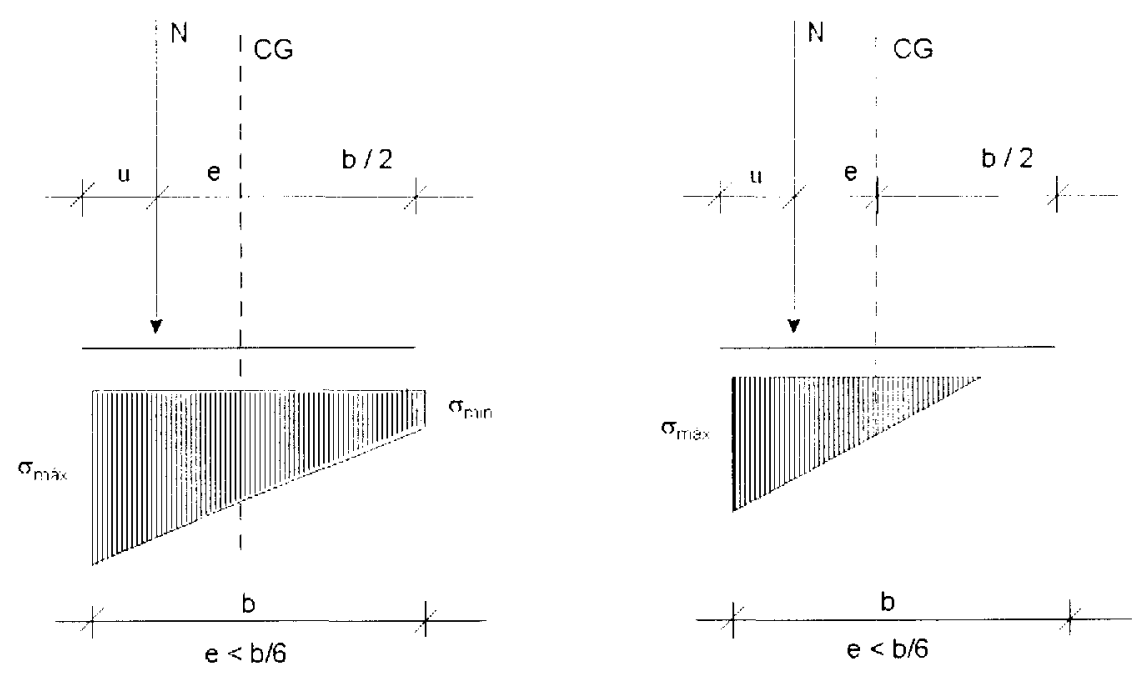

Figura 3.10 - Distribuição de tensões no solo, Migliore (1987). 
Quando a resultante vertical tem sua excentricidade em relação ao CG da sapata menor que B/6, as tensões máximas e mínimas, apresentam as seguintes equações:

$$
\begin{aligned}
& \sigma_{\max }=\frac{N}{B}\left(1+\frac{6 e}{B}\right) \\
& \sigma_{\text {min }}=\frac{N}{B}\left(1-\frac{6 e}{B}\right)
\end{aligned}
$$

Quando a excentricidade da tensão máxima em relação ao CG da sapata é maior que $\mathrm{B} / 6$, ela é designada por:

$$
\sigma_{\max }=\frac{2}{3} \frac{N}{u}
$$

\section{3 - Cálculo dos Esforços Solicitantes}

Para o desenvolvimento do cálculo dos esforços solicitantes, a estrutura de contenção é decomposta em dois elementos: a parede e a sapata.

A parede, geralmente uma laje vertical, recebe as pressões provocadas pelo maciço de terra e as transmite à sapata. A sapata por sua vez transmite estas pressões ao solo.

\subsection{1 - Parede}

O diagrama de distribuição de tensões da parede pode ser apresentado de duas maneiras 
Para o caso de haver sobrecarga sobre o maciço de terra acima da parede, seja sobrecarga de pedestre ou veículos, a distribuição será trapezoidal. Isto ocorre porque a sobrecarga é transformada em uma altura $h_{0}$ e acrescida à altura total $h$. Assim, a altura final será: $H=h+h_{0}$.

Para o caso de não existir sobrecarga a distribuição será triangular

O cálculo dos esforços solicitantes (momento fletor e força cortante) na parede, se faz a partir da determinação do momento de engastamento na base da parede, devido aos empuxos provenientes da sobrecarga e da carga de terra atuando sobre o muro.

A expressão para determinação do momento fletor é mostrada a seguir:

$$
M=\frac{q_{e p 1} x^{2}}{2}+\frac{q_{e p 2} x^{2}}{6}
$$

onde: $q_{\text {ep } 1}=$ ação devido à sobrecarga

$$
\mathrm{q}_{\mathrm{ep} 2}=\text { ação de terra atuando sobre o muro (empuxo). }
$$

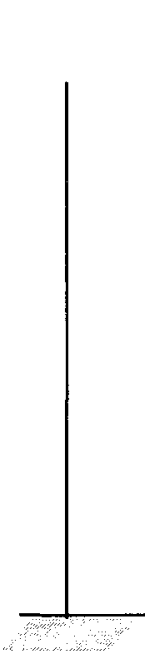

$\mathrm{e}_{\text {psup }}$

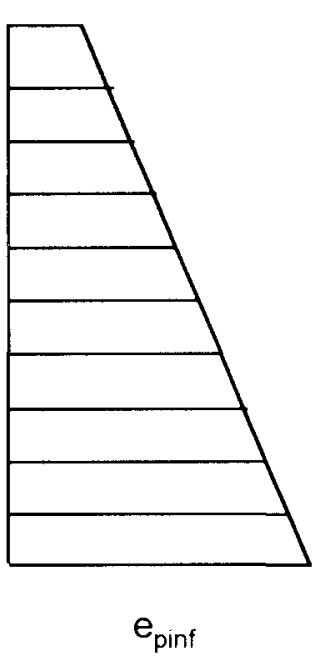

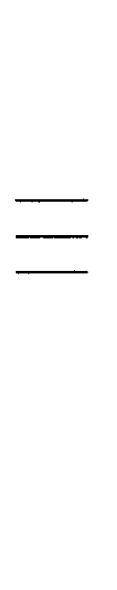
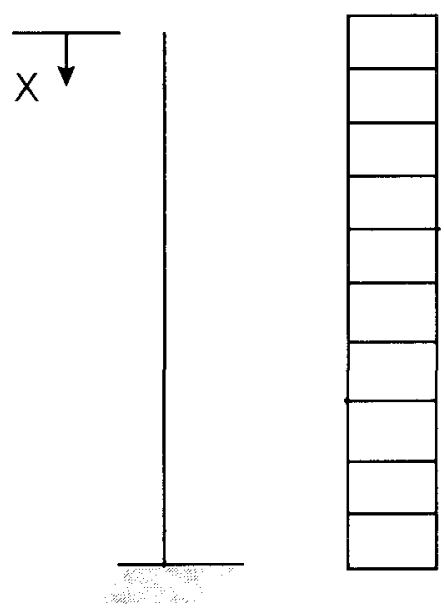

$q_{e p 1}$

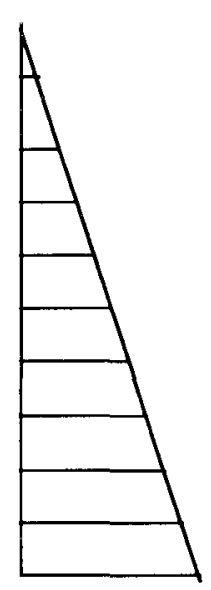

$q_{e p 2}$

Figura 3.11 - Esforços atuantes na parede do muro. 


\subsection{2 - Sapata}

Para o cálculo dos esforços atuantes na sapata devem ser primeiramente determinadas as pressões no terreno, em seu plano inferior, ou seja, a tensão máxima e a tensão mínima. Esses valores devem ser comparados com a pressão admissivel do solo.

Divide-se a sapata em duas partes: extremidade da sapata e talão da sapata, de acordo com a Figura 3.12.

\section{Esforços na sapata}

No talão da sapata, além do peso próprio e do peso de terra, esta ainda atuando a reação do solo.

$\mathrm{Na}$ ponta da sapata estão atuando as cargas devido ao peso próprio e ao peso de terra sobre ela, como mostra a Figura 3.13.
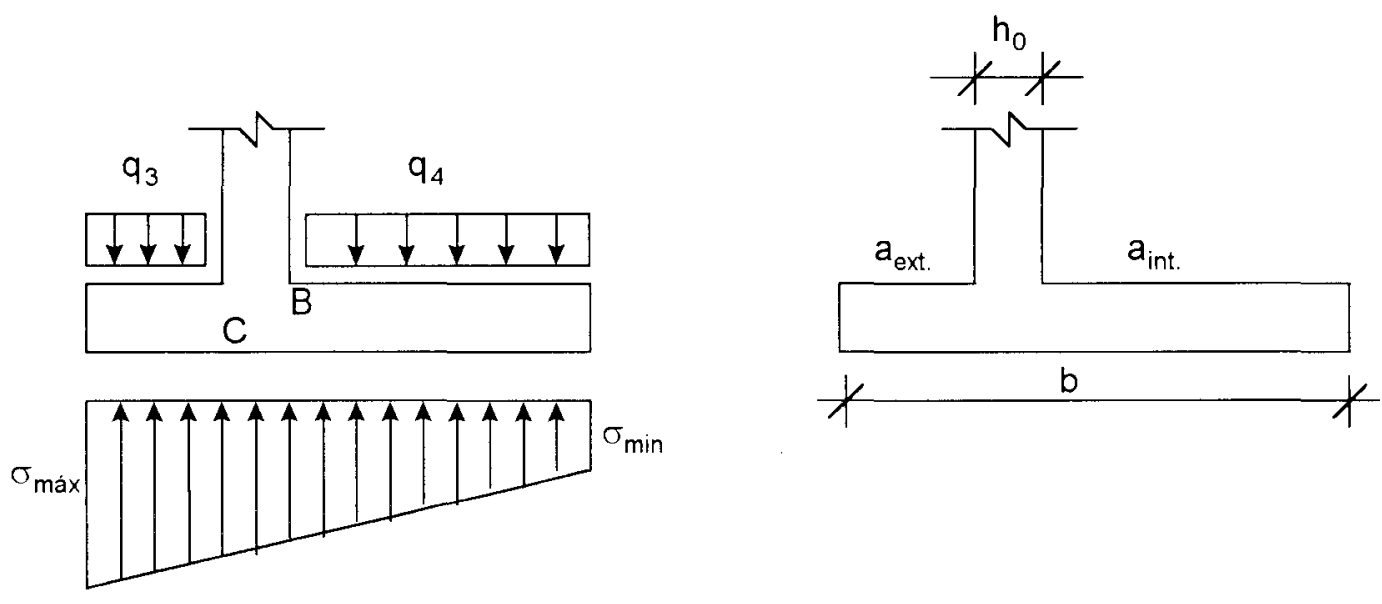

Figura 3.12 - Ações solicitantes na sapata. 

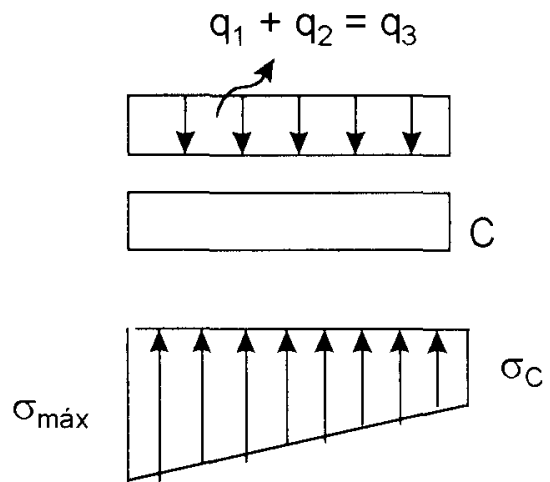

$g_{1}=$ peso próprio da sapata;

$g_{2}=$ peso de aterro sobre a extremidade da sapata;

$\sigma=$ reação de apoio do solo de fundação

Figura 3.13 - Esforços solicitantes no talão e na ponta da sapata.

O cálculo dos momentos fletores no ponto $B$ e no ponto $C$ são definidos pelas seguintes expressões:

$$
\begin{aligned}
& M_{B}=\left(\frac{\sigma_{\text {min }} a^{2}}{2}\right)+\left(\frac{\left(\sigma_{c}-\sigma_{\min }\right) a^{2}}{6}\right)-\left(\frac{q_{4} a^{2}}{2}\right) \\
& M_{c}=\left(\frac{\sigma_{c} c^{2}}{2}\right)+\left(\frac{\left(\sigma_{\max }-\sigma_{c}\right) c^{2}}{6}\right)-\left(\frac{q_{3} c^{2}}{2}\right)
\end{aligned}
$$

Para obtenção da verificação do equilíbrio da sapata, é necessário calcular o momento das ações à direita de $\mathrm{C}$ (inclusive devidos ao empuxo) em relação ao mesmo ponto ponto $C$, sendo $\Sigma M=0$. 


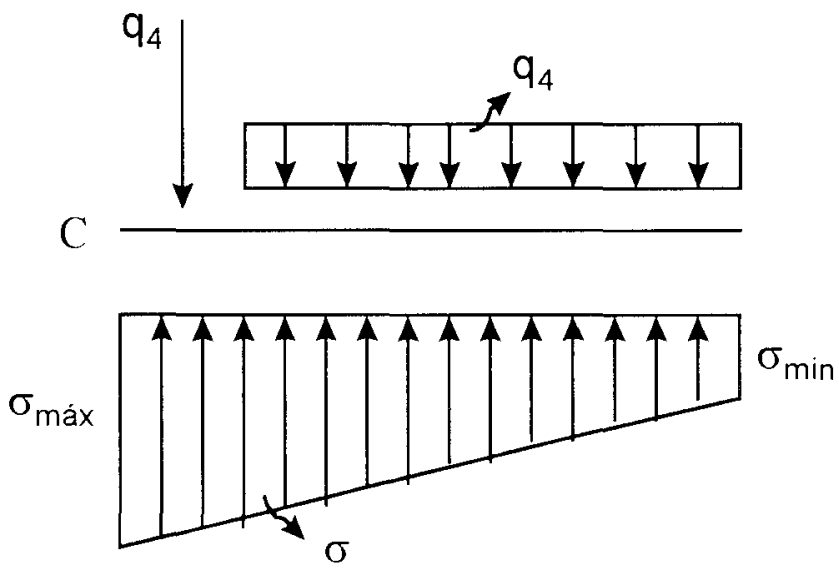

Figura 3.14 - Verificação do equilibrio da sapata.

\section{4 - Dimensionamento das armaduras}

Sendo conhecidos os esforços solicitantes fazem-se 0 dimensionamento das armaduras para cada metro de muro ao longo da altura da parede e da sapata.

O dimensionamento é obtido com base na NBR 6118, onde são calculadas as armaduras necessárias, e a verificação da necessidade de armadura de cisalhamento para as lajes, bem como, a verificação do estado de fissuração.

\section{5 - Verificação da Segurança para Muro Isolado com Contrafortes}

Para o projeto do muro de arrimo com contrafortes, devem ser considerados os aspectos indicados a seguir: 


\subsection{1 - Pré-dimensionamento}

O pré-dimensionamento do muro é feito de acordo com o item 3.1 deste capítulo. Já o pré-dimensionamento dos contrafortes é baseado em obras já realizadas, cujas dimensões seguem o modelo abaixo:
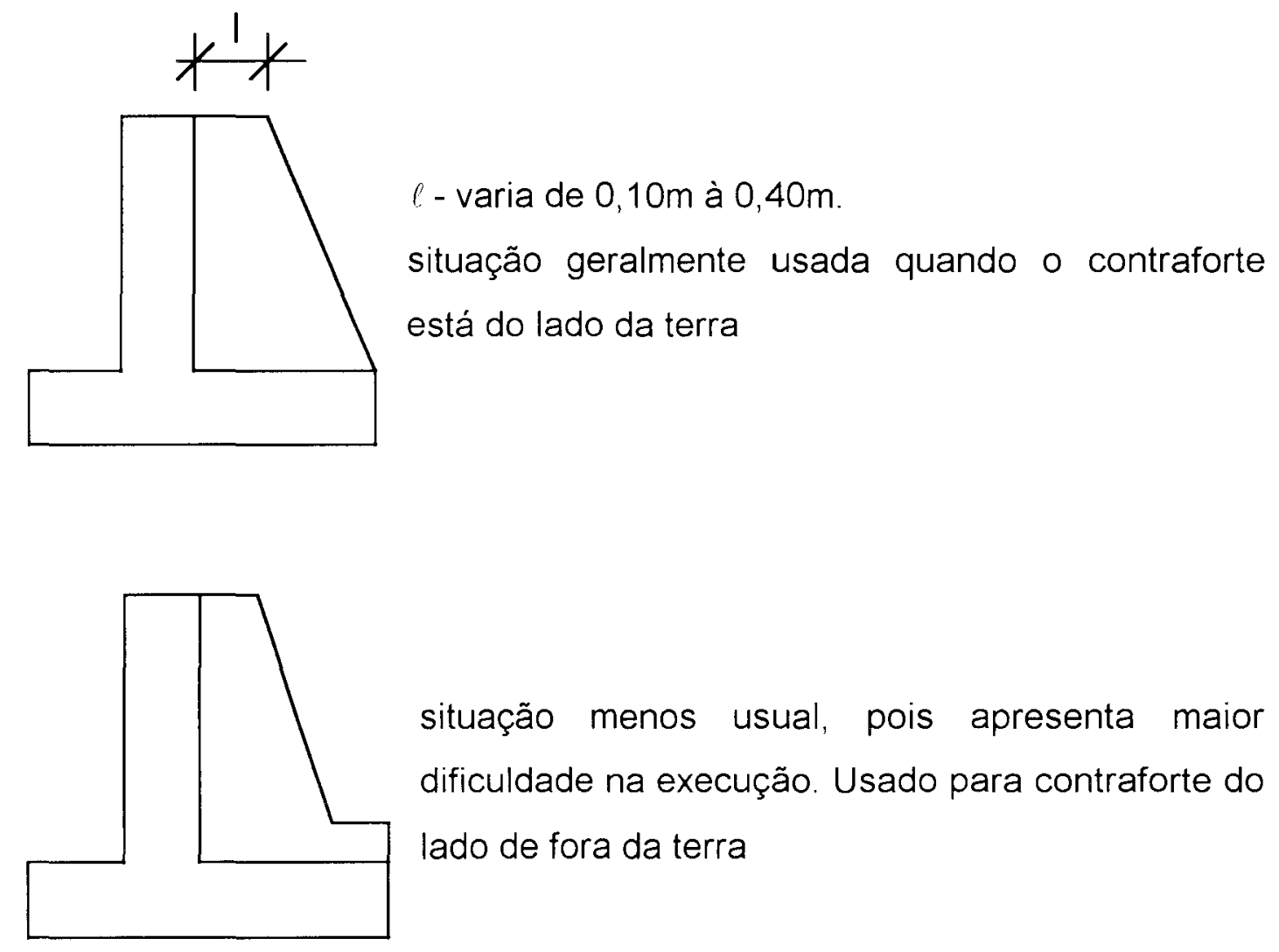

Figura 3.15 - Pré-dimensionamento dos contrafortes

\subsection{2 - Cortina entre os contrafortes}

São apresentadas três possiveis soluções:

a - Cortina com espessura constante

b - Cortina com espessura constante e vigas intermediárias

c - Cortina com espessura variável. 
Para a cortina com espessura constante, ela pode ser armada apenas em uma direção e apoiada nos contrafortes (quando horizontal) ou apoiada na viga de coroamento e na sapata (quando vertical).

Podem também ser armada em cruz quando satisfazer a relação $H / \ell \leq 2$ onde $H$ é a altura da cortina e $\ell$ o comprimento

A cortina armada apenas no sentido vertical não é recomendada pois concentra o empuxo devido à pressão de terra na viga de coroamento e na sapata, sendo que ela poderia ir diretamente para os contrafortes quando usada a alternativa da cortina armada apenas no sentido horizontal.

\subsection{3 - Viga de coroamento de topo}

A viga de coroamento é calculada com uma carga uniformemente distribuida e apoiada nos contrafortes. Esta carga é resultado de uma ação triangular devido ao empuxo. Para efeito de cálculo são usados os coeficientes de redução:

$K x=0,770$ (no sentido horizontal)

$\mathrm{Ky}=0,230$ (no sentido vertical)

\subsection{4 - Viga de ancoragem}

Aumenta a resistência passiva do conjunto, garantindo maior estabilidade contra deslizamento e transfere parte da carga da sapata para os contrafortes.

Geralmente, dimensionam-se as armaduras para o plano de flexão correspondente ao carregamento da sapata, mas a rigor sua verificação deveria ser feita para a solicitação na flexão oblíqua. 


\subsection{5 - Contrafortes ou gigantes}

Os contrafortes tem a função de transmitir à sapata as ações provenientes das cortinas, devidas ao empuxo e aos pesos da cortina e do contraforte.

O contraforte tem uma armadura principal resistente que deve se situar na parte inclinada deste e estribos distribuídos ao longo de toda sua altura, como na Figura 3.16.
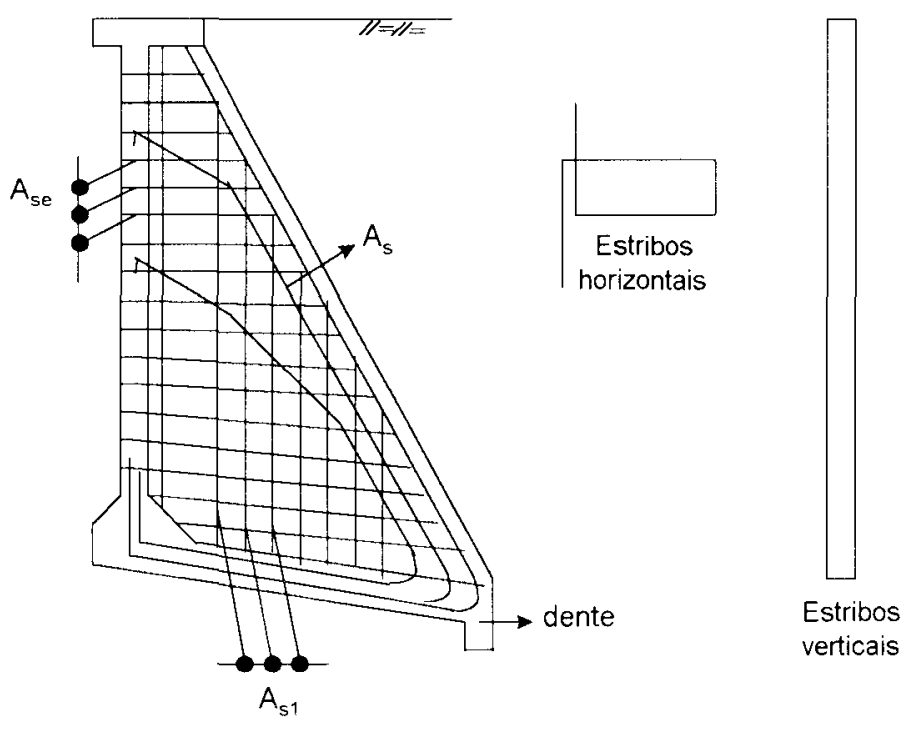

Figura 3.16 - Armadura dos contrafortes.

Para os casos de muro de maior importância, o cálculo deve ser feito para várias seções do contaforte, traçando-se o diagrama de momentos fletores em cada ponto.

A armadura principal é obtida pela expressão:

$$
A_{S}=\frac{\gamma_{f} R_{s t}}{f_{y d}} \quad \text { onde: } R_{s t}=\frac{M_{y}}{z}
$$


A armadura dos estribos é definida por:

$$
A_{s e}=\frac{\gamma_{f} V_{y}}{f_{y d}} \text { onde: } V_{y}=\text { força cortante }
$$

O contraforte do lado da terra é tracionado.

Para o caso de contrafortes do lado da terra, eles devem ser verificados à flexo-compressão ou adotar dispositivos de travamentos para evitar a flambagem dos gigantes.

\subsection{6 - Sapata}

A laje de fundação (sapata) apresenta três alternativas estruturais:

Uma primeira alternativa seria adotar a solução de laje isostática apoiada na cortina e na viga de ancoragem.

A laje apoiada apenas nos contrafortes seria uma segunda solução.

E uma ultima alternativa seria uma laje armada em cruz, ou seja, apoiada nos contrafortes, na cortina e na viga de ancoragem.

A solução mais recomendada é a primeira, por apresentar maior facilidade de execução, pois diminui a interferência entre as armações do contaforte com a laje da sapata.

A determinação dos esforços solicitantes atuantes na sapata é obtido pela diferença de cargas atuantes na vertical, estando num sentido o peso de terra e o peso próprio da sapata e no outro sentido a reação do solo.

Devido a este tipo de carregamento faz-se necessário a armação da laje de fundação nas duas faces, de acordo com o resultado final dos momentos fletores.

Para o muro sobre fundação direta, é necessário a inclinação da sapata para garantir melhores condições de atrito solo/sapata. A inclinação deve ser perpendicular à resultante $R$ (resultante devida ao empuxo e ao peso próprio) como mostrado na Figura 3.7. 
No caso de muro apoiado sobre estacas, é necessário um bloco rígido, ocasionando modificações em toda a estrutura, principalmente em relação aos contrafortes, que podem apresentar seção constante ao longo da altura. 


\section{4 - EXEMPLOS DE CÁLCULO DE MUROS DE ARRIMO}

\section{1 - Muro de Arrimo Isolado}

Projetar um muro de arrimo isolado, com fundação em sapata, para um talude vertical de altura $4 \mathrm{~m}$.

Dados:

- Peso específico aparente do solo $\mathrm{g}=18 \mathrm{kN} / \mathrm{m}^{3}$

- Angulo de atrito natural do solo $\phi=30^{\circ}$

- Tensão admissivel do solo $\sigma_{s, a d m}=200 \mathrm{kN} / \mathrm{m}^{2}$

- Ação variável normal no terrapleno $=5 \mathrm{kN} / \mathrm{m}^{2}$

- Posição relativa parede/sapata $\rightarrow$ a critério do projetista.

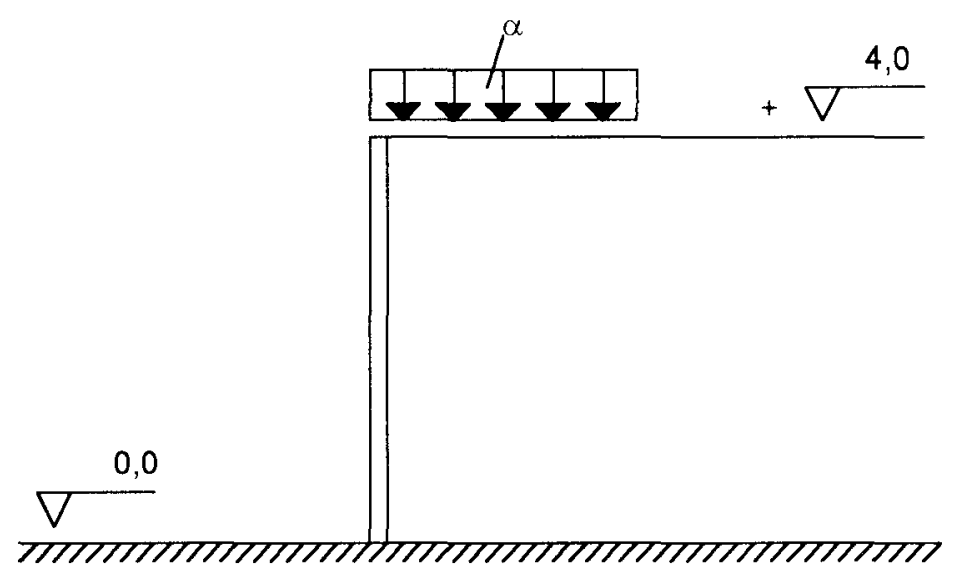

Obs.: Este projeto foi desenvolvido originalmente pelos Profs. Paulo dos Santos Netto e José Samuel Giongo para a disciplina SET 158 Estruturas Correntes de Concreto Armado II na EESC-USP 


\section{1 - PRÉ-DIMENSIONAMENTO}

O pré-dimensionamento segundo Santos Neto resulta

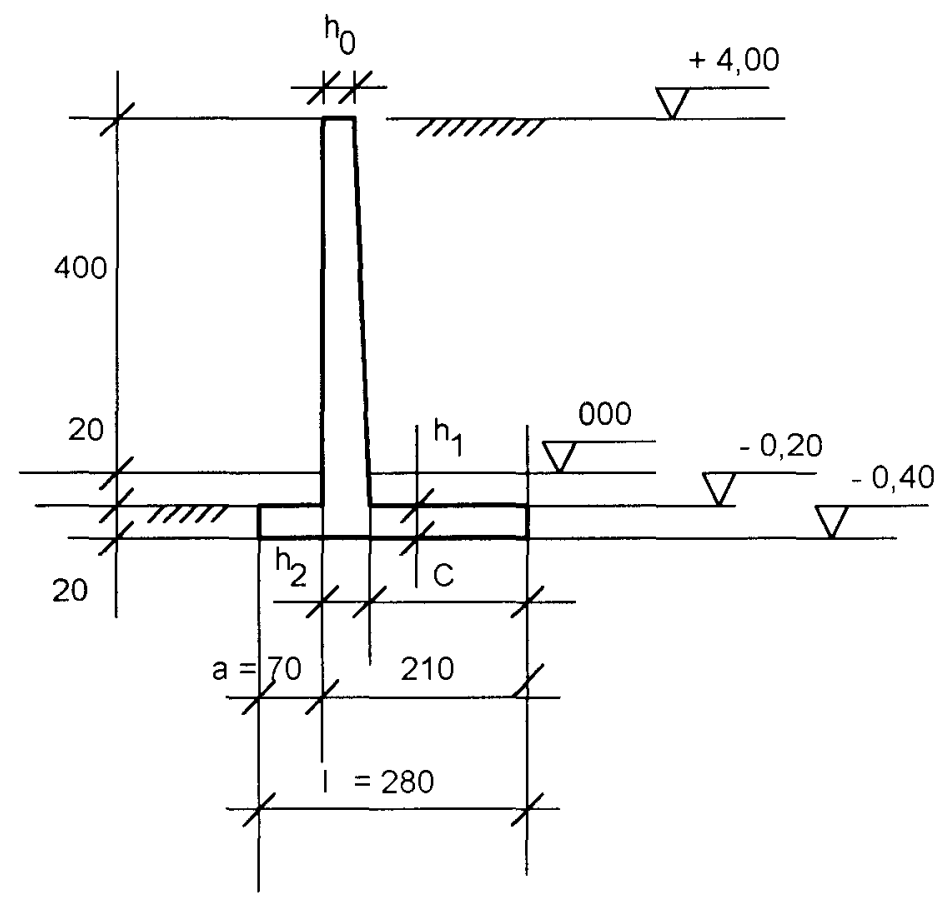

\section{1 - Largura total da sapata}

$$
\begin{array}{cl}
0,40 \leq \ell \leq 0,70 \mathrm{H} \rightarrow & 0,40 \times 4,2 \leq \ell \leq 0,70 \times 4,2 \\
H=4,20 \mathrm{~m} & 1,68 \leq \ell \leq 2,94 \mathrm{~m} \\
& \text { Adotado }=\ell=2,80 \mathrm{~m}
\end{array}
$$

\section{2 - Parte externa da sapata}

$$
a=\frac{H}{6}=\frac{4,20}{6}=0,70 m \leftarrow \text { Adotado }
$$


1.3 - A espessura $h_{2}$ da seção da parede do muro depende do valor do momento fletor atuante.

As espessuras $h_{0}$ e as externas da sapata são adotadas com valores mínimos de $15 \mathrm{~cm}$.

A espessura $h_{1}$ da laje da sapata depende do momento fletor atuante.

Nesta fase de pré-dimensionamento é preciso verificar o tombamento e deslizamento. Como não se conhecem as dimensões definitivas do muro de arrimo, podem-se verificá-los considerando apenas as ações devidas ao peso próprio do terreno e sobrecarga, adotando para peso específico do terreno um valor fictício $\left(\gamma_{\text {fict. }}\right)$ que leve em conta o valor do peso específico aparente do concreto. Este procedimento também pode ser adotado para verificar as pressões na fundação (sapata).

$$
\begin{aligned}
& O \text { valor de } \gamma_{\text {fict }} \text { deve ter um valor entre } \gamma_{\text {conc }}=25 \mathrm{KN} / \mathrm{m}^{3} \text { e } \\
\gamma_{\text {solo }}= & 18 \mathrm{KN} / \mathrm{m}^{3} \text {. }
\end{aligned}
$$

Se for adotado $\gamma_{\text {fict }}=\gamma_{\text {solo }}$ as verificações na fase de ante-projeto ficaram a favor da segurança.

Para este projeto adotou-se $\gamma_{\text {fict }}=19,5 \mathrm{KN} / \mathrm{m}^{3}$.

\section{4 - Verificação da estabilidade}




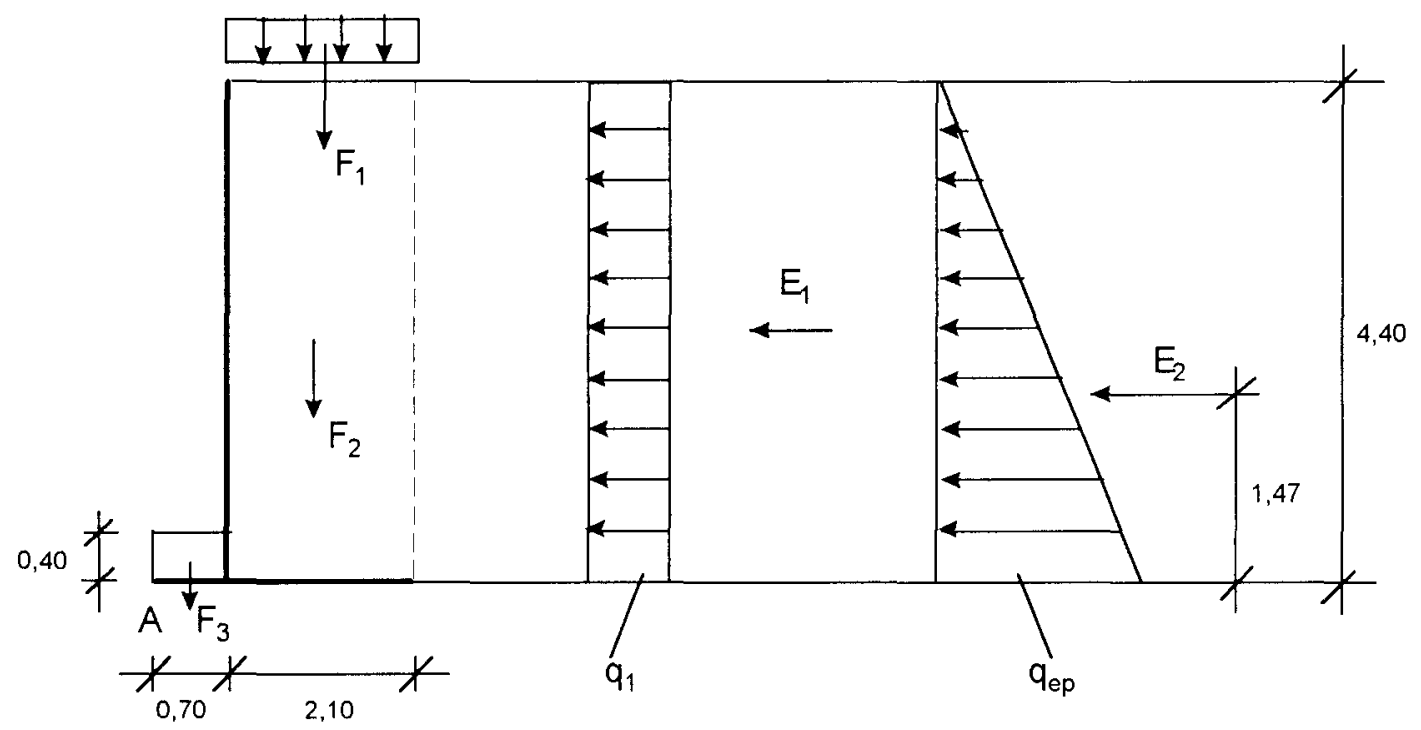

Diagrama de ações

$$
\begin{aligned}
& \text { Resultantes ações verticais } \\
& \text { Braço Momento (A) } \\
& F_{1}=2,10 \times 5,0 \\
& =10,5 \mathrm{KN} / \mathrm{m}-1,75 \mathrm{~m}-18,4 \mathrm{KNm} / \mathrm{m} \\
& F_{2}=2,10 \times 4,40 \times 19,5=180,2 \mathrm{KN} / \mathrm{m}-1,75 \mathrm{~m}-315,4 \mathrm{KNm} / \mathrm{m} \\
& F_{3}=0,70 \times 0,40 \times 19,5=\frac{5,5 \mathrm{KN} / \mathrm{m}}{196,2 \mathrm{KN} / \mathrm{m}}-0,35 \mathrm{~m}-1,9 \mathrm{KNm} / \mathrm{m} \\
& \Sigma F=196,2 \mathrm{KN} / \mathrm{m} \\
& \Sigma M=335,7 \mathrm{KNm} / \mathrm{m}
\end{aligned}
$$

Distância da resultante do ponto $\mathrm{A}$

$$
d_{0}=\frac{335,7}{196,2}=1,71 \mathrm{~m}
$$

Resultantes horizontais - Empuxos ativos

$$
K_{a}=\operatorname{tg}^{2}\left[45^{\circ}-\frac{30^{\circ}}{2}\right]=\operatorname{tg}^{2} 30^{\circ}=0,333
$$




$$
\begin{array}{ll}
q_{1}=K_{a} \cdot q=0,333 \times 5,0 & =1,7 \mathrm{KN} / \mathrm{m}^{2} \\
q_{e p}=K_{a} \cdot \gamma_{\text {solo }} \cdot H_{1}=0,333 \times 18 \times 4,40 & =26,4 \mathrm{KN} / \mathrm{m}^{2} \\
E_{1}=q_{1} \cdot H_{1}=1,7 \times 4,40 & =7,5 \mathrm{KN} / \mathrm{m}^{2} \\
E_{2}=\frac{1}{2} \times q_{e p} \times H_{1}=\frac{1}{2} \times 26,4 \times 4,40 & =58,1 \mathrm{KN} / \mathrm{m}^{2}
\end{array}
$$

\subsection{1 - Verificação do tombamento}

Momento de tombamento:

$$
M_{\text {tom, } A}=E_{1} \times 2,20+E_{2} \times 1,47=101,9 \mathrm{KNm} / \mathrm{m}
$$

Momento restaurador:

$$
\mathrm{M}_{\text {rest }, \mathrm{A}}=\Sigma \mathrm{M}_{\mathrm{F}, \mathrm{A}}=335,7 \mathrm{KNm} / \mathrm{m}
$$

Fator de segurança $=\frac{M_{\text {rest }, A}}{M_{\text {tomb }, A}}=\frac{335,7}{101,9}=3,3>1,5$

O fator de segurança não deve ser inferior à 1,5 .

Conclusão: Não haverá tombamento.

\subsection{2 - Verificação do deslizamento}




$$
\begin{aligned}
& \Sigma F_{H}=E_{1}+E_{2}=7,5+58,1=65,6 \mathrm{KN} / \mathrm{m} \\
& F_{\text {H,resist }}=F_{\text {ATRITO }}=\mu . \Sigma F_{V} \\
& \mu=\operatorname{tg}\left[\frac{3}{2} \phi\right]=\operatorname{tg}\left[\frac{2}{3} \cdot 30\right]=0,36 \\
& \begin{aligned}
\Sigma F_{V} & =0,9\left[F_{2}+F_{3}\right]+F_{1} \\
& =0,9[180,2+5,5]+10,5 \\
& =177,6 \mathrm{KN} / \mathrm{m} \\
F_{\text {ATRITO }} & =0,36 \times 177,6=63,9 \mathrm{KN} / \mathrm{m}
\end{aligned}
\end{aligned}
$$

Fator de segurança $=\frac{F_{\text {ATRITO }}}{\Sigma F_{H}}=\frac{63,9}{65,6}=0,97<1,5$

O fator de segurança não deve ser inferior à 1,5

Conclusão: Como o fator de segurançva foi inferioe à 1,5 , haverá possibilidade de deslizamento

Soluções: 1. Criar um consolo (chave) para aumentar a superfície de deslizamento que provoca atrito solo-solo.

2. Inclinar a base da sapata

3. Aumentar o comprimento $(1-a)$ que aumentaria $\Sigma F_{v}$ sem aumentar $\Sigma \mathrm{F}_{\mathrm{H}}$.

OBS.: O coeficiente 0,9 indicado na NBR 8681 afeta as ações permanentes favoráveis que, neste caso se não ocorrerem ficam contra a segurança.

Numa primeira tentativa para aumentar o fator de segurança será adotada a solução com chave na sapata. 


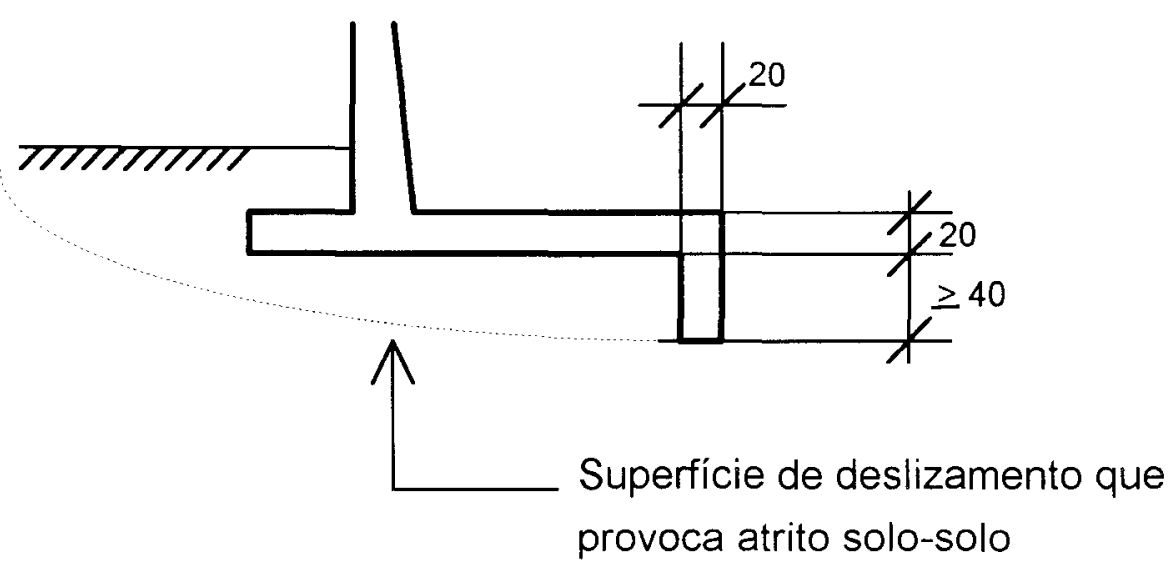

Com esta solução o coeficiente de atrito fica:

$$
\begin{aligned}
& \mu=\operatorname{tg} \phi=\operatorname{tg} 30^{\circ}=0,577 \\
& \therefore F_{\text {ATRITO }}=\mu \quad \Sigma F_{V}=0,577 \times 177,6=102,5 \mathrm{KN} \\
& \text { F.S. }=\frac{102,5}{65,6}=1,56
\end{aligned}
$$

Conclusão: Esta solução foi suficiente para que não ocorra deslizamento. Caso não o fosse, teriamos que inclinar a base da sapata ou aumentar o seu comprimento.

\section{5 - Verificação das pressões no solo}

A verificação das pressões no solo é feita a partir do carregamento devido às ações verticais. 

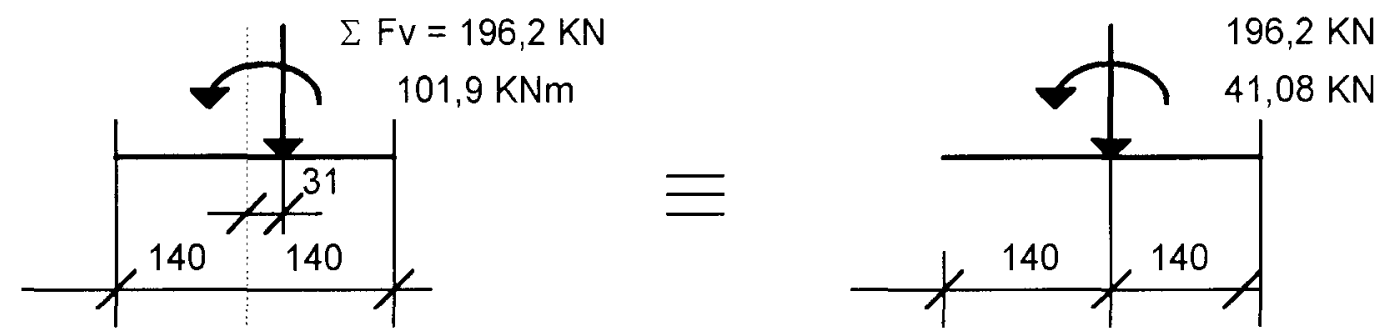

$$
1=0,21 \mathrm{~m}
$$

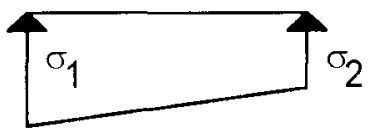

$$
\begin{aligned}
& \sigma_{1,2}=\frac{\mathrm{N}}{\mathrm{A}}\left[1 \pm \frac{6 \mathrm{e}}{\ell}\right] \\
& \sigma_{1,2}=\frac{196,2}{2,8 \times 1,0}\left[1 \pm \frac{6 \times 0,21}{2,8}\right] \\
& \sigma_{1}=101,6 \mathrm{KN} / \mathrm{m}^{2}<\sigma_{\text {adm }}=200 \mathrm{KN} / \mathrm{cm}^{2} \\
& \sigma_{2}=38,5 \mathrm{KN} / \mathrm{m}^{2}<\sigma_{\text {adm }}=200 \mathrm{KN} / \mathrm{cm}^{2}
\end{aligned}
$$

\section{6 - Previsão da espessura da parede do muro}

$\mathrm{Na}$ determinação da espessura da parede do muro não deve ser esquecido o cobrimento de $3 \mathrm{~cm}$, pois há contato direto com o solo.

$$
\begin{aligned}
& M_{\text {base }}=M_{\text {tom }}=101,9 \mathrm{KNm} / \mathrm{m} \\
& \mathrm{C} 20 ; C A 50 A \rightarrow K_{c} \lim =2,2 \\
& K_{c}=\frac{b_{w} d_{0}^{2}}{M_{d}} \Rightarrow \frac{2,2 \times 1,4 \times 101,90}{100}=d_{0}^{2} \\
& \therefore d_{0}^{2}=313,9 \rightarrow d_{0}=18 \mathrm{~cm}
\end{aligned}
$$

O valor adotado foi de $\mathrm{h}=25 \mathrm{~cm} \rightarrow \mathrm{d}=21 \mathrm{~cm}$ 


\section{2 - DIMENSIONAMENTO}

A partir de medidas verificadas no pré-dimensionamento é feita agora o dimensionamento com as medidas definitivas.

2.1 - Forma da seção do muro

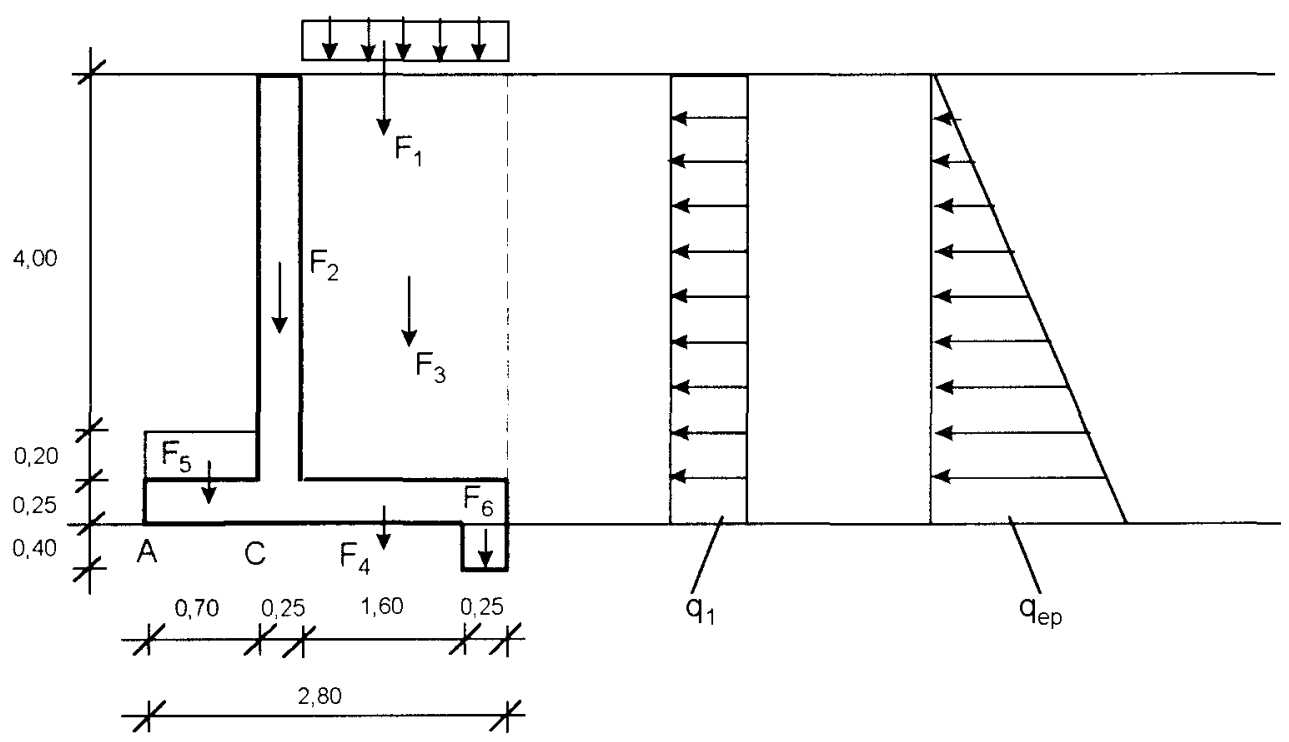

$$
\begin{aligned}
& q_{1}=1,7 \mathrm{KN} / \mathrm{m}^{2} \\
& q_{\text {ep }}=0,333 \times 18 \times 4,20=25,17 \mathrm{KN} / \mathrm{m}^{2} \\
& E_{1}=1,7 \times 4,20=7,14 \mathrm{KN} / \mathrm{m}^{2} \\
& E_{2}=\frac{1}{2} \times 25,17 \times 4,20=52,86 \mathrm{KN} / \mathrm{m}^{2}
\end{aligned}
$$

2.2 - Cálculo dos momentos em relação do ponto $A$ 


$$
\begin{aligned}
& \text { Forças Braço }(\mathrm{m}) \text { Momentos } \\
& F_{1}=Q=5,0 \times 1,85=9,25 \quad 1,875 \quad 17,34 \\
& F_{2}=G_{p p, p a r}=0,25 \times 4,20 \times 25=26,25 \quad 0,825 \quad 21,66 \\
& F_{3}=G_{p p, s o l}=1,85 \times 4,20 \times 18=139,86 \quad 1,875 \quad 262,24 \\
& F_{4}=G_{p p, \text { sap }}=0,25 \times 2,80 \times 25=17,50 \quad 1,400 \quad 24,50 \\
& F_{5}=G_{p p, s o l}=0,70 \times 0,20 \times 18=2,52 \quad 0,350 \quad 0,88 \\
& F_{6}=G_{p p, c o n s}=0,40 \times 0,25 \times 25=\frac{2,50}{197,88} \quad 2,675 \quad \frac{6,69}{333,41} \\
& x_{0}=\frac{333,41}{197,88}=1,68 m \leftarrow \text { Distância da resultante ao ponto } A
\end{aligned}
$$

\section{3 - Momento de tombamento}

$$
\begin{aligned}
& M_{\text {tom }, A}=7,14 \times\left(\frac{1}{2} \times 4,20+0,25\right)+52,86\left(\frac{1}{3} \times 4,20+0,25\right) \\
& M_{\text {tom }, A}=104 \mathrm{KNm} / \mathrm{m}
\end{aligned}
$$

\section{4 - Verificação do tombamento}

A verificação ao tombamento deve apresentar fator de segurança superior à 1,5 .

F.S. $=\frac{M_{\text {rest }, A}}{M_{\text {tom }, \mathrm{A}}}=\frac{333,41}{197,88}=3,2>1,5$

$\therefore$ Verifica, não ocorrerá tombamento. 


$$
\begin{aligned}
& \mu=\operatorname{tg} \phi=\operatorname{tg} 30^{\circ}=0,577 \\
& F_{\text {ATRITO }}=0,9 \times 197,88 \times 0,577=102,76 \mathrm{KN} \\
& \Sigma E=E_{1}+E_{2}=60 \mathrm{KN} \\
& \text { F.S. }=\frac{F_{\text {ATRITO }}}{\Sigma E}=\frac{102,76}{60,00}=1,7>1,5
\end{aligned}
$$

$\therefore$ Verifica, não ocorrerá deslizamento.

\section{6 - Verificação das pressões no solo de apoio}
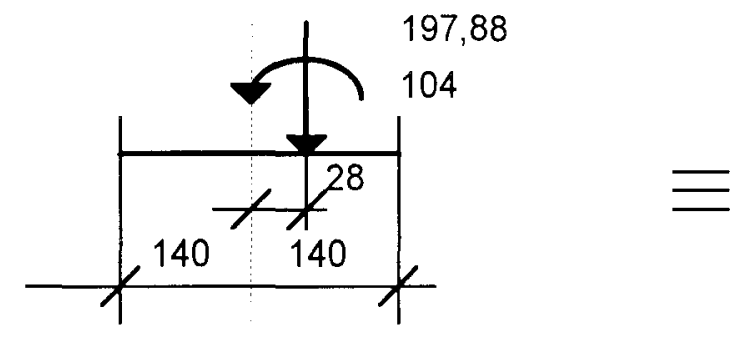

$$
\begin{aligned}
& \sigma_{1,2}=\frac{197,88}{2,80 \times 1,00} \cdot\left[1 \pm \frac{6 \times 0,25}{2,80}\right] \\
& \sigma_{1}=108,56 \mathrm{KN} / \mathrm{m}^{2} \\
& \sigma_{2}=32,8 \mathrm{KN} / \mathrm{m}^{2} \\
& \sigma_{\text {adm }}=200 \mathrm{KN} / \mathrm{m}^{2}
\end{aligned}
$$

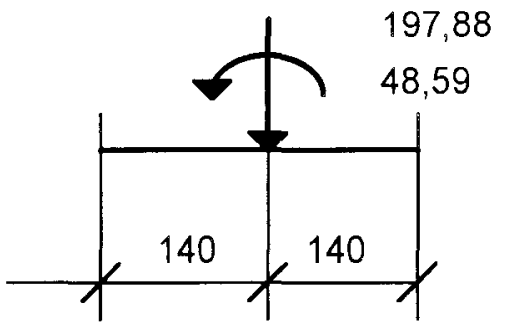

$\mathrm{I}=0,25 \mathrm{~m}$ 
$\therefore$ Verifica, pois nenhuma tensão foi superior à tensão admissível.

2.7 - Cálculo dos esforços solicitantes na parede do muro de arrimo (Ponto B)

Os esforços atuando sobre a parede são as ações devido à sobrecarga e ao peso de terra atuando sobre ela.

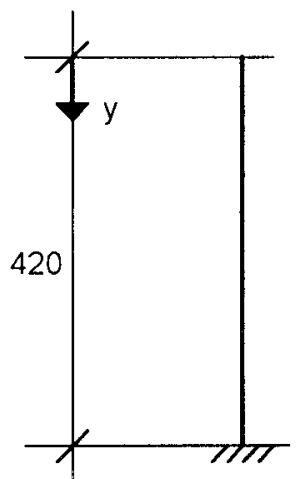

$\mathrm{B}$

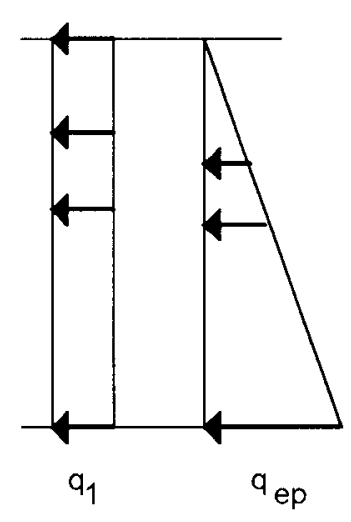

$M_{y}=\frac{q_{1} \cdot y^{2}}{2}+\frac{1}{6} \cdot q_{e p} \cdot \frac{y^{3}}{\ell}$

$\mathrm{q}_{1}=1,7 \mathrm{KN} / \mathrm{m}^{2}$

$q_{\mathrm{ep}}=25,17 \mathrm{KN} / \mathrm{m}^{2}$

Cálculo dos momentos fletores atuantes na parede:

$\begin{array}{ccc}\mathrm{y}(\mathrm{m}) & \mathrm{M}_{\mathrm{k}}(\mathrm{KNm} / \mathrm{m}) & \mathrm{M}_{\mathrm{d}} \\ 0 & 0 & 0 \\ 1,0 & 1,85 & 2,6 \\ 2,0 & 11,39 & 16,0 \\ 3,0 & 34,62 & 48,5 \\ 4,2 & 88,99 & 124,6\end{array}$

Cálculo da força cortante na parede para $y=4,2 \mathrm{~m}$. 


$$
\begin{aligned}
& V_{B, K}=1,7 \times 4,20+\frac{1}{2} \times 25,17 \times 4,20 \\
& V_{B, K}=60 \mathrm{KN}
\end{aligned}
$$

\section{8 - Cálculo dos esforços solicitantes na sapata do muro de arrimo}

As ações a considerar são o peso próprio da sapata, o peso do aterro sobre a extremidade da sapata e a reação de apoio do solo de fundação.

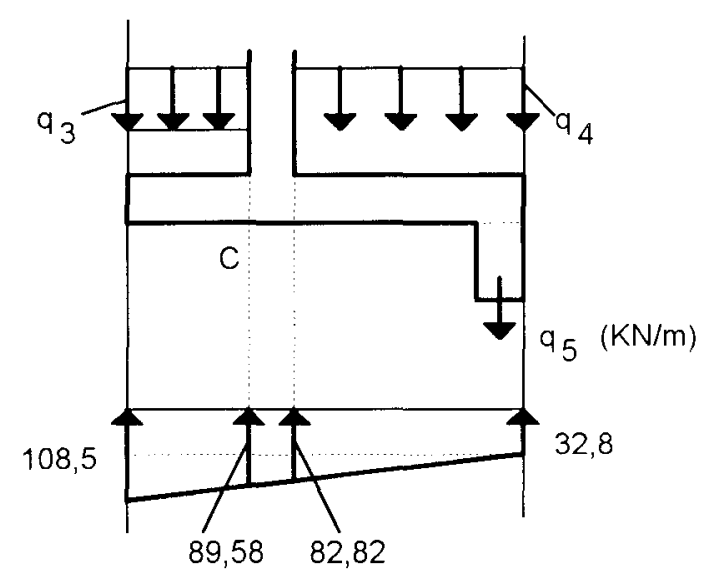

$$
\begin{aligned}
& \frac{108,5-32,8}{2,80}=\frac{y_{1}}{2,10} \rightarrow y_{1}=56,78 \rightarrow \sigma_{\text {solo. },}=89,58 \frac{\mathrm{KN}}{\mathrm{m}^{2}} \\
& \frac{108,5-32,8}{2,80}=\frac{y_{2}}{1,85} \rightarrow y_{2}=50,02 \rightarrow \sigma_{\text {solo }, 8}=82,82 \frac{\mathrm{KN}}{\mathrm{m}^{2}} \\
& \mathrm{q}_{1}=0,20 \times 18+0,25 \times 25=9,85 \mathrm{KN} / \mathrm{m}^{2} \\
& \mathrm{q}_{4}=\underset{5,0}{q}+4,20 \times 18+0,25 \times 25=86,85 \mathrm{kN} / \mathrm{m}^{2}
\end{aligned}
$$

Momento fletor na seção C: 


$$
\begin{aligned}
M_{C, K}= & 89,58 \times 0,70 \times \frac{0,70}{2}+\frac{1}{2}(108,5-89,58) \times 0,70 \times \frac{2}{3} \times 0,70 \\
& -9,85 \times 0,70 \times \frac{0,70}{2} \\
M_{C, K}= & 22,62 \mathrm{KNm} / \mathrm{m} \rightarrow \text { Tração fibras inferiores } \\
V_{C, K}= & 89,58 \times 0,70 \times(108,5-89,58) \times \frac{1}{2} \times 0,70-9,85 \times 0,70 \\
M_{C, K}= & 62,43 \mathrm{KN} / \mathrm{m}
\end{aligned}
$$

Momento fletor na seção B:

$$
\begin{aligned}
M_{B, K}= & 32,8 \times 1,85 \times \frac{1,85}{2}+\frac{1}{2}(82,82-32,8) \times 1,85 \times \frac{1}{3} \times 1,85 \\
& -86,85 \times 1,85 \times \frac{1,85}{2}-0,25 \times 0,40 \times 25 \times 1,725= \\
M_{B, K}= & 68,27 \mathrm{KNm} / \mathrm{m} \rightarrow \text { Tração fibras superiores }
\end{aligned}
$$

Verificação do equilíbrio dos momentos em relação ao ponto $C$.

$$
\begin{aligned}
M_{c, \text { esq }} & =22,62 \mathrm{KNm} / \mathrm{m} \\
M_{c, \text { dir }} & =26,25 \times \frac{0,25}{2}+(86,85 \times 1,85)\left(\frac{1,85}{2}+0,25\right)- \\
& -32,8 \times 2,10 \times \frac{2,10}{2}+0,25 \times 0,40 \times 25 \times\left(2,10-\frac{0,25}{2}\right) \\
& -\frac{1}{2} \times(89,58-32,8) \times 2,10 \times \frac{1}{3} \times 2,10= \\
M_{c, \text { dir }} & =82,96 \mathrm{KNm} / \mathrm{m} \\
M_{c, \text { acima }} & =M_{\text {tomb. }}=104 \mathrm{KNm} / \mathrm{m}
\end{aligned}
$$




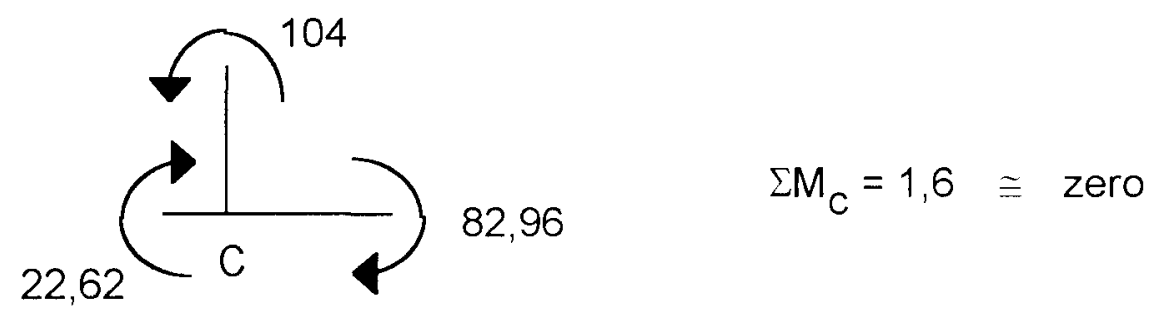

2.9 - Diagramas de $M_{d} /$ Detalhamento

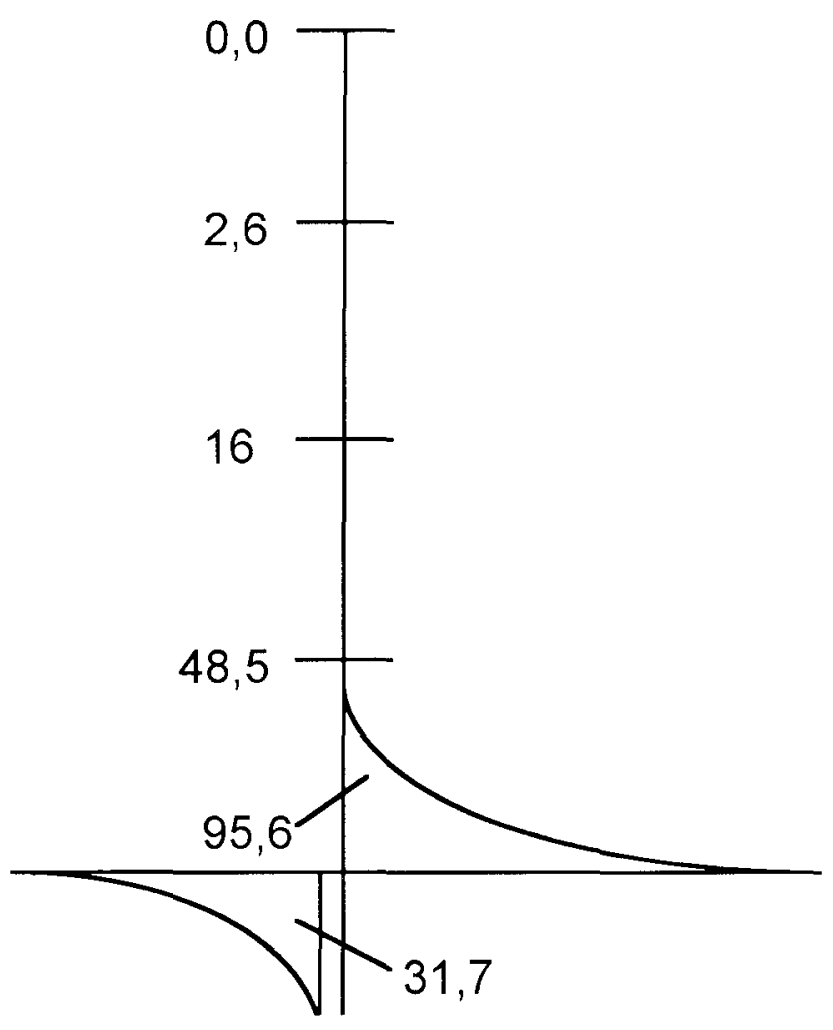

2.10 - Cálculo das armaduras 
C $20 ; C A 50 A ; h=25 \mathrm{~cm} ; d=21 \mathrm{~cm}$

$$
A_{s \text { min }}=0,15 \times 25=3,75 \mathrm{~cm}^{2} / \mathrm{m}
$$

$\begin{array}{ccccccc}\mathrm{M}_{\mathrm{d}} & \mathrm{K}_{\mathrm{c}} & \mathrm{K}_{\mathrm{s}} & \mathrm{A}_{\mathrm{s}} & \mathrm{A}_{\text {s ef }} & \phi & \mathrm{s} \\ 12460 & 3,5 & 0,027 & 16,0 & 18,0 & 16 & 12,5 \\ 4850 & 9,1 & 0,024 & 5,6 & 9,0 & 16 & 25,0 \\ 1600 & 27,6 & 0,023 & 1,75 & 3,79 & 12,5 & 33,0 \\ 260 & 169,6 & 0,023 & 0,28 & 3,79 & 12,5 & 33,0 \\ 9560 & 4,6 & 0,026 & 11,84 & 12,50 & 12,5 & 10,0 \\ 3170 & 13,9 & 0,024 & 3,6 & & 16,0 & 15,0\end{array}$



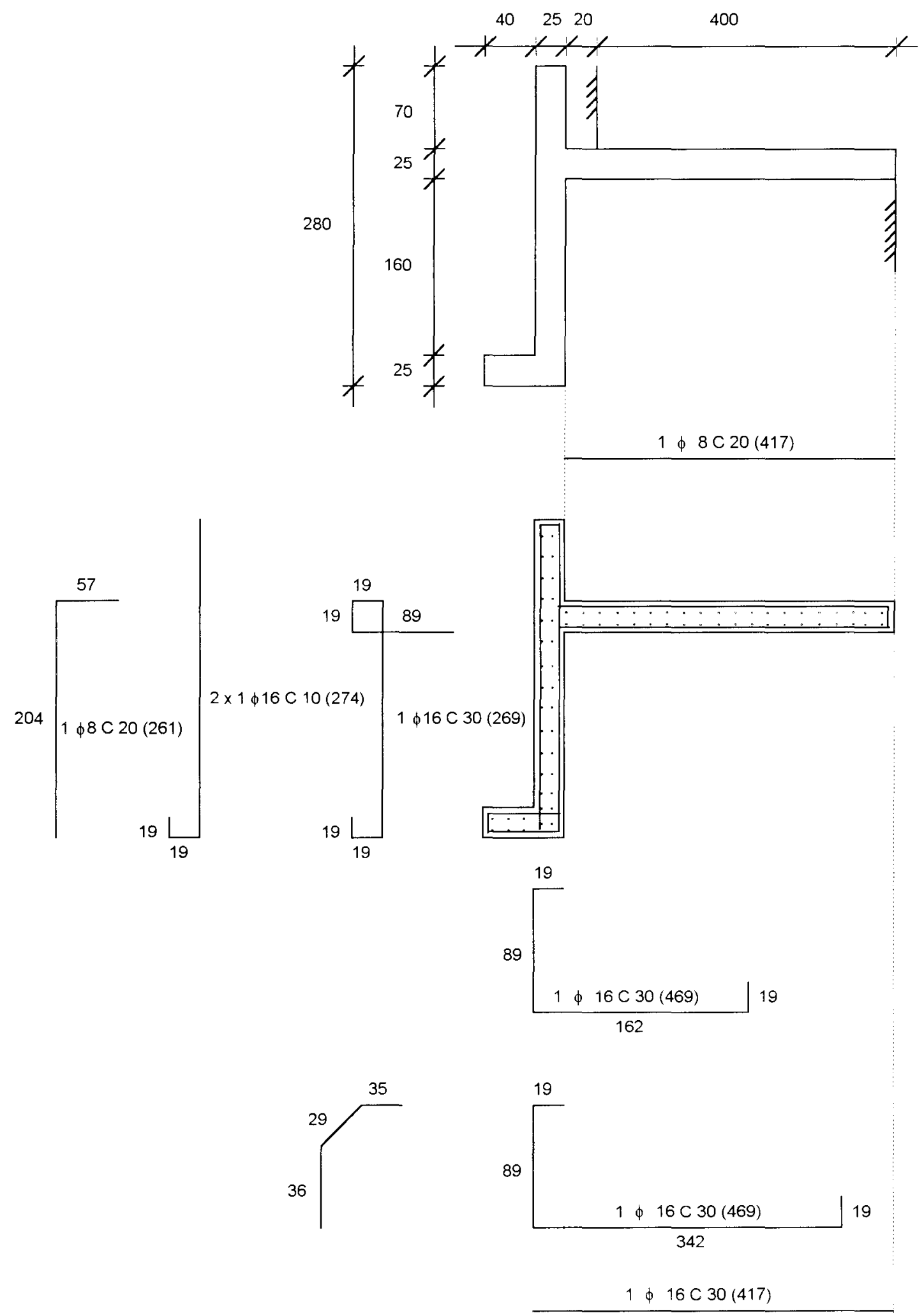


$$
\begin{gathered}
A 1 \phi 16=26 \mathrm{~cm} 2 \rightarrow 9 \phi 16 / \mathrm{m} \rightarrow A s=18 \mathrm{~cm}^{2} / \mathrm{m}(-4 \%) \\
\therefore \phi 16 \mathrm{c} / 12,5
\end{gathered}
$$

Adotaram-se os seguintes valores para o detalhamento das armaduras:

$$
\begin{array}{ll}
a_{\ell}=1,5 \mathrm{~d}=1,5 \times 21=31,50 \mathrm{~cm} & \text { (laje) } \\
\ell_{\mathrm{b}}=44 \phi=44 \times 16=70 \mathrm{~cm} & \text { (Boa aderência) } \\
10 \phi=16 \mathrm{~cm} & \\
\text { cobrimentos }=3 \mathrm{~cm} &
\end{array}
$$

Armaduras de distribuição horizontal

$$
\begin{aligned}
& \text { Até 1,20m : } A_{\mathrm{s}, \text { dist }}=\frac{16,7}{5}=3,34 \mathrm{~cm}^{2} / \mathrm{m} \rightarrow \phi 8 \mathrm{c} / 15 \\
& 1,20 \mathrm{~m} \text { a } 2,20 \mathrm{~m}: \quad=\frac{5,8}{5}=1,16 \mathrm{~cm}^{2} / \mathrm{m} \rightarrow \phi 8 \mathrm{c} / 30
\end{aligned}
$$

$2,20 \mathrm{~m}$ a $4,20 \mathrm{~m}: \phi 8 \mathrm{c} / 30$

$$
\text { Lembrar que: } \mid \begin{aligned}
& A_{s, \text { dist }}=\frac{A_{s}}{5}>0,9 \mathrm{~cm}^{2} / \mathrm{m} \\
& S_{\text {MAX }}=33 \mathrm{~cm}
\end{aligned}
$$

Armaduras construtivas do lado externo da parede

$$
\begin{gathered}
\frac{0,1}{100} \times b_{w} \times h=2,5 \mathrm{~cm}^{2} / \mathrm{m} \rightarrow \frac{\phi \mathrm{c} / 20}{\mid} \\
\text { Vertical e horizontal }
\end{gathered}
$$

Verificação da força cortante

$$
\begin{aligned}
& V_{\mathrm{K}}=60 \mathrm{KN} \rightarrow \text { Parede, Ponto B } \\
& \mathrm{V}_{\mathrm{d}}=84 \mathrm{KN}
\end{aligned}
$$




$$
\begin{aligned}
\tau_{\mathrm{wd}} & =\frac{84}{100 \times 21}=0,04 \mathrm{KN} / \mathrm{cm}^{2}=0,40 \mathrm{MPa} \\
\tau_{\mathrm{wu}}^{*} & =\left[\frac{1}{3}+\frac{25}{90}\right] \times 0,30 \times \frac{20}{1,4}=2,62 \mathrm{MPa} \\
\tau_{\mathrm{wd}} & <\tau_{\mathrm{wu}}^{*}
\end{aligned}
$$

Dispensa de armadura transversal

$$
d=21 \mathrm{~cm}<\frac{865}{20}=43,25 \mathrm{~cm}
$$

pois, $L=2 I=2 \times 432,5=865 \mathrm{~cm}$

$\therefore \psi_{4}=0,14 \cdot \alpha \cdot k$; para C.U.D.

$K=16-d=1,6-0,21=1,39 \geq 1,0$

$\alpha=1+50 \rho_{1}=1+50 \times 0,0072=1,36 \leq 1,5$

$\rho_{1}=\frac{18}{100 \times 25}=0,0072 \quad(0,72 \%)$

$\therefore \psi_{4}=0,14 \cdot 1,36 \cdot 1,39=0,26$

$\tau_{\mathrm{wu} 1}=\psi_{4} \sqrt{f_{c k}}=0,26 \cdot \sqrt{20}=1,16 \mathrm{MPa}<1,0 \mathrm{MPa}$

$\tau_{\text {wu1 }}=0,40<\tau_{\text {wu1 }}=1,0 \mathrm{MPa}$

Conclusão: não há necessidade de armadura transversal.

Verificação da força cortante atuante na sapata

$$
\mathrm{V}_{\mathrm{C}, \mathrm{K}}=62,43 \mathrm{KN}
$$

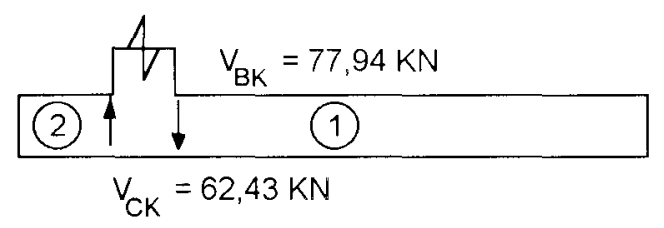

$$
\begin{aligned}
\mathrm{V}_{\mathrm{B}, \mathrm{K}} \text { na sapata } & =(82,82-32,8) \cdot \frac{1,35}{2}+32,5 \times 1,35-86,85 \times 2,10= \\
& =-77,94 \mathrm{KN} \\
\mathrm{V}_{\mathrm{B}, \mathrm{K}} \text { na sapata } & =-77,94 \mathrm{KN}
\end{aligned}
$$


Laje 01 (sapata): $\tau_{\mathrm{wd}} \leq \tau_{\mathrm{wn}}(\leq 4,5 \mathrm{MPa})$

Verificação:

$$
\begin{gathered}
\tau_{\mathrm{wd}} \leq \tau_{\mathrm{wn}}: \tau_{\mathrm{wd}}=\frac{\mathrm{V}_{\mathrm{d}}}{\mathrm{b}_{\mathrm{wd}}}=\frac{1,4 \times 77,94}{100 \times 21}=0,052 \frac{\mathrm{KN}}{\mathrm{cm}^{2}}=0,52 \mathrm{MPa} \\
\tau_{\mathrm{wn}}=\beta .0,30 \mathrm{~F}_{\mathrm{dd}}=\left(\frac{1}{3}+\frac{25}{90}\right) \cdot 0,30 \times \frac{2,0}{1,4}=0,262 \frac{\mathrm{KN}}{\mathrm{cm}^{2}}=2,62 \mathrm{MPa}
\end{gathered}
$$

Portanto $\quad \tau_{w d}<\tau_{w n}$

Verificação para dispensar armadura transversal: $\tau_{\text {wd }} \leq \tau_{\text {wus }}$

$$
\tau_{\text {wus }}=\psi_{4} \sqrt{F_{\mathrm{CK}}} \leq 1,0 \mathrm{MPa}
$$

Para ações uniformemente distribuídas:

$$
\begin{aligned}
& \psi_{4}(d, L) \\
& L=2 I \text { (lajes em balanço } \\
& L=2\left(185+\frac{25}{2}\right)=395 \mathrm{~cm} \\
& d=21 \mathrm{~cm}>\frac{L}{20}=-19,75 \mathrm{~cm}
\end{aligned}
$$

$$
\psi_{4}=0,12 \cdot \frac{\alpha \mathrm{K}}{1-\frac{3 \mathrm{~d}}{\ell}}
$$

onde: $d=21 \mathrm{~cm}$

$$
\begin{aligned}
& 1=195+\frac{25}{2}=197,5 \mathrm{~cm} \\
& K=1,6-d=1,6-0,21=1,39(>1) \\
& \alpha=1+50 \rho_{1} \leq 1,5 \\
& \rho_{1}=\frac{A_{\text {sef }}}{\text { Area de concreto }}=\frac{12,50 \mathrm{~cm}^{2}}{25 \times 100}=0,0050 \\
& \alpha=1,25 \leq 1,5 \\
& \alpha \mathrm{K}=1,74 \leq 1,75
\end{aligned}
$$




$$
\begin{aligned}
& \psi_{4}=0,12 \cdot \frac{1,74}{1-\frac{3 \times 21}{197,5}}=0,307 \\
& \tau_{\text {wu1 }}=0,307 \sqrt{20}=1,373 \mathrm{MPa}>1 \mathrm{MPa} \rightarrow \tau_{\text {wu1 }}=1,0 \mathrm{MPa}
\end{aligned}
$$

Portanto:

$$
\tau_{\text {wd }}=0,52 \mathrm{MPa}<\tau_{\text {wu1 }}=1,0 \mathrm{MPa} \text { Armadura transversal dispensada }
$$

\section{Laje 02 (sapata)}

Não foi feita a verificação, pois a força cortante é menor.

\section{2 - Muro de Arrimo Isolado com Contrafortes}

Projetar um muro de arrimo isolado com contrafortes, com fundação em sapata, para um talude vertical de altura $4 \mathrm{~m}$.

Este exemplo segue com os mesmos dados do exercício anterior, inclusive as dimensões, de acordo com a figura abaixo. 

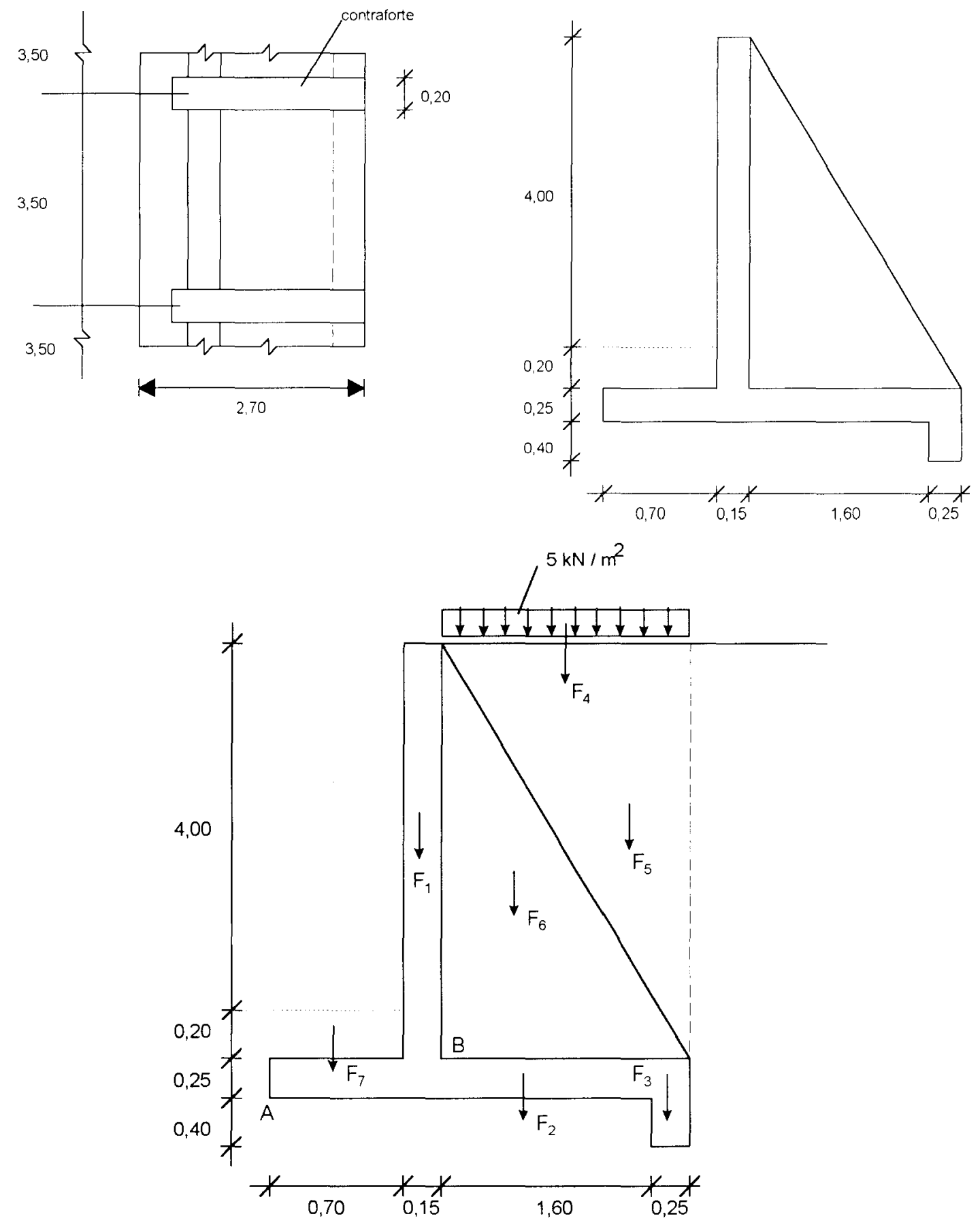


\section{1 - Cálculo dos movimentos em relação ao ponto $A$}

\begin{tabular}{|l|c|c|c|}
\hline \multicolumn{1}{|c|}{ Ações verticais } & $(\mathrm{kn})$ & Braço $(\mathrm{m})$ & $\begin{array}{c}\text { Momentos } \\
(\mathrm{kN} . \mathrm{m})\end{array}$ \\
\hline $\mathrm{F}_{1}=0,15 \times 4,20 \times 25$ & 15,75 & 0,775 & 12,20 \\
\hline $\mathrm{F}_{2}=0,25 \times 2,70 \times 25$ & 16,87 & 1,350 & 22,77 \\
\hline $\mathrm{F}_{3}=0,40 \times 0,25 \times 25$ & 2,50 & 2,575 & 6,44 \\
\hline $\mathrm{F}_{4}=5 \times 1,85$ & 9,25 & 1,725 & 15,96 \\
\hline$F_{5}=1,85 \times 4,20 \times 18$ & 139,86 & 1,725 & 241,25 \\
\hline$F_{6}=\left(\left(\frac{1,85 \times 4,20}{2}\right) \times 0,20 \times 25\right.$ & 19,42 & 1,467 & 28,49 \\
\hline$F_{7}=0,70 \times 0,20 \times 18$ & & & \\
\hline$\Sigma$ & 206,17 & & 327.99 \\
\hline
\end{tabular}

\section{2 - Ações horizontais (empuxo)}

$$
\begin{aligned}
& q_{1}=K_{a} \cdot q=0,333 \times 5=1,7 \mathrm{kN} / \mathrm{m}^{2} \\
& q_{\text {ep }}=K_{a} \cdot \gamma_{\text {solo }} \cdot N=0,333 \times 1,8 \times 4,20=25,17 \mathrm{kN} / \mathrm{m}^{2} \\
& \mathrm{Ka}=\operatorname{tg}^{2}\left(45-\frac{\varphi}{2}\right)=\mathrm{tg}^{2} 30=0,333 \\
& \mathrm{E}_{1}=\mathrm{q}_{1} \mathrm{H}=1,7 \times 4,20=7,14 \mathrm{kN} / \mathrm{m} \\
& \mathrm{E}_{2}=\frac{1}{2} \mathrm{q}_{\text {ep }} H=\frac{1}{2} \times 25,17 \times 4,20=52,86 \mathrm{kN} / \mathrm{m}
\end{aligned}
$$

Distância da resultante ao ponto A

$$
X_{0}=\frac{327,99}{206,17}=1,59 m
$$




\section{3 - Momento de tombamento}

$$
\begin{aligned}
& M_{\text {tomb }, A}=7,14 \times\left(\frac{1}{2} \times 4,20+0,25\right)+52,86\left(\frac{1}{3} \times 4,20+0,25\right) \\
& M_{\text {tomb }, A}=104 \mathrm{KNm} / \mathrm{m}
\end{aligned}
$$

\section{4 - Verificação do tombamento}

F.S. $=\frac{M_{\text {rest, } A}}{M_{\text {tomb }, A}}=\frac{327,99}{104}=3,15>1,5$

$\therefore$ Verifica

\section{5 - Verificação do deslizamento}

$$
\begin{aligned}
& \mu=\operatorname{tg} 30^{\circ}=0,577 \\
& \Sigma F_{H}=E_{1}+E_{2}=7,14+52,86=60 \mathrm{KN} / \mathrm{m} \\
& F_{\text {ATRITO }}=0,9 \times 206,17 \times 0,577=107,06 \mathrm{KN} \\
& \text { F.S. }=\frac{F_{\text {ATRITO }}}{\Sigma F_{H}}=\frac{107,06}{60}=1,78>1,5 \\
& \therefore \text { Verifica. }
\end{aligned}
$$


-86-

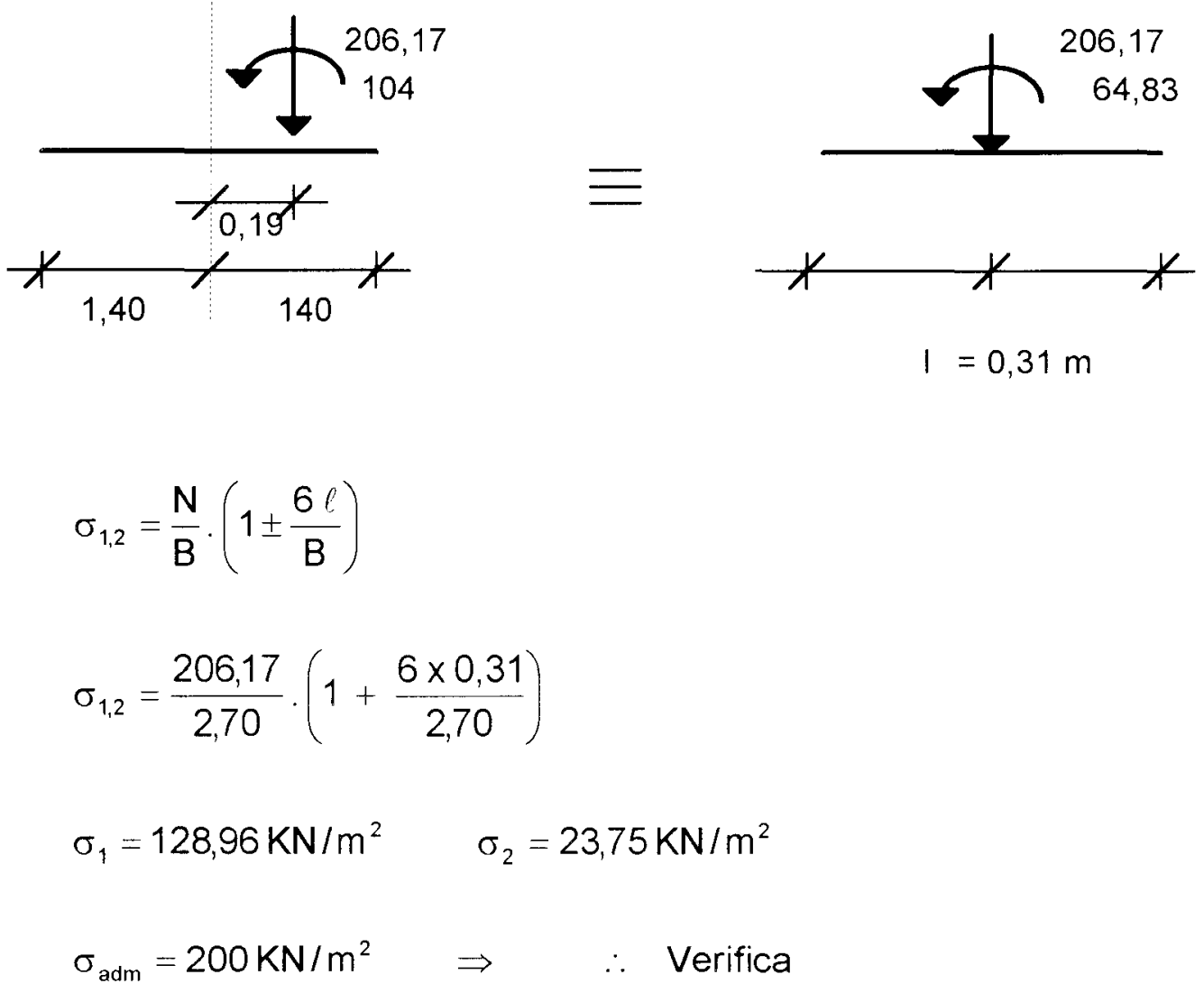

1.7 - Cortina entre os gigantes (lajes verticais) laje engastada nos contrafortes e na laje de fundo e apoio livre na borda superior
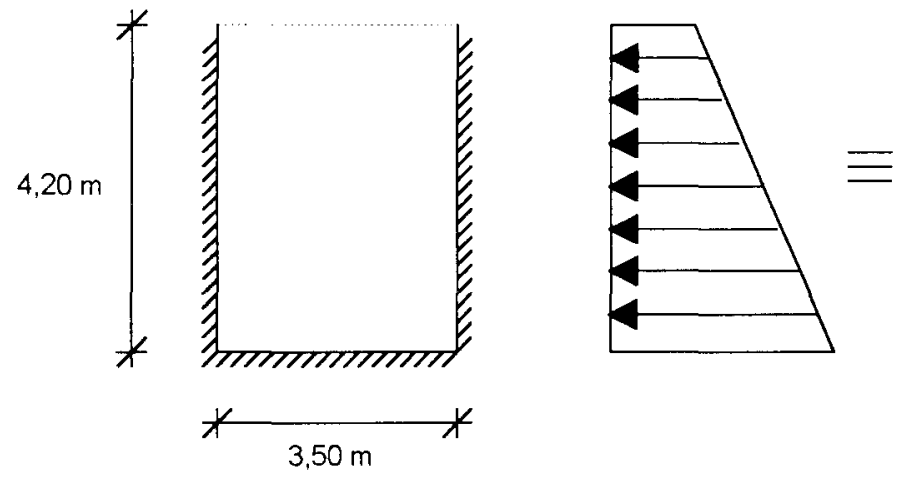
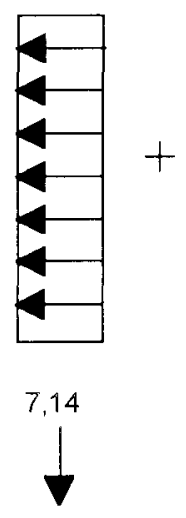

tipo 10

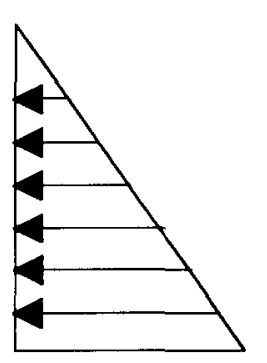

52,86

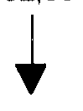

tipo 22

Laje tipo 22 (tabela $2.6 \mathrm{e} \rightarrow$ Tabelas e Abacos de Libânio Miranda Pinheiro) 


$$
\begin{array}{ll}
\frac{\ell a}{\ell b}=\frac{4,20}{3,50}=1,20 & \mathrm{~m}=\mu \frac{\mathrm{p} \ell^{2}}{100} \\
\mu_{\mathrm{x}}=0,86 & \mathrm{~m}_{\mathrm{x}}=5,56 \mathrm{kN} / \mathrm{m}^{2} \\
\mu_{\mathrm{x}}^{\prime}=3,74 & \mathrm{~m}_{\mathrm{x}}^{\prime}=24,22 \mathrm{kN} / \mathrm{m}^{2} \\
\mu_{\mathrm{y}}=1,48 & \mathrm{~m}_{\mathrm{y}}=9,58 \mathrm{kN} / \mathrm{m}^{2} \\
\mu_{\mathrm{yb}}=0,82 & \mathrm{~m}_{\mathrm{yb}}=5,31 \mathrm{kN} / \mathrm{m}^{2} \\
\mu_{\mathrm{y}}^{\prime}=3,47 & \mathrm{~m}_{\mathrm{y}}^{\prime}=22,47 \mathrm{kN} / \mathrm{m}^{2} \\
\mu_{\mathrm{yb}}^{\prime}=1,00 & \mathrm{~m}_{\mathrm{yb}}^{\prime}=6,47 \mathrm{kN} / \mathrm{m}^{2}
\end{array}
$$

Laje tipo 10 (tabela 2.5 e)

$$
\begin{array}{ll}
\frac{\ell a}{\ell b}=\frac{4,20}{3,50}=\gamma=1,20 & \\
\mu_{x}=1,24 & m_{x}=1,08 \mathrm{kN} / \mathrm{m}^{2} \\
\mu_{x}^{\prime}=5,57 & m_{x}^{\prime}=4,87 \mathrm{kN} / \mathrm{m}^{2} \\
& \\
\mu_{y}=3,27 & m_{y}=2,86 \mathrm{kN} / \mathrm{m}^{2} \\
\mu_{y b}=4,43 & m_{y b}=3,87 \mathrm{kN} / \mathrm{m}^{2} \\
\mu_{y}^{\prime}=7,34 & m_{y}^{\prime}=6,42 \mathrm{kN} / \mathrm{m}^{2} \\
\mu_{y b}^{\prime}=8,48 & m_{y b}^{\prime}=7,42 \mathrm{kN} / \mathrm{m}^{2}
\end{array}
$$

$$
\begin{aligned}
& d>\frac{\ell}{\Psi_{2} \Psi_{3}}=\frac{3,50}{1,7 \times 25}=8,23 \mathrm{~cm} \\
& h=15 \mathrm{~cm} \quad d=h-d^{\prime}=15-3=12 \mathrm{~cm} \\
& K_{c}=\frac{b d^{2}}{M d} \Rightarrow K_{s} \Rightarrow A_{s}
\end{aligned}
$$




\begin{tabular}{|c|c|c|c|c|c|c|}
\cline { 2 - 7 } \multicolumn{1}{c|}{} & $M d$ & $K_{c}$ & $K_{s}$ & $A_{s}$ & $\phi$ & $s$ \\
\hline$m_{x}$ & 9,29 & 15,50 & 0,024 & 1,85 & & \\
\hline$m_{x}^{\prime}$ & 40,72 & 3,53 & 0,026 & 8,82 & & \\
\hline$m_{y}$ & 17,41 & 8,27 & 0,024 & 3,48 & & \\
\hline$m_{y b}$ & 12,85 & 11,20 & 0,024 & 2,57 & & \\
\hline$m_{y}^{\prime}$ & 40,44 & 3,56 & 0,026 & 8,76 & & \\
\hline$m_{y b}^{\prime}$ & 19,45 & 7,40 & 0,024 & 3,89 & & \\
\hline
\end{tabular}

$A_{\text {smin }}=0,25 \% b d=3 \mathrm{~cm}^{2}$.

\section{8 - Cálculo dos esforços solicitantes na sapata}

Ações a considerar
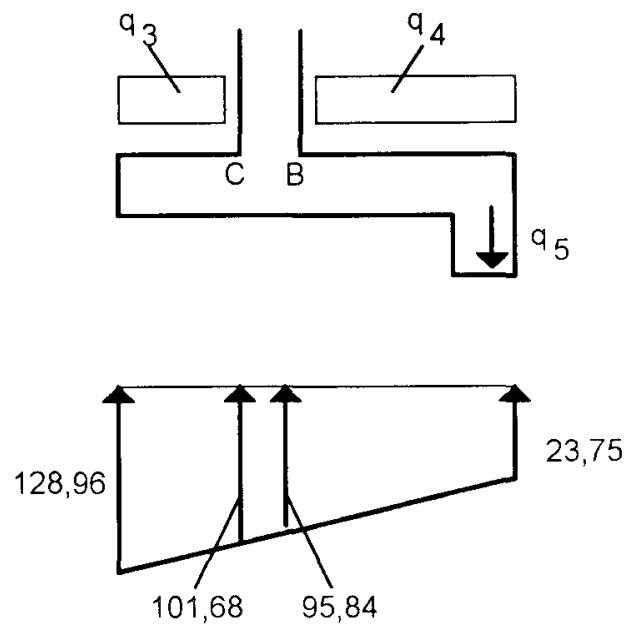


$$
\begin{aligned}
& \frac{128,96-23,75}{2,70}=\frac{y_{1}}{2} \rightarrow y_{1}=77,93 \\
& \frac{128,96-23,75}{2,80}=\frac{y_{2}}{1,85} \rightarrow y_{2}=72,09 \\
& \sigma_{\text {solo, }}=101,68 \mathrm{kN} / \mathrm{m}^{2} \\
& \sigma_{\text {solo,B }}=95,84 \mathrm{kN} / \mathrm{m}^{2} \\
& q_{1}=0,20 \times 18+0,25 \times 25=9,85 \mathrm{KN} / \mathrm{m}^{2} \\
& q_{4}=\underbrace{q}_{5,0}+4,20 \times 18+0,25 \times 25=86,85 \mathrm{KN} / \mathrm{m}^{2}
\end{aligned}
$$

Momento fletor na seção C:

$$
\begin{aligned}
M_{C, K}= & 101,68 \times 0,7 \times \frac{0,7}{2}+\frac{1}{2}(128,96-101,68) \times 0,7 \times 0,7 \times \frac{2}{3} \\
& -9,85 \times 0,7 \times \frac{0,7}{2} \\
M_{C, K}= & 26,95 \mathrm{KNm} / \mathrm{m} \rightarrow \text { Tracionando as fibras inferiores. } \\
V_{C, K}= & 101,68 \times 0,7 \times(128,96-101,68) \times \frac{1}{2} \times 0,7-9,85 \times 0,7 \\
V_{C, K}= & 73,83 \mathrm{KN} / \mathrm{m}
\end{aligned}
$$

Momento fletor na seção B:

$$
\begin{aligned}
M_{B, K}= & 23,75 \times 1,85 \times \frac{1,85}{2}+\frac{1}{2}(95,84-23,75) \times 1,85 \times \frac{1,85}{3} \\
& -86,85 \times 1,85 \times \frac{1,85}{2}= \\
M_{B, K}= & 66,85 \mathrm{KNm} / \mathrm{m} \rightarrow \text { Tracionando as fibras superiores }
\end{aligned}
$$

Verificação do equilibrio dos momentos em relação ao ponto C. 


$$
\begin{aligned}
& M_{\text {c,esq }}=26,95 \mathrm{KNm} / \mathrm{m} \\
& M_{c, \text { dir }}=15,75 \times \frac{0,15}{2}+\left[86,85 \times 1,85\left(\frac{1,85}{2}+0,15\right)\right] \text { - } \\
& -23,75 \times 2 \times \frac{2}{2}+\left[0,25 \times 0,4 \times 25\left(2-\frac{0,25}{2}\right)\right] \\
& -\frac{1}{2}(101,68-23,75) \times 2 \times \frac{2}{3} \\
& M_{c, \text { dir }}=79,13 \mathrm{KNm} / \mathrm{m} \\
& M_{c, \text { acima }}=M_{\text {tomb }, A}=104 \mathrm{KNm} / \mathrm{m}
\end{aligned}
$$

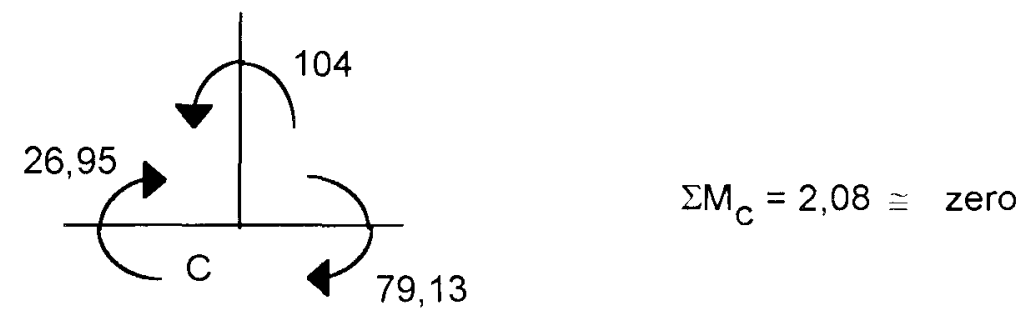

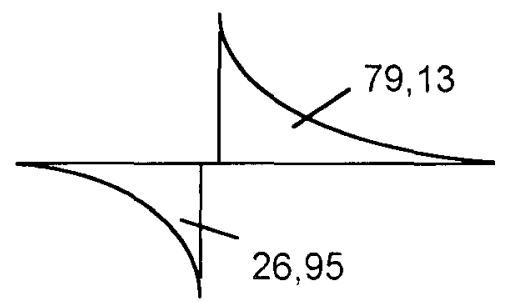

\begin{tabular}{|c|c|c|c|c|c|c|}
\cline { 2 - 7 } \multicolumn{1}{c|}{$M d$} & $\mathrm{~K}_{\mathrm{c}}$ & $\mathrm{K}_{\mathrm{s}}$ & $\mathrm{A}_{\mathrm{s}}$ & $\mathrm{A}_{\text {sef }}$ & $\phi$ & $\mathrm{s}$ \\
\hline 110,78 & 5,64 & 0,025 & 11,08 & 12,5 & 12,5 & 10 \\
\hline 37,73 & 16,56 & 0,024 & 3,62 & 3,79 & 12,5 & 33 \\
\hline
\end{tabular}

\section{9 - Dimensionamento da viga de ancoragem}

Devido ao tipo de esforço atuante na viga de ancoragem, ela funciona mais como uma laje com $A_{\text {smin }}$, com distribuição da ferragem em forma de estribo. 


$$
\begin{aligned}
& A_{\text {smin }}=\frac{0,15}{100} \mathrm{bwh} \\
& A_{\text {smin }}=\frac{0,15}{100} \times 65 \times 25=2,43 \mathrm{~cm}^{2}
\end{aligned}
$$

$1 \phi 6,3 \mathrm{cl} 13$

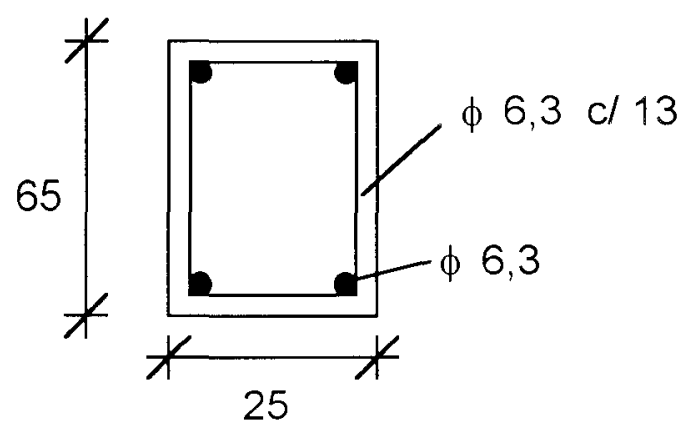

\subsection{0 - Dimensionamento do contraforte}
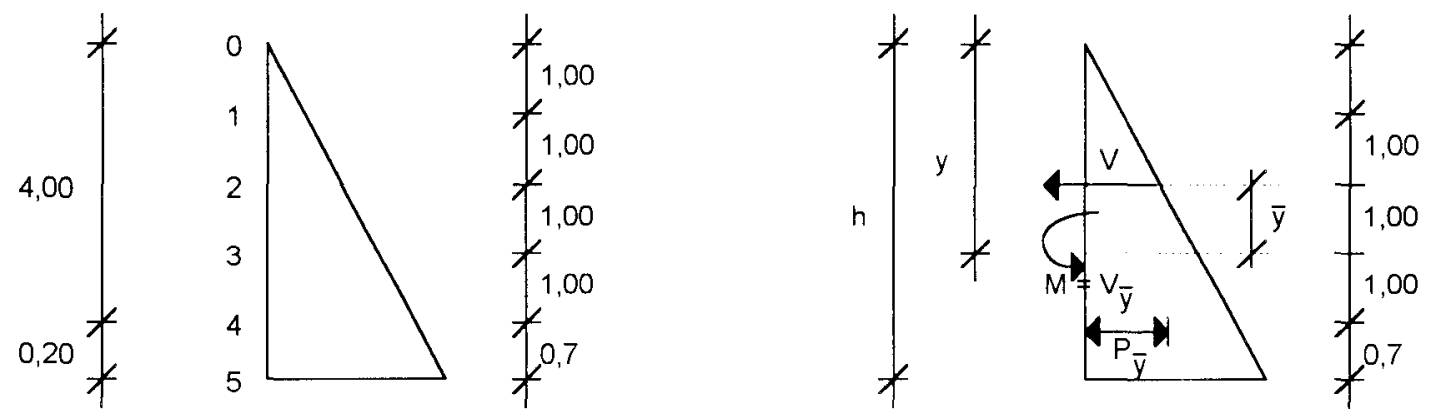

$$
\begin{aligned}
& P=k \gamma_{t} h=0,33 \times 18 \times 4,00=23,7 \mathrm{kN} / \mathrm{m}^{2} \\
& P_{h}=23,7 \times 3,50=82,95 \mathrm{kN} / \mathrm{m}
\end{aligned}
$$

Tabela de cálculo dos esforços.

\begin{tabular}{|c|c|c|c|c|}
\hline \multirow{2}{*}{ Seção } & \multirow{2}{*}{$\begin{array}{c}\text { Altura } \\
(y)\end{array}$} & $\begin{array}{c}\text { Pressão } \\
\left(P_{y}\right)\end{array}$ & \multicolumn{2}{|c|}{ Esforços } \\
\cline { 4 - 5 } & 0 & 0,0 & 0 & $M$ \\
\hline 0 & 0 & 20,8 & 10,4 & 0 \\
\hline 1 & 1,00 & 41,6 & 41,6 & 27,7 \\
\hline 2 & 2,00 & &
\end{tabular}




\begin{tabular}{|c|c|c|c|c|}
\hline 3 & 3,00 & 62,4 & 93,6 & 93,6 \\
\hline 4 & 4,00 & 83,2 & 166,4 & 221,8 \\
\hline 5 & 4,20 & -- & 166,4 & 338,3 \\
\hline
\end{tabular}

\section{Diagramas}

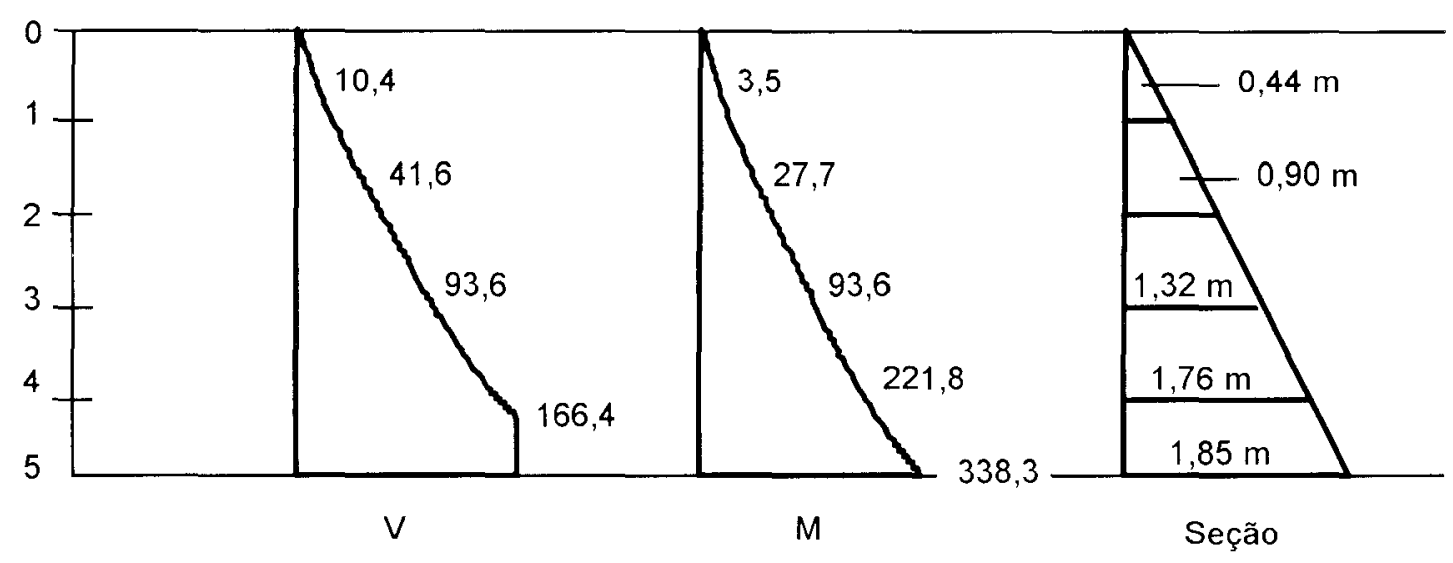

Tabela da ferragem (armação longitudinal)

\begin{tabular}{|c|c|c|c|c|c|}
\hline \multirow{2}{*}{ Seção } & \multicolumn{2}{|c|}{$M(\mathrm{kN} . \mathrm{cm})$} & \multicolumn{3}{|c|}{ Armação } \\
\cline { 4 - 6 } & $M$ & $M_{d}$ & $A_{s}$ & $A_{\text {smin }}$ & $\phi$ \\
\hline 1 & 35 & 49 & 0,30 & 1,32 & $2 \phi 16$ \\
\hline 2 & 277 & 388 & 1,17 & 2,70 & $2 \phi 16$ \\
\hline 3 & 936 & 1310 & 2,68 & 3,96 & $2 \phi 16$ \\
\hline 4 & 2218 & 3105 & 4,76 & 5,28 & $3 \phi 16$ \\
\hline 5 & 3383 & 4736 & 6,93 & 5,55 & $4 \phi 16$ \\
\hline
\end{tabular}




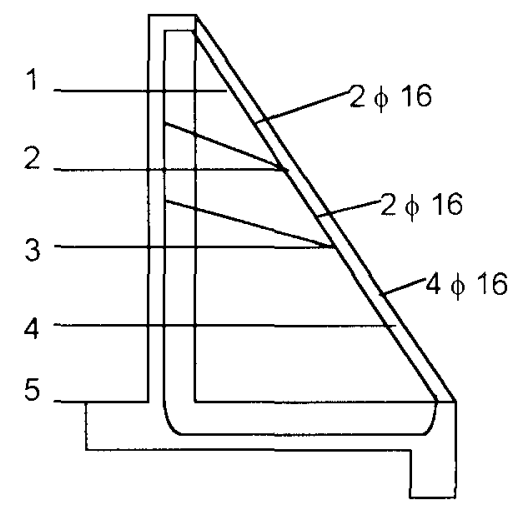

Armação transversal (estribos)
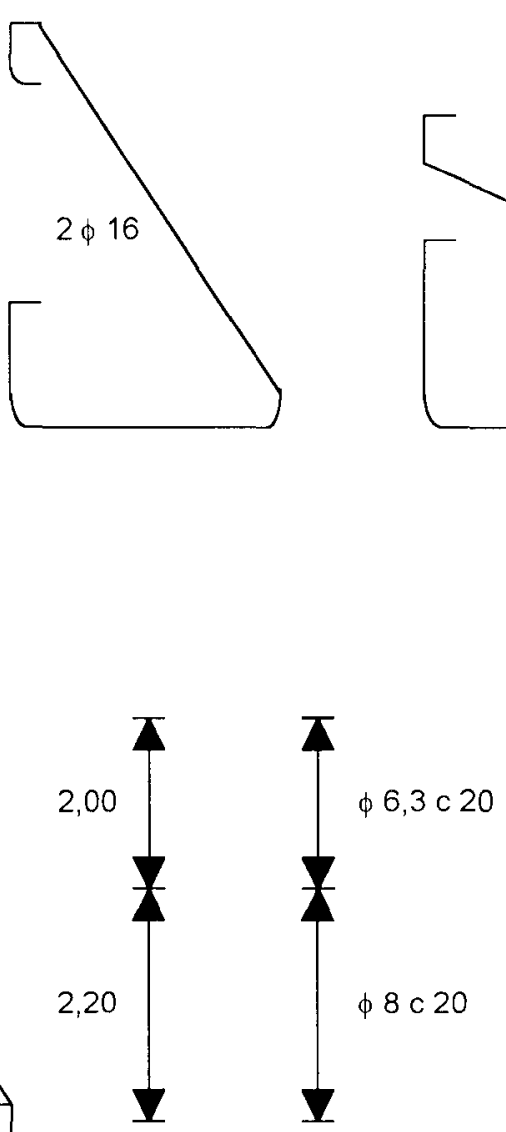


\section{CONCLUSÕES}

Com a resolução de exemplos práticos e bem detalhados, que foram desenvolvidos no último capítulo deste trabalho $e$, juntamente com a parte teórica, pretende-se dar apoio junto aos alunos de graduação de Engenharia Civil e profissionais da área na elaboração de um projeto de muro de arrimo em concreto armado.

Acompanhando o desenvolvimento da Engenharia Civil, novos tipos de muros de arrimo tem surgido, na tentativa de diminuir os custos e apresentar melhor desempenho estrutural.

O uso de estruturas metálicas, bem como blocos de concreto são algumas dessas novas alternativas.

A escolha do tipo de muro de arrimo a ser empregado esta diretamente ligado ao tipo de solo apoio e ao desnível a ser vencido.

Por isso, cada caso deve ser estudado separadamente e analisado qual a solução mais viável e econômica. 


\section{REFERÊNCIAS BIBLIOGRÁFICAS}

AMERICAN CONCRETE INSTITUTE. Building code requirements for reinforced concrete (ACI318M-83) Detroit, $\mathrm{ACI}, 1885$.

ASSOCIAÇÃO BRASILEIRA DE NORMAS TÉCNICAS. NB-51: Projeto e execução de fundações. Rio de Janeiro, ABNT, 1978.

ASSOCIAÇÃO BRASILEIRA DE NORMAS TÉCNICAS. NBR-6118: Projeto e execução de obras de concreto armado. Rio de Janeiro, ABNT, 1978.

ASSOCIAÇÃO BRASILEIRA DE NORMAS TÉCNICAS. NBR-8681: Ações e segurança nas estruturas. Rio de Janeiro, ABNT, 1984.

BORGES, L.A. et al. Algumas soluções de pré-fabricação em canteiro para galerias, caixas d'água, tubovias e paredes diafragmas. In: ENCONTRO NACIONAL DA CONSTRUÇÃO, 9, São Paulo, 16-20, out., Proceedings, p. 28-34, 1988.

BOWLES, J.E. Foundation analysis and design. 2 ed., Tokio, MacGrawHill, 1977.

DISMUKE, T.D. Retaining structures and excavations. In: WINTERKORN, H.F.; FANG, H.-Y, eds. Foundation engineering handbook. New York, Van Nostrand Reinhold, p. 447-481, 1975. 
FUSCO, P.B. Estruturas de concreto armado: solicitações normais. Rio de Janeiro, Guanabara Dois, 1981.

GUERRIN, A. Traité de béton armé. Paris, Dunot, v. 7, 1973.

HUNTINGTON, W.C. Earth pressure ande retaining walls. New York, John Wiley \& Sons, 1957.

LABORATÓRIO NACIONAL DE ENGENHARIA CIVIL. Impulsos de terra. Lisboa, LNEC, 1982.

LEME, R.S. Dicionário de engenharia geotécnica inglês-português. São Paulo, Renato Armando Silva Leme, 1987.

LEME, R.S. Métodos atuais de estabilização de taludes. São Paulo, Renato Armando Silva Leme, 1987.

LEONARDS, G.A. Foundation engineering. New York, MacGraw-Hill, 1962, p. 438-524.

LEONHARDT. F. Construções de concreto: verificação da capacidade de utilização. Rio de Janeiro, Interciência, 1978.

LEONHARDT. F. \& MONNIG, E. Construções de concreto: principios básicos de dimensionamento de estruturas de concreto armado. Rio de Janeiro, Interciência, v. 1, 1977.

MACGREGOR, J.G. Reinforced concrete: mechanics and design. 2. Ed. Englewood Cliffs, N.J., Prentice Hall, 1993b. 
MIGLIORE, A.R. Estrutura de contenção com elementos pré-moldados de argamassa armada. São Carlos, EESC-USP, 1987. (Tese de Doutorado).

MOLITERNO, A. Caderno de muros de arrimo. 2 ed. São Paulo, Edgard Blucher, 1980.

REIMBERT, M. Et A. Murs de Soutènement. Paris, Eyrolles, 1965.

ROCHA, A.M. Novo curso prático de concreto armado. Rio de Janeiro, Editora Científica, v. 3, 1974.

TSCHEBOTARIOFF, G.P. Fundações, estruturas de arrimo e obras de terra. São Paulo, MacGraw-Hill do Brasil, 1978, p. 293-333.

WU, T.H. Retaining walls. In: WINTERKORN, H.F.; FANG, H.-Y., eds. Foundation engineering handbook. New York, Van Nostrand Reinhold, 1975 , p. $402-417$. 